\title{
I. Die brandenburgische Nachkriegsjustiz unter Besatzungsbedingungen von Sommer 1945 bis Anfang 1948
}

\section{Agonie und Wiedereröffnung des Rechtswesens (Sommer 1945)}

\section{a. Der sowjetische Einmarsch}

Als die Rote Armee am 31. Januar 1945 erstmals die Oder überquerte, herrschte im Gau Kurmark der ungehemmte nationalsozialistische Terror. Die Massenmorde, die sich bis 1944 weitgehend auf die Lager und die von Deutschland besetzten Gebiete beschränkt hatten, schlugen nun auf das Reichsgebiet zurück. In der Nacht vom 30. auf den 31. Januar 1945 ermordete die Gestapo 735 Häftlinge im Zuchthaus Sonnenburg im Kreis Landsberg (östlich der Oder). Im Zuchthaus Brandenburg-Görden, wo Anfang 19454500 Häftlinge untergebracht waren, nahm die Zahl der Hinrichtungen drastisch zu. Während des Krieges starben hier 1722 Menschen unter dem Fallbeil, die meisten von ihnen zwischen August 1944 und April 19451.

Katastrophale Zustände entwickelten sich in den nationalsozialistischen Konzentrationslagern auf brandenburgischem Boden. Ende Januar 1945 begannen in Ravensbrück Massenmorde an angeblich marschunfähigen weiblichen Häftlingen, teils durch Erschießungen, teils in einer improvisierten Gaskammer. Das nahegelegene "Jugendschutzlager" Uckermark wurde zum Vernichtungslager für diese Frauen umfunktioniert. Dort ermordete die Lagerbesatzung an die 4000 Menschen durch Giftspritzen oder durch Aushungern ${ }^{2}$. Am 21. und 24. April 1945 brachen große Häftlingsgruppen zu sogenannten Todesmärschen aus Sachsenhausen, Ravensbrück und Uckermark in Richtung Mecklenburg auf 3 . Von den etwa 43000 Häftlingen, die unter erbärmlichsten Umständen in den Norden getrieben wurden, starb vermutlich jeder dritte an Erschöpfung oder wurde von den Bewachern ermordet ${ }^{4}$.

Mit dem Näherrücken der Front waren zunehmend auch bisher nicht aus der Gesellschaft ausgegrenzte Bevölkerungsgruppen durch Morde bedroht. Eine Grundlage dafür bildete die Verordnung des Reichsjustizministeriums zur Errichtung von Standgerichten vom 15. Februar 1945. Es kam zu einer Vielzahl stand-

1 Vgl. Vorwort Hermann Weber in: Uhlmann, Sterben um zu leben, S. 14, der 2032 Hingerichtete nennt.

2 Ebbinghaus, Frauen gegen Frauen, S. 275-300.

3 Vgl. Jacobeit, Die "Todesmärsche“" von Ravensbrück.

4 Zonik, Anus Belli, S. 350. Genauere Forschungen stehen hier noch aus. 
rechtlicher Erschießungen wegen „defaitistischen“ Verhaltens, so wegen Hissens der weißen Fahne ${ }^{5}$. Die Schlacht um Berlin machte Brandenburg binnen weniger Tage zu einem der größten Gräberfelder des Krieges ${ }^{6}$. Dabei kamen auch zahllose Zivilisten zu Tode, sei es bei den artilleristischen Bombardements, sei es bei Luftangriffen auf die Städte und Flüchtlingskonvois. Seit Anfang 1945 waren endlose Kolonnen Ostdeutscher auf dem Weg nach und durch Brandenburg. Allein Frankfurt/Oder passierten etwa 300000 Personen 7 . Die Eroberung Brandenburgs und Berlins führte zu massiven Zerstörungen, vor allem südostlich der Reichshauptstadt. Eine Vielzahl von Gerichtsgebäuden erlitt schwere Treffer und war nur noch zum Teil bzw. gar nicht mehr zu gebrauchen. Von den unversehrten Bauten wurden die meisten zunächst für Zwecke der Besatzungsmacht beschlagnahmt.

Mit der Einnahme von Potsdam am 30. April 1945 war die sowjetische Eroberung Brandenburgs weitgehend abgeschlossen. Für die Mehrheit der brandenburgischen Bevölkerung war das Eintreffen der Roten Armee wohl weniger mit dem Gefühl der Befreiung verbunden als vielmehr mit dem der Erleichterung über das Kriegsende $^{8}$. Befreit wurden alle Insassen der Gefängnisse, egal ob politische oder nichtpolitische, die Häftlinge der Konzentrationslager sowie die Regimegegner und die Verfolgten, die in der Illegalität oder auf andere Weise das Dritte Reich überlebt hatten. $\mathrm{Zu}$ ihnen gehörten auch die zahlreichen $\mathrm{Zwangsarbeiter}$ und Kriegsgefangenen aus den alliierten Staaten.

Ein anderes Bild des sowjetischen Einmarsches bekamen die meisten einheimischen Brandenburger; sie sahen sich oftmals den Ausschreitungen von Rotarmisten ausgesetzt. Die Ursachen für die Gewalttaten von sowjetischen Soldaten waren vielfältig. Die Vergeltung für die deutsche Gewaltherrschaft im Osten spielte eine zentrale Rolle, kann allein aber nicht alles erklären. Von Bedeutung waren auch die personelle Zusammensetzung der Einheiten, der Verfall der Truppenmoral, die extrem harten Kämpfe seit Sommer 1944 sowie die radikale Propaganda, und höchstwahrscheinlich ebenso die Befehlsgebung auf allen Ebenen. Man kann davon ausgehen, daß die Führung der Roten Armee östlich von Oder und Neiße systematisch erheblich brutalere Ausschreitungen gegen die deutsche Bevölkerung zuließ als westlich davon'.

Auf die regulären Einheiten folgten die NKWD-Truppen. Sie waren unter anderem für Massenverhaftungen von Funktionären des NS-Regimes und potentiellen Gegnern der sowjetischen Besatzungsherrschaft zuständig. Wie bei allen Alliierten fielen bestimmte Gruppen von deutschen Partei- und Staatsfunktionären unter „automatischen Arrest“. Im Gegensatz zum Westen gerieten die Festgenommenen im Osten allerdings in die Fänge einer totalitären Geheimpolizei. Im Januar/Februar 1945, als sie noch weitgehend östlich der Oder agierten, hatten

5 Am Beispiel Süddeutschlands ausführlich: Henke, Die amerikanische Besetzung Deutschlands, S. 845 ff.

6 Vgl. Richard Lakowski, Das Ende der Naziherrschaft in Brandenburg.

7 Buwert, Festung Frankfurt, S. 51; vgl. Dietrich/Eichholtz, Soziale Umbrüche in Brandenburg, S. $155 \mathrm{ff}$.

8 Für Potsdam vgl. Kasack, Dreizehn Wochen.

$9 \mathrm{Vgl}$. Zeidler, Kriegsende im Osten, S. $135 \mathrm{ff}$. 
allein die NKWD-Truppen der 1. Belorussischen Front über 4800 Personen festgenommen, von denen aber die Hälfte wieder freikam ${ }^{10}$.

Noch vor dem Angriff auf Berlin zeichnete sich jedoch ein gewisser Kurswechsel der Moskauer Führung gegenüber der deutschen Bevölkerung ab, der nun vor allem die Einwohner westlich der Oder betraf. Am 14. April attackierte die Prawda den antideutschen Extremismus von Ilja Erenburg; am 18. April nahm der Chef der Geheimpolizei Beria eine Neuregelung der Festnahme-Kategorien vor, zwei Tage später erfolgte der Stop der wahllosen Massendeportationen ${ }^{11}$.

Das Problem der Gewalt gegen Zivilisten blieb jedoch bestehen. Verblieben die durchziehenden Einheiten der ersten Welle meist nur kurz an einzelnen Orten, so ging ein Großteil der Gewalttaten auf das Konto der unmittelbar nachrückenden Truppen. Zahlreiche „Siegesfeiern“ in der Woche vom 1. bis 9. Mai 1945 waren von gewalttätigen Ausschreitungen gegen Zivilisten begleitet ${ }^{12}$. Am schlimmsten traf es meist die Frauen, die damals bei weitem die Mehrheit der Bevölkerung stellten. Wehrfähige deutsche Männer saßen im Sommer 1945 in der Regel in Kriegsgefangenschaft, viele in Internierung. Die Brutalität der Massenvergewaltigungen ist heute weitgehend bekannt, umstritten ist das Ausmaß. Allein gemessen an den Unterlagen der Gesundheitsämter, die über die Zunahme von Abtreibungen und Geschlechtskrankheiten Auskunft geben, muß ein großer Teil der Frauen direkt oder indirekt betroffen gewesen sein, teilweise bis in die Jahre 1947/48. So meldete die SMA Brandenburg etwa im Mai 1946 sieben Fälle von Vergewaltigung durch sowjetische Soldaten und weitere 42 durch „Marodeure“. In Gebieten nahe der Demarkationslinien wie Frankfurt/Oder oder Garnisonsstädten wie Fürstenwalde waren Frauen ständig bedroht ${ }^{13}$. Erst nach dem Sommer 1945 gingen die Militärbehörden schärfer gegen diese Form der Gewalt vor, die Bestrafungen fielen jedoch lokal sehr unterschiedlich aus.

Neben Plünderung, Raub und Vergewaltigung sind auch nach dem Sommer 1945 zahllose Morde zu verzeichnen, Schätzungen gehen bis zu mehreren tausend Opfern. Allein in Kleinmachnow am Südrand Berlins erschossen Rotarmisten ab dem 26. April vermutlich über 200 Zivilisten. Aus Königs Wusterhausen berichtet Günter de Bruyn von der Erschießung einer Frau durch Rotarmisten, die in ihr Haus einbrachen ${ }^{14}$. Nach dem Durchzug der kämpfenden Einheiten verschärfte sich die Gewalt gegen Zivilisten in einer zweite Welle im Juni 1945. Die Hundert-

10 Semirjaga, Aspekte sowjetischer Besatzungspolitik, S. 573.

1 Naimark, Russians in Germany, S. 76f.; Zeidler, Kriegsende im Osten, S. 160-167; früher datiert bei Foitzik, Sowjetische Militäradministration - Struktur, S. 67; NKWD-Befehle Nr. 00101, 22. 2. 1945, und 00315, 18. 4. 1945, Agde, Sachsenhausen bei Berlin, S. 46-51; Faksimile bei Prieß, Erschossen im Morgengrauen, S. 15-17. Vgl. den Tagesbefehl der 1. Belorussischen Front, 15.4. 1945, Wir waren damals 19, S. 97 f., und die Befehle der 1. Ukrainischen Front (20. 4. 1945) und der 1. Belorussischen Front (22.4. 1945) über die Veränderung im Verhältnis zur deutschen Bevölkerung, Bitwa sa Berlin, S. $220 \mathrm{f}$.

12 Keiderling, Als Befreier unsere Herzen zerbrachen, S. 234-243. Ende April flauten die Gewalttaten zunächst ab: Sie wurden von den Kommandanten auf 2-3 pro Dorf (und Tag?) geschätzt, $\mathrm{Be}$ richt Politabteilung 8. Gardearmee, 29. 4. 1945; Bericht Militär-StA 1. Belorussische Front, 2. 5. 1945 in: Bitwa sa Berlin, S. 229, $245 \mathrm{f}$.

13 Naimark, Russians in Germany, S. 87 f.; vgl. Foitzik, Sowjetische Militäradministration - Struktur, S. $59 \mathrm{ff}$.

14 Bloch, Zwischen Hoffnung und Resignation, S. 31-33; de Bruyn, Zwischenbilanz, S. 300; vgl. auch Biddiscombe, Werwolf, S. $270 \mathrm{f}$. 
tausenden von Flüchtlingen besonders aus der Neumark hatten vielfach schon vorher Erfahrungen mit Gewalttaten an ihren Heimatorten und unterwegs sammeln müssen. Sie hatten fast alles verloren, die Transporte kamen in Brandenburg oftmals noch 1946 in katastrophalem Zustand an ${ }^{15}$. Die Gewalttaten von Rotarmisten hielten bis ins Jahr 1947 an, als die Kasernierung die Truppen von der deutschen Bevölkerung weitgehend isolierte. In der Nähe von Kasernen fürchteten die Brandenburger weiter um ihre Sicherheit.

Erheblich verunsichert fühlte sich die Bevölkerung auch durch die große Zahl befreiter Fremdarbeiter und Kriegsgefangener, nicht zuletzt aus Angst vor Racheakten für deren oftmals brutale Behandlung. Mehrere tausend Polen zogen durch den Kreis Forst, einige plünderten dort ${ }^{16}$. Das Lager Sachsenhausen diente im Sommer 1945 zeitweise zur Unterbringung von Displaced Persons; die Oranienburger Bevölkerung beklagte sich über deren Überfälle ${ }^{17}$. Doch nicht für alle Fremdarbeiter bedeutete der Einmarsch der Roten Armee eindeutig die Befreiung. Die Repatriierungsbehörden transportierten zahlreiche Ukrainer wie Gefangene ab, die Gräber ihrer verstorbenen Leidensgenossen wurden eingeebnet. Ein geringer Teil der Repatriierten landete im Gulag, ein größerer jedoch als Zwangsarbeiter im Donez-Becken ${ }^{18}$.

Insgesamt war das Rechtsbewußtsein weiter Kreise der deutschen Bevölkerung im Frühjahr 1945 schwer gestört. Viele Brandenburger hatten unter der NS-Diktatur gelitten, weit mehr noch unter dem Chaos und der Gewalt in den letzten Tagen des Krieges. Für die Anhänger des NS-Regimes war eine Welt zusammengebrochen. Und sie alle standen vor einer ungewissen Zukunft, wußten nicht, was die sowjetische Besatzung nach dem verlorenen Krieg bringen würde.

\section{b. Die Herrschaft der Kommandanturen der Roten Armee}

Nachdem die Kampfverbände durch die Orte hindurchgezogen waren, richtete die Rote Armee in allen Kreisen und größeren Ortschaften Kommandanturen ein ${ }^{19}$. Diese übten zunächst die direkte Herrschaft in ihrem jeweiligen Bereich aus. Am 9. Juni konstituierte sich die Sowjetische Militäradministration in Deutschland, die zentrale Besatzungsinstanz. Es dauerte bis in den August hinein, daß die SMAD volle Kontrolle über die örtlichen Kommandanturen ausüben konnte.

Aber auch danach führten die lokalen sowjetischen Militärmachthaber noch ein relativ eigenständiges Regiment. Sie ernannten Landräte wie Bürgermeister und behielten sich die Genehmigung aller Personalentscheidungen auf kommunaler Ebene vor. Die Kommandanturen konnten selbständig über die Delegierung von Aufgaben an die Kommunalverwaltungen entscheiden ${ }^{20}$.

Vgl. Pape, Flüchtlinge und Vertriebene, S. 113.

SAPMO, NY 4182/853, Bl. 97-98, Bericht über den Landkreis Forst, o.D.

17 BLHA, Rep. 330, I/2/6, Bl. 156, KPD Oranienburg an KPD-Bezirksleitung, 6. 10. 1945.

18 Vgl. Poljan, Schertwy dwuch diktatur, S. $293 \mathrm{ff}$.; Sacharov/Filippovych/Kubina, Tschekisten in Deutschland, S. 325 f.; de Bruyn, Zwischenbilanz, S. 301.

19 Zur Organisation der Kommandanturen Foitzik, Sowjetische Militäradministration - Struktur, S. 155 f.; am Beispiel Frankfurt/Oder: Wir waren damals 19, S. $187 \mathrm{ff}$.

20 Vgl. den Aufgabenkatalog der 1. Ukrainischen Front für die Arbeit der Kommandanturen mit den 
In den Wochen nach dem sowjetischen Einmarsch, verschiedentlich auch schon davor, bildeten sich autonome Ausschüsse, die kurzerhand die kommunale Verwaltung selbst in die Hand nahmen. Diese sogenannte Antifa-Bewegung war im Raum Brandenburg relativ schwach. Vor allem in den Städten um Berlin herum bildeten sich spontan größere Ausschüsse ${ }^{21}$. So konstituierte sich am 3. Mai 1945 ein "Antifaschistischer Vollzugsrat" in Potsdam. Zahlreiche andere Kommunalverwaltungen wurden ad hoc von Angehörigen der Widerstandsgruppen oder deren Umfeld übernommen, die auch aus den Gefängnissen und Lagern zurückgekehrt waren. Die Ausschüsse unternahmen auf eigene Faust oder mit Genehmigung der Kommandantur bereits erste Aktionen gegen NS-belastete Bürger. Viele wurden entlassen, viele der Besatzungsmacht übergeben. Mancherorts mußten NSDAP-Mitglieder öffentliche Zwangsarbeiten verrichten. Bei Niemegk errichtete die Antifa sogar ein Arbeitslager für belastete Nazis, das später von der Justizverwaltung übernommen wurde22. Meist hatten diese „revolutionären“ Verwaltungen und Komitees auch eine Stelle für Polizei und Justiz, in Potsdam sogar zusätzlich für die Rechtsanwaltschaft ${ }^{23}$. Die Kommandanturen und die provisorischen Kommunalverwaltungen bestimmten in den meisten Städten über die Wiedereröffnung der Justizbehörden.

\section{c. Gerichtswesen auf kommunaler Ebene}

Der staatliche Zusammenbruch im Frühjahr 1945 hatte auch das Justizsystem erfaßt. Etwa im März/April 1945 war die reguläre Tätigkeit der Justiz im Gau Kurmark größtenteils zum Erliegen gekommen. Ein erheblicher Teil des Justizpersonals war zur Wehrmacht oder zum Volkssturm eingezogen worden, viele überlebten die Kampfhandlungen oder die Flucht vor der Roten Armee nicht.

Solche Staatsanwälte und Richter, die in der Wehrmachtsjustiz tätig gewesen waren, sollten nach den Richtlinien des NKWD festgenommen werden. Darunter fielen auch alle Richter des Reichsgerichts und vereinzelt des Berliner Kammergerichts, das damals noch die für Brandenburg übergeordnete Instanz war. Unter den letzteren war nur wenig brandenburgisches Personal, mehr schlugen hingegen die Festnahmen von Richtern der Sondergerichte zu Buche. Hin und wieder wurden auch andere Angestellte der Gerichte vom NKWD verhaftet, dann meist aber wieder freigelassen ${ }^{24}$.

Genaue Daten über den Verbleib des Justizpersonals liegen nicht vor. Aus anderen Gebieten ist jedoch überliefert, daß beim Einmarsch der Roten Armee manchmal nur noch ein Drittel der Richter, Staatsanwälte und Angestellten anwesend war. Trotz des enormen Ausmaßes an Zerstörung und Flucht ist es jedoch

Verwaltungen (13.5. 1945), der keine Anweisungen zur Behandlung der Justiz enthält, Bitwa sa Berlin, S. 391-398.

21 Vgl. Errichtung des Arbeiter- und Bauernstaates, S. 45; SAPMO, NY 4036/684, Bl. 1-10, Vorläufiger Bericht der Landwirtschaftsabt. der brandenburgischen Provinzialverwaltung, 9. 8. 1945. Für Brandenburg ist diese Bewegung noch nicht hinreichend erforscht.

22 Vgl. BLHA, Rep. 330, Nr. 10, Bl. 26, Sitzung Antifa Belzig, 3. 8. 1945; BLHA, Rep. 212, Nr. 1195 , Bl. 31-34, Tätigkeitsbericht Abt. Strafvollzug MdJ an SMA (Gofschtein), 3. 1. 1947.

23 Manfred Uhlemann, Neubeginn in Potsdam., S. 302.

24 BLHA, Rep. 212, Nr. 596, Bl. 1c, OStA an Oberbürgermeister Potsdam, 23. 7. 1945. 
übertrieben, von einer völligen Zerschlagung des Justizapparates in Brandenburg zu sprechen ${ }^{25}$. Zahlreiche Amts- und Landgerichte konnten mit reduziertem Personal alsbald weitergeführt werden. Im Vergleich mit der Provinz Sachsen und den Ländern Sachsen bzw. Thüringen war der Einschnitt jedoch tief.

Parallel zur Weiterführung der regulären Gerichte entstanden in Brandenburg Bezirks-, Stadt- und Volksgerichte. Dieser unstrukturierte Wildwuchs des Gerichtswesens war auf Initiative der lokalen Herrschaftsträger zustande gekommen, resultierte aber aus dem Zusammenbruch zentraler Justizorgane und des ganzen Kommunikationssystems. Im havelländischen Brieselang beispielsweise ordnete der sowjetische Kommandant die Bildung einer Polizeistation und eines Ortsgerichts an. Die Ortsgruppe der KPD schlug dafür das Personal vor ${ }^{26}$. In Altlandsberg richtete die KPD sogar eine „politische Abteilung“ für das Stadtgericht ein ${ }^{27}$. Noch im Dezember 1945 forderte die KPD in Wittenberge ein Volksgericht gegen Überfälle. Erst als in einer öffentlichen Versammlung sofortige Hinrichtungen verlangt wurden, zog die Partei die Bremse an ${ }^{28}$.

Die Eröffnung der Gerichte gestaltete sich sehr unterschiedlich. Sie war abhängig vom Drängen der jeweiligen Kommandantur, von der Verfügbarkeit von Räumlichkeiten und Personal. Das Amtsgericht Perleberg arbeitete ohne Unterbrechung ab dem 8. Mai 1945 weiter, das Schöffengericht beim Stadtgericht Potsdam hatte seine erste Verhandlung am 16. Julii29. Neben den Zerstörungen und Beschlagnahmungen der Gebäude war der eklatante Mangel an Justizpersonal sicher das zweite Hauptproblem der „Stunde Null“. Die meisten Kommandanturen suspendierten alle NSDAP-Mitglieder unter den Richtern und Staatsanwälten oder ließen nur noch ihre befristete hilfsweise Heranziehung zu. Da nun aber ein erheblicher Teil dieses Personals „Parteigenosse“ gewesen war, zeigte sich hier wie in allen anderen Bereichen der Politik sofort das Dilemma zwischen Personalbedarf einerseits und politischen Vorgaben andererseits. Denn auf Volljuristen wollte etwa die Stadtkommandantur Potsdam auf keinen Fall verzichten. Beim dortigen Stadtgericht und Stadtobergericht wurden schließlich 20\% der vorhandenen Juristen übernommen und $30 \%$ durch neue Kräfte ersetzt ${ }^{30}$. Als „Richter im Soforteinsatz" ernannten die Kommandanturen und Stadtverwaltungen vor allem bekannte NS-Gegner, aber auch reaktivierte alte Juristen, Rechtsanwälte und Justizfunktionäre aus dem mittleren Dienst. Insgesamt war der Anteil der Juristen im „Soforteinsatz“ in Brandenburg zwar vergleichsweise hoch, jedoch nie dominant. Er betrug Ende $194522 \%$ beim höheren Justizpersonal in der SBZ, in Brandenburg etwa ein Drittel aller Richter und die Hälfte aller Staatsanwälte ${ }^{31}$. Daß dabei vielfach Personen zum Einsatz kamen, die nur wenig oder keine Erfahrung

25 So: Zur Geschichte der Rechtspflege 1945-1949, S. 44.

26 Anders, Demokratisierung, in: JfG, S. 386.

27 SAPMO, NY 4182/1197, Bl. 15, Brief des Leiters der „Politischen Abteilung im Stadtgericht Altlandsberg" an das ZK der KPD, o.D. (1945).

28 BLHA, Rep. 330, Nr. 11, Bl. 54-62, Denkschrift KPD Kreis Westprignitz, 5. 3. 1946.

29 BA, DP-1 VA 12, Bl. 169-182, DJV/III-Bericht über die Revision des AG Perleberg am 29.6. 1948; BLHA, Rep. 212, Nr. 596, Bl. 1c, OStA an Obgm. Potsdam, 23. 7. 1945.

30 BLHA, Rep. 212, Nr. 469, Bl. 1-23, Vermerk Abt. Justiz Brandenburg, 4. 8. 1945 (als Bericht an SMA versandt).

31 Zur Geschichte der Rechtspflege 1945-1949, S. 90; Amos, Justizverwaltung, S. 140. 
in der Rechtsprechung hatten, wurde wegen der Beschränkung auf die Behandlung von Eigentumsdelikten und Scheidungssachen nicht als schwerwiegend angesehen.

Über das bestehende Gerichtssystem hinaus gab es örtliche Initiativen, sogenannte Orts- oder Friedensgerichte für Bagatellsachen einzurichten. Dies galt besonders in solchen Gebieten, die wegen ihrer geographischen Lage und wegen der Verkehrsverhältnisse vom Justizsystem abgeschnitten waren. Sondergerichte zur schnellen Aburteilung von NS-Verbrechern entstanden vor allem im Kreis Bernau $^{32}$. Anfang September machte der Oberlandrat von Bernau den Vorschlag, solche Volksgerichte aus einem Berufsrichter und vier Laien, davon zwei NS-Opfer, flächendeckend einzurichten: „Unserer Meinung nach ist die Bevölkerung schon ungeduldig und wartet darauf, daß Denunzianten, SA Angehörige, die auf Arbeiter eingeschlagen haben oder stadtbekannte Großschieber endlich bestraft werden." ${ }^{33}$ "Für die Verfolgung von volksschädlichen oder rechtswidrigen Handlungen der Mitglieder der aufgelösten nationalsozialistischen Partei“ ordnete daraufhin der Landrat von Niederbarnim die Einrichtung eines Volksgerichtes mit umfassenden Zuständigkeiten und ohne Berufungsmöglichkeit an ${ }^{34}$. Ähnliche Initiativen starteten die Polizeidezernenten der Kreise, offensichtlich nach zentraler Abstimmung ${ }^{35}$. Eine flächendeckende Installierung solcher Volksgerichte kam jedoch nicht zustande, ihre Tätigkeit blieb nur eine kurze Episode ${ }^{36}$.

Blickt man auf das Jahr 1945 zurück, so unterlag die Justiz in Brandenburg und in den anderen Gebieten östlich der Elbe zunächst einem weiteren Verfall. Waren viele Gerichte im Nationalsozialismus zu Werkzeugen des NS-Terrors geworden, so fehlte es nun an der Infrastruktur, am Personal und an einheitlichen Richtlinien. Für mehrere Monate, bis in den September 1945 hinein, atomisierte sich das Rechtswesen in kommunale Einheiten. Dabei war der Wunsch der Bevölkerung nach rechtlicher Sicherheit und Ahndung von Unrecht so groß wie nie. Aber entwickelte sich daraus auch das Bestreben nach einem völligen Wandel in der Justiz, gar ein revolutionäres Rechtsbewußtsein? Bei der überwiegenden Mehrheit der Bevölkerung wohl nicht. Denn nicht die Umwälzung des Rechtssystems stand im Vordergrund, sondern die Rückkehr zu einem gesicherten und geordneten Leben.

32 BA, DP-1 VA 597, Ano. Prov.präs. über die Reorganisation der Justiz, 17. 9. 1945; Zur Geschichte der Rechtspflege 1945-1949, S. 213.

33 BLHA, Rep. 212, Nr. 486, Bl. 1, Oberlandrat Bernau (Neddermeyer) an Landräte und Provinzialverwaltung, 1. 9. 1945.

34 Ebenda, Bl. 3-4, Landrat Niederbarnim an AGe Bernau, Rüdersdorf, Stadtgericht Oranienburg, 6. 9.1945.

35 BLHA, Rep. 203, Nr. 111, Bl. 17-18, Rundschreiben Abt. Polizei Provinzialverwaltung, 4. 9. 1945, mit Resolution der Tagung der Polizeidezernenten.

36 Volksgerichte in Lebus und Brüssow, letzteres bereits geschlossen, verzeichnet noch SAPMO, DY 30/IV 2/13/407, Revisionsbericht Benjamin über Justizbehörden in Eberswalde, 25. 11. 1946. 


\section{Der Aufbau der Provinzialjustiz}

\section{a. Die Provinzialverwaltung}

Mit der Bildung der Provinz Mark Brandenburg am 9. Juli 1945 war die Phase der Atomisierung der Herrschaft offiziell zunächst abgeschlossen. Zumindest auf dem Papier gab es wieder eine Provinzialverwaltung. Zeitgleich wurde die Einrichtung einer Sowjetischen Militäradministration (SMA) Brandenburg angeordnet. Sie entstand aus den in Brandenburg stationierten Truppenteilen der Roten Armee. Der sogenannte Stellvertreter für Zivilangelegenheiten, Wassilij Michajlowitsch Scharow, war nun der eigentliche Herrscher der Provinz. Scharow galt etwa im Vergleich zu seinem thüringischen Kollegen Kolesnitschenko - als relativ gemäßigter Vertreter der Militärverwaltung ${ }^{37}$.

Die SMA war ab Herbst 1945 die entscheidende Instanz in Brandenburg, sie konnte in nahezu allen Bereichen die Politik bestimmen. Eingeschränkt waren ihre Befugnisse lediglich durch die übergeordnete SMAD in Berlin-Karlshorst und in den Bereichen Demontage sowie Geheimpolizei. Das NKWD/MGB war in Brandenburg mit einem - seit Dezember 1946 so genannten - Operativen Sektor vertreten, dem mehrere Operative Gruppen und Truppeneinheiten unterstanden 38 . Während die exekutiven NKWD-Einheiten in den Verwaltungsapparat eingebaut wurden, war die eigentliche Geheimpolizei, das MGB, in Brandenburg mit etwa 90 Offizieren unter den Generalmajoren Fokin und (ab März 1946) Filatow weitgehend unabhängig von der SMA ${ }^{39}$.

Den Aufbau der deutschen Provinzialverwaltung nahm eine Vertrauensperson der sowjetischen Behörden in die Hand, Bernhard Bechler. Bechler war Major der Wehrmacht gewesen und im Raum Stalingrad in Kriegsgefangenschaft geraten. Dort schlug er sich relativ schnell auf die sowjetische Seite und nahm an der Gründung des Nationalkomitees „Freies Deutschland“ (NKFD) und des Bundes Deutscher Offiziere teil, in dessen Vorstand er anschließend saß. Bis zum Juni 1945 machte Bechler eine steile Karriere: $1944 \mathrm{kam}$ er in die Zentrale AntifaSchule Krasnogorsk und wurde dann NKFD-Frontbevollmächtigter in der 2. Belorussischen Front, in deren NKFD-Frontschule er auch lehrte. Ende April 1945

37 Scharow war angeblich im Krieg Kommandeur einer Partisanenabteilung in Weißrußland gewesen, Sägebrecht, Nicht Amboß, S. 311 ff. Neben Kotikow wurde Scharow als Nachfolger von Tjulpanow gehandelt, vgl. SWAG, Uprawlenie propagandy, S. 216, 223.

38 Im Oktober 1946 wurden die „Opergruppen" vom MWD an das MGB übergeben, Sacharov/Filippovych/Kubina, Tschekisten in Deutschland, S. $300 \mathrm{ff} ., 331$. Zeitweise gab es als Zwischenebene Operative Bezirke in Potsdam, Cottbus und Eberswalde. Es bestand vermutlich eine Operative Gruppe mit bis zu 24 Mann in jedem Landkreis, nachweisbar in Bernau, Eberswalde, Frankfurt/ Oder, Neuruppin, Potsdam. In Neuruppin residierten acht Offiziere, acht Dolmetscher, weiteres Hilfspersonal sowie $20 \mathrm{MWD}$-Soldaten; Foitzik, Organisationseinheiten und Kompetenzstruktur, S. 130; Lipinsky, Ketschendorf, S. 367, 375 f., erwähnt darüber hinaus das 221. und das 322 . Konvoiregiment.

39 Foitzik, SMAD, S. 56, 60; ders., Sowjetische Militäradministration - Struktur, S. 453, 461; Semirjaga, Aspekte sowjetischer Besatzungspolitik, S. 574; Filatows Stellvertreter war Oberst E. P. Gorelow (Von Potsdam nach Workuta, S. 11), sein Stabschef Oberstleutnant „Kunieczow“ (BLHA, Rep. 212 Nr. 29, Bl. 14, Vermerk MdJ, 14. 5. 1948). Als Chef der Gegenspionage „Smersch“ Brandenburg ermittelte Lipinsky, Ketschendorf, S. 369, einen Major Kusulow (Von Potsdam nach Workuta, S. 11: M. F. Polukejew). 
gelangte er zunächst wieder nach Berlin ${ }^{40}$. Entscheidend für Bechlers Einsatz waren die Vorschläge der KPD-Initiativgruppe unter Walter Ulbricht, die sich seit Mai 1945 in der Reichshauptstadt befand. Sie schlug den ehemaligen Major zunächst für einen Posten in der Berliner Polizeiführung vor ${ }^{41}$, beorderte ihn dann aber zur Einrichtung der brandenburgischen Provinzialverwaltung. Anfang Juni 1945 begab sich Bechler deshalb nach Potsdam, wo er zunächst einmal mit sowjetischem Einverständnis die Beamten des Regierungspräsidiums entließ42.

Bechler sollte für die nächsten vier Jahre eine Schlüsselrolle in der brandenburgischen Politik spielen. Er stand von Beginn an bedingungslos loyal zur Besatzungsmacht. Dies hatte er im Kriege auch intern immer wieder betont, etwa wenn er - so ein Zeuge - die Ausschreitungen von Rotarmisten rechtfertigte: „Ich werde immer das machen, was Moskau mir sagt “43. Zwar wurde Bechler im Sommer 1945 offiziell noch als parteilos geführt; tatsächlich hatte er aber schon ein Jahr zuvor einen Aufnahmeantrag in die KPD gestellt. Sein Mitgliedsbuch erhielt er erst Ende Juni $1945^{44}$.

Es war Bechler, der der sowjetischen Verwaltung einen SPD-Verwaltungsfachmann als Kandidaten für den Posten des Provinzialpräsidenten vorschlug. Carl Steinhoff war bis dahin in seiner Partei kaum hervorgetreten. Seine Ernennung nahm er an, ohne seine gerade im Aufbau befindliche Partei zu informieren. In der Folgezeit geriet er mehr und mehr unter den Einfluß der KPD ${ }^{45}$. Steinhoff trat seine Arbeit offiziell am 29. Juni 1945 an; die vollständige Einrichtung der Provinzialverwaltung dauerte jedoch bis in den November hinein. Als territorialer Unterbau der Provinzialverwaltung dienten vier Oberlandratsämter. Durch SMADBefehl Nr. 13 vom 25. Juli 1945 wurden sie in Bernau, Brandenburg, Eberswalde und Cottbus eingerichtet, die Stadt Potsdam bildete eine eigene Verwaltungseinheit ${ }^{46}$. Die Oberlandratsämter sollten Ersatz für die Regierungspräsidien bieten, die nach dem Einmarsch aufgelöst worden waren.

In den oberen Rängen der Verwaltung war die KPD von Anfang an stark vertreten. Neben Bechler saß für die KPD noch Edwin Hoernle (ab September Heinrich Rau) im Präsidium der Provinz, das SPD-Mitglied Fritz Rücker kam gerade aus einer sowjetischen Antifa-Schule. In der Provinzialverwaltung gehörten die meisten von den organisierten Angestellten der kommunistischen Partei an. Unter den vier Oberlandräten stellte die KPD zwei, von den 25 Landräten 13, von den neun Oberbürgermeistern sechs ${ }^{47}$. Auf dem Lande hingegen war die KPD vergleichsweise schwach verankert. Gestützt auf die sowjetische Militärverwaltung, hatten die Kommunisten eigentlich von Anfang an einen unbegrenzten Machtanspruch, der mit demokratischen Mitteln nicht mehr ablösbar war. Insofern war die Provinzial- bzw. Landespolitik schon 1945 nur noch in gewissen Grenzen offen.

40 Vgl. das Interview mit Bechler in: Papadopoulos-Killius, Es gibt zwei Deutschlands, S. 213-218.

41 Personalvorschläge für Berliner Magistrat, 9. 5. 1945, Keiderling, Gruppe Ulbricht, S. 316.

42 SAPMO, SgY 30/2204, Erinnerungen Bechler, Bl. 6-8, auch zum Folgenden.

43 Vgl. Einsiedel, Tagebuch der Versuchung, S. 169; Kopelew, Aufbewahren für alle Zeit, S. 645.

44 SAPMO, SgY 30/2204, Bl. 1, Erinnerungen Bechler.

45 SAPMO, NY 4090/303, Bl. 32, Charakteristik über Steinhoff, ca. Juni 1947; SAPMO, SgY 30/ 1307, Erinnerungen Carl Steinhoff, Bl. 5, 17; vgl. Steinhoff, In der Mark Brandenburg, S. $539 \mathrm{ff}$.

46 BLHA, Rep. 202 A, Nr. 81, Befehl der SMA Brandenburg Nr. 4, 4. 8. 1945.

47 Berichte der Landes- und Provinzialverwaltungen, S. 18. 
Neben der KPD konnte sich nur die SPD noch bis Ende 1945 problemlos etablieren. Die zwei Neugründungen im deutschen Parteienspektrum, die Christlich-Demokratische Union (CDU) und die Liberal-Demokratische Partei (LDP), hatten in Brandenburg wie anderswo mit großen Problemen zu kämpfen. Insbesondere verweigerten viele Kommandanturen die obligatorische Zulassung der Ortsgruppen ${ }^{48}$. Diese Benachteiligung im politischen System konnten diese Parteien auch später nicht mehr wettmachen.

\section{b. Einrichtung und Etablierung der Provinzialjustizverwaltung}

Da eine brandenburgische Verwaltungsspitze mit dem Wegfall der in Berlin ansässigen Instanzen nicht mehr vorhanden war, mußte sie erst einmal von Grund her aufgebaut werden. Das galt auch für die Justizverwaltung, für die Bechler - neben seinen Hauptarbeitsgebieten Inneres und Polizei - zunächst verantwortlich zeichnete. Schon im Juli 1945 ging er daran, die entsprechenden Abteilungen in der Provinzialverwaltung einzurichten. Während er selbst für die Abteilungen I (Inneres) und IX (Polizei) zuständig blieb, wurde mit der Bildung der Abteilung VI (Justiz) zunächst Dr. Hermann Albrecht von der Demokratischen Partei beauftragt ${ }^{49}$. Die Justizabteilung ging in der letzten Juliwoche jedoch an Georg Remak, der seit Anfang des Monats im Provinzial-Präsidium saß. Ende Juli umfaßte die Abteilung ganze sechs Personen, unter anderem Albrecht als Remaks Stellvertreter ${ }^{50}$. Georg Remak gehörte seit 1929 der Deutschen Demokratischen Partei, nach dem Krieg den Demokraten (später LDP) an. Er war zu diesem Zeitpunkt 55 Jahre alt und ein erfahrener Jurist. Nach Jurastudium und Referendariat hatte er von 1920 an in den preußischen Finanzbehörden gearbeitet, seit 1928 beim PreuBischen Oberverwaltungsgericht. Danach ging er in die Innenverwaltung, ins Oberpräsidium Königsberg und danach ins Regierungspräsidium in Oppeln. 1935 wurde er wegen „nichtarischer" Abstammung zwangspensioniert. Seit 1943 zur Zwangsarbeit verpflichtet, tauchte er von 1944 bis zum Kriegsende unter ${ }^{51}$.

In vielem glich Remaks Ernennung der Berufung von Eugen Schiffer zum Präsidenten der Deutschen Justizverwaltung. Beide waren in der Weimarer Republik im Linksliberalismus aktiv, beide wegen ihrer jüdischen Herkunft im Nationalsozialismus verfolgt. Die Berufung von Angehörigen der Demokratischen Partei in die Justizressorts zeigte zwar die Kooperationsbereitschaft der KPD-Führer, gleichzeitig aber auch, daß dieses Ressort von letzteren nicht als zentral angesehen wurde.

Bereits Anfang August 1945 gab Provinzialpräsident Steinhoff bekannt, daß die Justizabteilung errichtet sei52. In Wirklichkeit sollte es bis in den Spätherbst des Jahres dauern, bis eine weitgehend funktionsfähige Abteilung etabliert war. Eine

48 Reinert, Brandenburgs Parteien, S. $52 \mathrm{ff}$.

49 Ansprache Bechlers auf der ersten Konferenz der Landräte und Oberbürgermeister der Provinz Mark Brandenburg, 17. 7. 1945, Berichte der Landes- und Provinzialverwaltungen, S. 67-71.

50 BLHA, Rep. 203, Nr. 25, Bl. 37-48, Personalaufstellung Provinzialverwaltung, 30.7. 1945; SAPMO, DY 30/IV 2/13/221, Personalia Provinzialverwaltung zum 15. 10. 1945: hier wird Albrecht als parteilos aufgeführt.

51 BLHA, PA Rep. 212, Nr. R/7560, Personalakte Georg Remak.

52 BA, DP-1 VA 7, Bl. 1, Rundschreiben Präsident Provinzialverwaltung an OStAe, 8. 8. 1945. 
erste Anweisung der SMA an die Justizverwaltung ist für den 1. August nachweisbar, der erste Runderlaß der Behörde selbst stammt vom 10. August ${ }^{53}$. In Remaks Amt war sein Stellvertreter Albrecht für das Gerichtswesen zuständig. Zu den ersten Angestellten gehörte Dr. Alexander Fähnrich (CDU), der sich um die Rechtsanwälte und Notare kümmern sollte. Am 3. September stieß als Referent Walther Hoeniger zu ihnen, der später die dominierende Gestalt der brandenburgischen Justiz werde. Hoeniger hatte sich selbst als Antifaschist und erfahrener Organisator im Justizwesen anerboten: „Meine heiße Liebe gehört unserem Vaterland. [...] Ich bin von jeher sozialistisch und demokratisch eingestellt, ohne mich irgendwann parteipolitisch gebunden zu haben." ${ }^{54} \mathrm{Er}$ stammte aus einer liberalen jüdischen Familie, die zum Christentum konvertiert war. Hoeniger selbst war konfessionslos. Seit 1920 gehörte er dem Landgericht Berlin an, seit 1930 war er beim Kammergericht als Referent für Organisationsfragen. Nach 1933 fungierte er als Spruchrichter in einem seiner Zivilsenate und brachte es bis zum Kammergerichtsrat. 1942 zwangsweise pensioniert, schlug er sich als freiberuflicher Rechtsgutachter durch, bis er im September 1944 für das Heeresbekleidungsamt verpflichtet wurde. Nach Kriegsende erhielt Hoeniger eine Stelle als Amtsrichter im Kreis Teltow und wechselte anschließend in die Justizverwaltung. Dabei dürfte ihm seine Bekanntschaft zu Werner Gentz zugute gekommen sein, der seit kurzem in der DJV tätig war. Zusammen mit Hoeniger arbeiteten im März 1946 zwölf Referenten in der Abteilung VI55.

Bis ins Jahr 1946 hinein wurde die Justizabteilung zahlenmäßig von Mitgliedern der CDU und der LDP dominiert, Sozialdemokraten waren dort nur wenige tätig, Kommunisten gar keine. Lediglich Martin Löwenthal, seit Oktober in der Provinzialjustizverwaltung, war gerade einen Monat zuvor der SPD beigetreten; Hoeniger folgte im Mai 1946 in die SED. Trotz dieser Besetzung ging es hier nicht darum, einfach an die preußischen Strukturen von 1932 wieder anzuknüpfen. Die Abteilung lebte in dem Bewußtsein, in einer „neuen Zeit“ tätig zu sein. Wer da nicht mitzog, dessen Stelle war alsbald gefährdet. Das spürten als erste Remak und Albrecht. Remak stürzte schließlich wegen seines Widerstandes gegen die Bodenreform, Albrecht wurde angegriffen, weil er sich angeblich den Zeitumständen nicht anpasse ${ }^{56}$.

Die politische Stellung der Justizabteilung ergab sich aus vielen Faktoren. Zuallererst war sie - wie die ganze Provinzialregierung - Auftragsverwaltung der SMA. In der ersten Zeit der Besatzung beschränkte sich die SMA weitgehend auf die Weitergabe der Anordnungen der SMAD, griff aber kaum direkt ins Justizgeschehen ein. Die SMAD wiederum meldete eigentlich erst mit ihrem Befehl Nr. 49 vom 4. September 1945, auf den noch einzugehen sein wird, ihren zentralen An-

53 BLHA, Rep. 212, Nr. 37, Verzeichnis der Runderlasse und Rundverfügungen Nr. 1-336 der Abt. Justiz.

54 BLHA, Rep. 401, Nr. 18288, Personalakte Walther Hoeniger, auch zum folgenden, Zitat Bl. 40, Hoeniger an Provinzialverwaltung, 25. 8. 1945.

55 BLHA, Rep. 212, Nr. 158, Geschäftsverteilungsplan Abt. VI Justiz Brandenburg, 15. 3. 1946.

56 BLHA, PA Rep. 212, Nr. L/6699, Hoeniger an Steinhoff, 29. 9. 1945. Möglicherweise besteht ein Zusammenhang mit der Beschlagnahme von Albrechts Wohnung durch sowjetische Stellen, vgl. BLHA, Rep. 203, Nr. 25, Bl. 7, Provinzialverwaltung an Stadtkommandant Potsdam, 12. 7. 1945. 
spruch auf Regelung der Justizfragen an ${ }^{57}$. Weit größere Probleme schufen die Einflußnahmen der Kreis- und Stadtkommandanturen. Sie, die oftmals selbst über Aufbau und Besetzung der Gerichte in ihrem Bereich bestimmt hatten, wollten in vielen Fällen auch auf deren Tätigkeit einwirken. Das konnte die SMA, die ihrerseits der SMAD verantwortlich war, nur in engen Grenzen dulden. Als sich der Landrat von Bernau bei der Justizabteilung erkundigte, inwieweit Weisungen der Ortskommandantur für die Amtsgerichte bindend seien, teilte sie mit, daß die Gerichte zwar weisungsgebunden seien, die Befehle aber schriftlich vorliegen müßten ${ }^{58}$. Dies war im Regelfall jedoch nicht durchsetzbar.

Von den Beschränkungen der Besatzungsherrschaft abgesehen, schien die Provinzialjustizverwaltung einen weit größeren Spielraum zu haben als vor dem Kriegsende. Die "Verreichlichung“ aus der Zeit des Nationalsozialismus war rückgängig gemacht worden, die Länder und Provinzen konstituierten zuerst und allein die deutsche Staatlichkeit. Insofern hatte sich die Justizabteilung vor allem in die allgemeine Politik des Provinzialpräsidiums einzuordnen. Dessen Präsident Steinhoff war selbst Jurist gewesen ${ }^{59}$ und schaltete sich in Grundsatzfragen beim Neuaufbau der Justiz ein. Er und Bechler regelten auch - nach Absprache mit der SMA - die Besetzung der wichtigsten Posten in Justiz und Justizverwaltung. Mit dem SMAD-Befehl Nr. 110 vom 22. Oktober 1945 erhielt die Provinzialverwaltung auch offiziell das Recht zum Erlaß von Gesetzen und Verordnungen, obwohl letztere bis dahin schon zahlreich ergangen waren.

Während Steinhoff im allgemeinen als recht konziliant galt, war Bechler aus einem anderen Holz geschnitzt. Hin und wieder war er dabei auch der Kritik der SMA ausgesetzt, so als er in Potsdam zahlreiche Wohnungen zwangsweise räumen ließ 60 . Bechler forderte autoritär die reibungslose Unterordnung der ganzen Verwaltung unter „eine klare politische Linie“61. Im September/Oktober 1945, als es zu Auseinandersetzungen mit Remak über die Bodenreform kam, zeichnete Bechler die meisten Erlasse der Justizabteilung selbst.

Erfolgreicher als gegen die Vorstöße von seiten der Kommandanturen und von Bechler konnte sich die Provinzialjustizabteilung bis Ende 1945 gegen eine andere neue Instanz behaupten: die Deutsche Justizverwaltung (DJV). Diese - wohl auch im Vorgriff auf gesamtdeutsche Verwaltungen - durch SMAD-Befehl am 27. Juli 1945 gegründete Zoneninstanz beanspruchte für sich die Aufsicht und Leitung der Justiz in der SBZ. Ähnlich wie in der Provinzialverwaltung waren dort zunächst kaum kommunistische Einflüsse zu spüren. Am 10. September machten Remak und Hoeniger ihren Antrittsbesuch beim Präsidenten der DJV Schiffer. Dieser behauptete, er habe ein weitgehendes Verordnungsrecht, und reklamierte die Dienstaufsicht über die brandenburgische Justiz ${ }^{62}$. In diesem Sinne bildete die

57 So die Interpretation von Scholz, Berlin und seine Justiz, S. 34.

58 BLHA, Rep. 212, Nr. 468, Bl. 2-3, Abt. Justiz an Landrat Bernau, (11. 9. 1945).

59 Vgl. Breithaupt, Rechtswissenschaftliche Biographie DDR, S. 502.

60 Ribbe, Das Land Brandenburg in der SBZ/DDR, S. 692.

61 Besonders bei der Ansprache Bechlers auf der ersten Konferenz der Landräte und Oberbürgermeister der Provinz Mark Brandenburg, 17. 7. 1945, Berichte der Landes- und Provinzialverwaltungen, S. 67-71.

62 BLHA, Rep. 212, Nr. 469, Bl. 33, Vermerk Abt. Justiz Brandenburg, 12. 9. 1945; vgl. BA, DP-1 VA 
DJV in Berlin inzwischen Kommissionen für den Aufbau der Justiz in den Ländern und Provinzen. Ursprünglich sollte Erich Rosenthal-Pelldram, Leiter der Abteilung Gerichtsorganisation, nach Potsdam kommen, um Kontakt mit den brandenburgischen Behörden aufzunehmen. Er entsandte jedoch eine Delegation unter dem Vizepräsidenten der DJV, Karl Kleikamp63. Kleikamp sprach am 24. und 25. September 1945 zunächst mit Remak und Hoeniger über den Wiederaufbau der Gerichtsstruktur. Beim Treffen Kleikamps mit Provinzialpräsident Steinhoff zeichnete sich der Kompetenzkonflikt bereits ab. Steinhoff hielt die Einrichtung der DJV zwar für eine wichtige Maßnahme, wollte jedoch die ganze Justizhoheit bei der Provinz belassen ${ }^{64}$. Auch in Fragen der Entnazifizierung und des Strafvollzuges versuchte die DJV relativ frühzeitig zentrale Regelungen zu treffen ${ }^{65}$.

Zu offenen Reibereien kam es dann, als die DJV im November/Dezember 1945 ihr „vorläufiges Statut“ vorlegte. Darin beanspruchte sie die Kontrolle der Justiz, insbesondere der Personalpolitik, sowie weitere Rechte gegenüber Ländern und Provinzen. Insbesondere auf einer Tagung bei Marschall Schukow am 13./14. November 1945 beschwerten sich die Länderpräsidenten über die Kompetenzansprüche der Zentralverwaltungen. Daraufhin ermahnte die SMAD-Rechtsabteilung Schiffer zur Zurückhaltung; die genaue Abgrenzung der Kompetenzen blieb freilich in der Schwebe ${ }^{66}$. Erst 1946 gelang es der DJV dann, Weisungsbefugnisse gegenüber den Ländern in einzelnen Sektoren zu erhalten.

Die Abteilung Justiz in Potsdam war eine Behörde, die relativ klein war und anfangs Schwierigkeiten hatte, sich gegen die etwas früher etablierten Gerichte durchzusetzen. Es war in der damaligen Situation nicht einfach, selbst Rundverfügungen an alle Gerichte zu schicken, geschweige denn den Kontakt in Einzelfragen aufrechtzuerhalten. Durch den weitgehenden Zusammenbruch des Verkehrs- und Kommunikationssystems waren vor allem die Justizbehörden im Südosten der Provinz kaum erreichbar. So führten zahlreiche Gerichte noch bis 1946 ein relativ autonomes Eigenleben. Die Provinzialjustizabteilung wollte insbesondere verhindern, daß einzelne Gerichte direkten Kontakt mit der DJV aufnahmen. Jeglicher Briefwechsel sollte über Potsdam laufen ${ }^{67}$. Aber zunächst mußte das Gerichtswesen wieder komplett hergestellt werden.

2, Bl. 9-11, Niederschrift über Besprechung Abt. 1 DJV am 3. 9. 1945. Vgl. zum folgenden Wentker, Errichtung und Transformation, S. $82 \mathrm{ff}$.

63 BA, DP-1 VA 2, Bl. 20-21, DJV an Zentralkommandantur, 17. 9. 1945; BLHA, Rep. 212, Nr. 469, Bl. 42-44, DJV an Abt. Justiz Brandenburg, 18. 9.1945.

${ }_{64}$ BA, DP-1 VA 597, Bericht DJV (Kleikamp) über Verhandlungen mit Provinzialverwaltung Potsdam, 25. 9. 1945.

65 Lorenz, Deutsche Zentralverwaltung der Justiz, S. 153; BLHA, Rep. 212, Nr. 1195, Bl. 6-7, Vermerk Abt. Justiz Brandenburg (vermutlich Fähnrich), 23. 10. 1945.

66 Anders, Diss., Teil II, Bl. 37. Zur unklaren Datierung des Statuts vgl. Wentker, Errichtung und Transformation, S. 84.

67 BLHA, Rep. 212, Nr. 251, Bl. 10, Abt. Justiz Brandenburg an DJV, 22. 1. 1946. 


\section{c. Reorganisation der Gerichte}

Grundlage für den Aufbau der Gerichte war der SMAD-Befehl Nr. 49. Dieser sah eine Wiederherstellung des traditionellen dreistufigen deutschen Gerichtssystems vor (Amtsgericht - Landgericht - Oberlandesgericht). In Brandenburg konnte es aber nicht einfach um die Wiedereröffnung aller alten Gerichte gehen; vielmehr mußte der neuen geographischen und administrativen Lage der Provinz Rechnung getragen werden. Den tiefsten Einschnitt in die bisherige Organisation bedeutete die Abtrennung der Neumark östlich der Oder. Dadurch entfielen die Landgerichte Landsberg und Guben mit dem größten Teil ihrer Bezirke ${ }^{68}$. Der Sonderstatus von Berlin und die relative Autonomie der Provinz hatten zur Konsequenz, daß elf Amtsgerichte, die bisher dem Berliner Landgericht zugeordnet waren, nun an die brandenburgische Justiz fielen. Im September 1945 ordnete die Provinzialverwaltung offiziell die Wiedereröffnung von fünf Landgerichten (Potsdam, Neuruppin, Prenzlau, Frankfurt/Oder, Cottbus) und den zugehörigen 64 Amtsgerichten an ${ }^{69}$. Von der Reetablierung des Landgerichts in Frankfurt wurde dann Abstand genommen, da die Stadt inzwischen an der äußersten Grenze der Provinz lag. Statt Prenzlau bestimmte die Justizverwaltung Eberswalde - als Stadt mit einem Oberlandrat - zum Sitz eines Landgerichts ${ }^{70}$. Die Landgerichte in Potsdam und Neuruppin bestanden schon im September 1945, das Landgericht Cottbus befand sich gerade im Aufbau. Zuletzt folgte im Oktober das Landgericht Eberswalde, dessen Strafkammern schließlich im Februar $1946 \mathrm{zu}$ arbeiten begannen. Die vorgesehenen Amtsgerichte kamen aus Personalmangel nicht alle zustande, ihre Amtsgerichtsbezirke mußten zunächst von anderen Gerichten mit betreut werden ${ }^{71}$.

Völlig neu war das Oberlandesgericht in Potsdam. Während das Reichsgericht ganz geschlossen wurde, entfiel das Berliner Kammergericht als dritte Instanz der brandenburgischen Justiz, die zugleich für die dortige Justizverwaltung zuständig gewesen war. Zunächst war ein Oberlandesgericht gemeinsam für Magdeburg und Potsdam im Gespräch. Schon in einem der ersten Schreiben an die SMA plädierte die Provinzialjustizabteilung aber für die Errichtung eines eigenen Oberlandesgerichts mit eigener Generalstaatsanwaltschaft ${ }^{72}$. Damit erklärte sich der Vertreter der DJV, Kleikamp, und die brandenburgische SMA einverstanden. Nicht durchsetzen konnte sich DJV-Präsident Schiffer mit seinem Vorschlag, anstatt der Bezeichnung Oberlandesgericht von den „Märkischen Senaten des Kammergerichts" zu sprechen ${ }^{73}$. Mit dem Aufbau wurde offiziell zum 1. Oktober begonnen.

68 Vgl. Ein Jahr Bewährung, S. 49.

69 BA, DP-1 VA 597, Ano. Prov.präs. über die Reorganisation der Justiz, 17. 9. 1945. Vgl. Vössing, Gerichtsorganisation in der sowjetischen Besatzungszone, $\mathrm{S}$. $142 \mathrm{f}$.

70 BA, DP-1 VA 597, Bericht DJV (Kleikamp) über Verhandlungen mit Provinzialverwaltung Potsdam betr. Gerichte, 25. 9. 1945; Ano. Provinzialverwaltung (i.V. Remak), 18. 9. 1945; vgl. BLHA, Rep. 212, Nr. 495 zur Einrichtung des LG Eberswalde 1945.

7 BA, DP-1 VA 7, Bl. 23-25, Aktennotiz Kleikamp, 28. 9. 1945; BLHA, Rep. 212, Nr. 494, Bl. 1, OLRat an Obgm. Cottbus, 29. 10. 1945; BLHA, Rep. 240 Eberswalde, Nr. 1, LG-Präsident Eberswalde an Abt. Justiz, 26. 2. 1946.

72 BLHA, Rep. 212, Nr. 469, Bl. 16, Vermerk Abt. Justiz Brandenburg, 4. 8. 1945; BA, DP-1 VA 597, Bericht DJV (Kleikamp) über Verhandlungen mit Provinzialverwaltung Potsdam, 25. 9. 1945.

73 BLHA, Rep. 212, Nr. 491, Bl. 3, Remak an Hoeniger, 13. 10. 1945. 
Ein Senatspräsident hatte diese Arbeiten zu organisieren, die Richter sollten zunächst aus dem Land- und Amtsgericht Potsdam und die Staatsanwälte aus Angehörigen der Justizabteilung hilfsweise herangezogen werden. Zum kommissarischen Senatspräsident ernannte die Provinzialverwaltung Walther Hoeniger, laut Kleikamp eine ,in jeder Hinsicht geeignete Persönlichkeit" ${ }^{47}$. Hoeniger nahm sich dieser Funktion nebenbei an; beim Aufbau wurde er vor allem von Fritz Fehr unterstützt. Erst im August 1946 erhielt Martin Löwenthal, der ebenfalls in der Justizabteilung arbeitete, die Ernennung zum ordentlichen Oberlandesgerichts-Präsidenten $^{75}$. Am 22. Januar 1946 fand die feierliche Eröffnung des obersten Gerichts Brandenburgs statt, zwei Wochen später führte es das erste Zivilverfahren ${ }^{76}$.

\section{d. Entnazifizierung}

Parallel zur organisatorischen Wiedereinrichtung der Justiz mußte eine neue Personalpolitik in die Wege geleitet werden, die 1945 fast völlig von der Entnazifizierung bestimmt war. Während Entnazifizierung ganz allgemein die Prüfung der NS-Verstrickung von Einzelpersonen bedeutete und eigentlich zu ihrer Re-Integration in die Gesellschaft führen sollte, beschränkte sie sich in Verwaltung und Justiz der SBZ auf Entlassungen. Die Personalpolitik in Verwaltung und Justiz war einer der Bereiche, in denen die Konzepte der einzelnen Alliierten am frühesten auseinanderliefen. Die SMAD hatte sich mit dem Befehl Nr. 49 von vornherein festgelegt, alle Mitglieder von NS-Organisationen aus den Gerichten und Staatsanwaltschaften zu entlassen. Das erst später, am 30. Oktober, erlassene Kontrollratsgesetz Nr. 4 sah nur die Entlassung von „aktiven Nazis“ aus diesem Bereich vor.

Die beiden zu dieser Zeit dominierenden Parteien KPD und SPD vertraten ähnliche Konzepte wie die sowjetische Militärverwaltung. Es ist kaum zu erkennen, daß die KPD die Entnazifizierung gerade in der Justiz als wichtigen Faktor einer gesellschaftlichen Umwälzung ansah, wie dies in anderen Bereichen nachweisbar ist. Vielmehr ging es den meisten Kommunisten und Sozialdemokraten um die Abrechnung mit einem Personal, das zu einem erheblichen Teil an den nationalsozialistischen Verfolgungen mitgewirkt hatte. An eine soziale Neuausrichtung des Justizpersonals war im Sommer und Herbst 1945 noch nicht zu denken, eine Konzeption für „Volksrichter“" noch nicht entwickelt. Die „bürgerlichen“ Parteien konnten in die Entnazifizierung 1945 nicht eingreifen. Zum einen waren sie an den SMAD-Befehl gebunden, zum anderen erfolgten die Parteizulassungen in Brandenburg erst nach der Entlassung der meisten Betroffenen aus dem Justizdienst ${ }^{77}$.

Im Jahre 1939 hatte es in Brandenburg (in den Grenzen von 1946) 251 Richter und 37 Staatsanwälte gegeben, davon waren 188 bzw. 27 in der NSDAP organi-

74 BA, DP-1 VA 7, Bl. 23-25, Aktennotiz Kleikamp betr. Durchführung des Befehls Nr. 49 in Brandenburg, 28. 9. 1945; BA, DP-1 VA 597, Besprechungsniederschrift Kleikamp, Remak, Hoeniger, 1. 10. 1945; BLHA, Rep. 212, Nr. 491, Bl. 1, Abt. Justiz Brandenburg an Hoeniger, 1. 10. 1945.

75 BLHA, Rep. 212, Nr. 491, Bl. 84, Steinhoff an Löwenthal, 23. 8. 1946.

76 Vgl. BLHA, Rep. 212, Nr. 493, Bl. 2-8, Ansprache Hoeniger, 22. 1. 1946; Artikel „Oberlandesgericht tagt", Der Märker vom 8. 2. 1946.

77 Welsh, Revolutionärer Wandel, S. 59 ff.; vgl. Schäfer, Entnazifizierung. 
siert gewesen, also 75 bzw. $73 \%$. Im Vergleich stellte das einen niedrigeren Anteil dar als in den anderen Ländern und Provinzen. Nun war schon ein erheblicher Teil dieses Personals beim Beginn der Besatzung nicht mehr anwesend. Die erste Entlassungswelle erfolgte dann lokal durch die Kommandanturen und die provisorischen Kommunalverwaltungen. Weiter fielen einige Juristen den periodischen Verhaftungswellen des NKWD im Sommer 1945 zum Opfer ${ }^{78}$. Schon am 25. August verfügte die Militärverwaltung in Potsdam, alle ehemaligen Mitglieder von NS-Gliederungen bis Jahresende aus dem öffentlichen Dienst zu entlassen, wie es auch der Landesaktionsausschuß von KPD und SPD gefordert hatte ${ }^{79}$. Die Entnazifizierung war also bereits in vollem Gange, als sie durch Befehl Nr. 49 am 4. September zentral für die Justiz angeordnet wurde. Der Präsident der Provinzialverwaltung hatte schon einen Tag zuvor die Entlassung aller "Pgs." in Verwaltung und Justiz verfügt, am 18. des Monats folgte die Abteilung Justiz mit der entsprechenden Anweisung, die nun auch die Angehörigen der NSDAP-Gliederungen betraf. Eine Vollzugsmeldung war bis Monatsende zu erstatten ${ }^{80}$. Zum 1. Oktober hatte man allerdings erst etwa $40 \%$ der NSDAP-Mitglieder unter Richtern und Staatsanwälten aus der Justiz entfernt. Bis September 1945 waren 25 Richter und 28 andere Justizangehörige entlassen, bis November kamen noch fünf Staatsanwälte und 185 Justizangestellte hinzu ${ }^{81}$.

Es war im Einzelfall gar nicht immer so einfach, die politische Belastung von Juristen zu prüfen. An kleineren Gerichten war in der Regel bekannt, wer Parteigenosse gewesen war und wer nicht. Schwieriger gestaltete sich die Überprüfung bei den Landgerichten und vor allen Dingen bei solchen Personen, die erst in letzter Zeit zugezogen waren. Der formale Ansatzpunkt war der Personalfragebogen, den jeder Justizangehörige vor seiner Anstellung auszufüllen hatte. Darin hatten zwei Personen, vorzugsweise Angehörige der zugelassenen Parteien, für den Betreffenden zu bürgen. Auf dieser Basis schlüpfte dann doch der eine oder andere formell Belastete durch das engmaschige Netz der „Säuberung“; so etwa der spätere Oberstaatsanwalt von Potsdam, dessen Vergangenheit erst 1949 nach einer Anfrage im Berlin Document Center aufgedeckt wurde 82.

Für die Justiz galt die Entnazifizierung bereits offiziell als abgeschlossen, als sie mit der Kontrollratsdirektive Nr. 24 vom 24. Januar 1946 in eine neue Phase trat. Mit dieser Direktive sollte in erster Linie eine systematische Durchleuchtung der ganzen Bevölkerung auf Provinz-Ebene erfolgen, die nun von eigens eingerichteten Kommissionen zu bewerkstelligen war. Im Bereich der Justiz wurden neue Kategorien von Entlassungsgründen angegeben, die über Mitgliedschaft in NS-

78 Es ist nicht klar, ob es eine generelle NKWD-Order zur Verhaftung von Juristen gab, wie es Kilian, Stalins Prophylaxe, S. 539, vermutet.

79 Errichtung des Arbeiter- und Bauernstaates, S. 94; Wille, Entnazifizierung, S. 51.

80 BLHA, Rep. 212, Nr. 469, B1. 35, Runderlaß Abt. Justiz Brandenburg (gez. Bechler), 18. 9. 1945. Nicht nachvollziehbar ist die Behauptung von Wille, Entnazifizierung, S. 80, auf Grund dieser Anordnung seien alle Richter und StA entlassen worden, die vor 1945 tätig gewesen waren.

81 Lorenz, Deutsche Zentralverwaltung der Justiz, S. 158; Verfügung 1. Vizepräsident Bechler, 3. 9. 1945, in: Freundschaft - Werden und Wachsen, S. 122 f. Zum Vergleich mit Sachsen und Thüringen: Welsh, Revolutionärer Wandel, S. $133 \mathrm{ff}$.

82 Vgl. BLHA, Rep. 217, Nr. 125, Bl. 209-215, Urteil LG Potsdam 2 KLs 6/50 ./. Wehner, 18. 10. 1950. Offiziell durften aber schon seit Mai 1948 keine Auskünfte mehr beim Document Center eingeholt werden, BStU, ZA, Allg. S 609/66, Bl. 7, Hausmitteilung MdI Brandenburg, 30. 4. 1948. 
Organisationen hinausgingen. Damit waren alle ehemaligen höheren Richter und Angehörige der Sondergerichte, auch solche ohne NSDAP-Parteiabzeichen, zu entlassen ${ }^{83}$. Nach Erlaß der Direktive kamen in Brandenburg sieben Richter und 41 Angestellte der Justizverwaltung zur Entlassung84. Noch im Januar 1947 beschwerte sich die DJV, in brandenburgischen Amtsgerichten würden weiter Nazis arbeiten $^{85}$.

Es gab von der pauschalen Entlassung aller ehemaliger NS-Organisierter auch Ausnahmen. Das Vorgehen der Kommandantur in Seelow, die auf der Weiterbeschäftigung der Richter mit NSDAP-Parteibuch bestand, war allerdings rechtlich nicht gedeckt und führte zu Protesten der Justizabteilung86. Mit Zustimmung der SMA beließ man zunächst zwölf NSDAP-Mitglieder in den oberen Rängen der Justiz ${ }^{87}$. In Ausnahmefällen konnten ehemalige Angehörige der Hitlerjugend in der Justiz verbleiben, insbesondere wenn eine „antifaschistische“ Tätigkeit nachweisbar war. DJV-Präsident Schiffer setzte sich für den Verbleib solcher Juristen ein, die erst nach 1939 - im Rahmen summarischer Aufnahmen - in die HJ gelangt waren. Allerdings wollte er im Einzelfall selbst entscheiden, wer von den HJ-Mitgliedern bei der SMAD zur Weiterbeschäftigung vorgeschlagen wurde ${ }^{88}$. Der bekannteste dieser Fälle war Walter Rosenthal, der Strafrechtsreferent in der brandenburgischen Justizverwaltung. Erst Anfang der fünfziger Jahre sah man die Zugehörigkeit zu den Jugendgliederungen der NSDAP nicht mehr als Hindernis für den Justizdienst an. Herbert Kern brachte es sogar vom brandenburgischen Volksrichter bis zum Sektorenleiter im Zentralkomitee und Staatssekretär im Justizministerium, obwohl er in der $\mathrm{HJ}$ gewesen war ${ }^{89}$. Immerhin gab es mittels der Sondergenehmigungen im September 1948 noch fünf Richter, zwei Staatsanwälte und 259 andere Angestellte mit NS-Belastung 90. Beim mittleren und einfachen Personal, im Mai 1945 etwa 2000 Beschäftigte, wurde keine vollständige Entnazifizierung durchgeführt. Brandenburg konnte Anfang 1948 der DJV melden, das Justizpersonal sei zu 93,5\% „entnazifiziert" $"$. Im Oktober 1952 fielen schließlich alle Beschränkungen für die ehemaligen HJ- und BDM-Mitglieder in der Justiz weg92.

83 Otto, Entnazifizierung in der Justiz, S. $29 \mathrm{f}$.

${ }_{84}$ Lorenz, Deutsche Zentralverwaltung der Justiz, S. 158.

85 BLHA, Rep. 212, Nr. 269, Bl. 8-9, DJV an MdJ Brandenburg, 21. 1. 1947, mit Nennung von 20 Beispielen.

86 BA, DP-1 VA 597, Besprechungsniederschrift Kleikamp, Remak, Hoeniger, 1. 10. 1945.

87 Tätigkeitsbericht der Abteilung Justiz der Provinzialverwaltung Mark Brandenburg für die Zeit von Mitte 1945 bis 5. Juli 1946, (Juli 1946), in: Berichte Landes- und Provinzialverwaltung, S. 292. Nach Erlaß des Befehls 204 wurden drei Richter und ein StA entlassen; zwei Richter und zwei StA, die unter den Befehl fielen, verblieben noch, Meinicke, Zur Entnazifizierung, S. 144.

88 BLHA, Rep. 212, Nr. 469, Bl. 69f., DJV an Abt. Justiz Brandenburg, 3. 10. 1946; Vermerk Abt. Justiz Brandenburg, 7.11. 1946.

89 BLHA, Rep. 212, Nr. 269, Bl. 8-9, DJV an MdJ Brandenburg, 21.1. 1947; BLHA, Rep. 332, Nr. 32, Bl. 9, Ref. Justiz (Fricke) an Sekretariat SED-LV, 5. 1. 1950.

90 Amos, Justizverwaltung, S. 144. Dem widerspricht allerdings die Feststellung, die SMA hätte im Oktober 1948 auf die Entlassung von 315 Frauen, die dem BDM angehört hatten, gedrängt; ebenda, S. 146.

9 SAPMO, DY 30/IV 2/13/109, Bl. 492, Mitteilungen der Länder an DVdI über Stand der Entnazifizierung auf Anfrage vom 2. 1. 1948; Meinicke, Zur Entnazifizierung, Band 2, S. LXI.

92 Amos, Justizverwaltung, S. 147. Anscheinend wurde auch nicht durchweg gekündigt, wenn die HJ-Mitgliedschaft (vor 1939) früher verschwiegen worden war, vgl. BStU, ASt. Potsdam, AOP 108/55, Beurteilung JVSt. Potsdam, 17. 4. 1953. 


\section{e. Personalpolitik als Verwaltung des Mangels}

Die Personalreferenten in der Abteilung Justiz hatten mit enormen Problemen zu kämpfen. Sie sollten alle NS-Belasteten ausschließen, möglichst schnell neue Juristen anwerben und die Gerichte notdürftig besetzen. Für den höheren Dienst war Hans Gollos (CDU) zuständig, für den gehobenen und einfachen Dienst Fritz Fehr ${ }^{93}$. Daß diese Posten nicht von SED-Genossen besetzt wurden, ist ein weiteres Indiz dafür, wie wenig wichtig die Partei die Justizpolitik in dieser Phase nahm. Erst im Herbst 1947 übernahmen SED-Juristen die Personalabteilung.

Die systematische Kontrolle der Personalpolitik erfolgte weniger durch die SED als vielmehr durch die Militärverwaltung; und auch sie setzte erst allmählich ein. Am 16. Oktober 1945 erhielt die Provinzial-Justizabteilung von der SMA den Auftrag, Charakteristiken über die leitenden Angehörigen der Gerichte abzugeben. Eine Woche später verlangte die SMAD die Einreichung von Stellenplänen für die Justiz ${ }^{94}$.

Die Arbeiterparteien und später die SED waren nicht in der Lage, auch nur die wichtigsten Gerichte mit Juristen aus den eigenen Reihen zu besetzen. Insbesondere konnte in Brandenburg kein Volljurist ermittelt werden, der schon vor 1933 der KPD angehört hatte. Lediglich im Oberlandesgericht stellte die SED mit Hoeniger, der im Mai 1946 der Partei beitrat, den geschäftsführenden Präsidenten. Hier hatte Provinzialpräsident Steinhoff frühzeitig darauf gedrängt, nur „politisch zuverlässige Kräfte" einzusetzen"5. Der eigentliche Präsident des Oberlandesgerichts, Martin Löwenthal, kam ursprünglich aus der DDP, also aus einer eher liberalen Juristentradition. Er hatte zwar Jura studiert, war jedoch nie an einem Gericht tätig gewesen. Vielmehr trat Löwenthal nach Studium und Kriegsdienst 1920 ins Reichsinnenministerium ein, wo er es bis zum Ministerialdirektor brachte. Dort arbeitete er an der Strafrechtsreform mit, insbesondere an einem Gesetz über das Reichsverwaltungsgericht. Wegen seiner jüdischen Vorfahren mußte Löwenthal 1933 aus dem Innenministerium ausscheiden und verdingte sich unter anderem als Archivar. Im September 1945 trat er der SPD bei, kurz danach begann er in der Abteilung Justiz zu arbeiten. Hoeniger schlug Löwenthal bald zu seinem Stellvertreter vor, wozu er am 1. Januar 1946 offiziell ernannt wurde. Sein Chef Hoeniger war es auch, der Löwenthal zum Nachfolger am Oberlandesgericht machen wollte9. Doch DJV-Präsident Schiffer meldete ernste Bedenken an: Zwar betonte er, Löwenthal sei für den Posten vor allem deshalb ungeeignet, weil er noch nie bei Gericht gearbeitet habe. Noch mehr war Schiffer jedoch darüber ungehalten, daß man die Ernennung nicht mit ihm abgesprochen hatte ${ }^{97}$. Doch die

93 BLHA, Rep. 212, Nr. 158, Geschäftsverteilungsplan Abt. VI Justiz Brandenburg, 15. 3. 1946. Gollos war bis 1945 Amtsgerichtsrat, BLHA, PA Rep. 212, Nr. G/5261, Personalakte Hans Gollos. Fehr war Rechtspfleger gewesen und hatte der Bekennenden Kirche angehört, BLHA, Landesregierung Brandenburg, Abgabe 1990, Bdl. 20, Nr. 1977, Personalakte Fritz Fehr.

94 BLHA, Rep. 212, Nr. 264, Bl. 8, Abt. Justiz Brandenburg an SMA, 6. 11. 1945, erwähnt eine Anweisung von Major Kurbatow vom 23. 10. 1945.

95 BA, DP-1 VA 597, Bericht DJV (Kleikamp) über Verhandlungen mit Provinzialverwaltung Potsdam betr. Gerichte, 25. 9. 1945.

96 BLHA, PA Rep. 212, Nr. L/6699, Personalakte Martin Löwenthal; vgl. Stenographische Berichte des Landtages, 12. Sitzung, 29. 5. 1947.

97 BA, DP-1 VA 1024, Bl. 22, 25, Vermerk DJV, 19. 10. 1946, Schiffer an SMAD, 30. 10. 1946. 
DJV konnte sich hier nicht durchsetzen, weil ihr die Kompetenzen fehlten und die SMAD mit Hoenigers Vorschlag einverstanden war. Neben Löwenthal saßen in den Senaten des Oberlandesgerichts erfahrene Juristen; Walter Gülzow leitete den Zivilsenat, Personalreferent Gollos den Strafsenat ${ }^{98}$.

Gleichzeitig mit der Einsetzung des neuen Präsidenten des Oberlandesgerichts wurde am 23. August 1946 auch die Ernennung eines Generalstaatsanwaltes für Brandenburg fällig. Diese Funktion hatte zunächst der Strafrechtsreferent in der Justizabteilung, Eberhard Boldt, geschäftsführend übernommen. Während dies für die Auswahl Löwenthals nicht nachweisbar ist, wurde der offizielle Generalstaatsanwalt vom Zentralsekretariat der SED vorgeschlagen: Helmut Ostmann. An dieser Schlüsselstelle der brandenburgischen Justiz saß das einzige ehemalige KPD-Mitglied, auch wenn Ostmann erst Ende 1945 der Partei beigetreten war ${ }^{99}$. Von den Spitzenjuristen hatte allein er schon vor 1933 der SPD angehört. Während der Weimarer Republik war er sogenannter Hilfsarbeiter im preußischen Justizministerium gewesen, mußte dort 1933 ausscheiden und wurde dann zeitweise als Vormundschaftsrichter eingesetzt. Nach dem Krieg nahm Ostmann eine eher subalterne Stellung ein, als Leiter der Rechtsabteilung im Landratsamt Mahlow. Um Konflikte wie im Fall Löwenthal zu vermeiden, wies die SMAD-Rechtsabteilung Hoeniger an, bei Ernennung Ostmanns mit der DJV Einvernehmen zu erzielen ${ }^{100}$. Der Generalstaatsanwalt war zweifellos der einzige Justizfunktionär, der von Anfang an klar der Parteilinie der KPD und später der stalinisierten SED folgte. Vizepräsident Bechler hatte Ostmanns Ernennung maßgeblich betrieben. Unter diesen Vorzeichen machte Ostmann auch in den fünfziger Jahren Karriere und brachte es schließlich bis zum Leiter der Hauptabteilung Gesetzgebung im Justizministerium der DDR ${ }^{101}$.

Im Gegensatz zum Oberlandesgericht wurden die Landgerichte von „bürgerlichen "Präsidenten geleitet, die meist schon von den Kommandanturen eingesetzt worden waren ${ }^{102} . \mathrm{Im}$ „Stadtobergericht" Potsdam, das bald wieder Landgericht hieß, war dies Richard von Horn. Vor 1933 DNVP-Mitglied, hatte er als Strafrichter im Dritten Reich Probleme mit der NSDAP gehabt. 1945 trat er der neuen CDU bei. Horn leitete das Landgericht nur geschäftsführend. Der Landgerichtspräsident in Cottbus, Arnold Theopold, war früher Mitglied der DDP gewesen und nun in der LDP, sein Pendant in Eberswalde, Hans Fricke, parteilos. Auch Fricke war einst mit der NSDAP aneinandergeraten; er nahm sich 1947 aus ungeklärten Motiven das Leben. Der Chef des Landgerichts Neuruppin, Kurt Zerkowski, mußte unter dem Nationalsozialismus sogar einige Zeit im Konzentrationslager verbringen. Erst im Dezember 1946 übernahm ein SED-Mitglied die Leitung eines Landgerichts, der Volljurist Kurt Regel in Potsdam. Vor 1933 hatte auch er der DDP angehört. Theopold wurde 1947 durch den CDU-Mann Eich-

98 BLHA, Rep. 212, Nr. 1464, Geschäftsverteilungsplan OLG, 24.1. 1946.

99 Ostmann hatte sich im November 1945 um Aufnahme beworben und wurde am 19.1.1946 Mitglied, BStU, ZA AP 3578/65, Bl. 8-10, Lebenslauf Ostmann, 5. 10. 1953.

100 BLHA, Landesregierung Brandenburg Abgabe 1991, Bdl. 25, Nr. 0/7219, Hoeniger an Steinhoff, 16. 8. 1946, Steinhoff an DJV, 27. 9.1946.

101 Vgl. den Nachruf auf Ostmann in NJ 1965, S. 112; BA, DP-1 VA 8470, Personalakte Ostmann.

102 Zum folgenden: BLHA, Rep. 212, Nr. 264, Bl. 1-6, Abt. Justiz Brandenburg an SMA, (Oktober 1945). 
holtz abgelöst. Bis ins Jahr 1947 hatte die SED also nur mäßigen personalpolitischen Einfluß in diesem Bereich.

Als personalpolitische Schlüsselstellen wurden von seiten der SED die Leiter der Staatsanwaltschaften angesehen. Immerhin zwei der vier Oberstaatsanwälte gehörten der SED an: die Volljuristen Heinz Schulz in Eberswalde und Hans Müller, der in Neuruppin nach kurzer Zeit auf den parteilosen Richard Bock gefolgt war. In Cottbus und Potsdam nahmen diese Position Sigwanz und Ernst Stargardt ein, beide in der CDU und letzterer in der Kirche aktiv. Als Stargardt zum brandenburgischen Justizminister aufstieg, folgte ihm Willi Wehner als Oberstaatsanwalt nach. Aber auch mit der ersten Generation von SED-Spitzenjuristen kam die Partei nur begrenzt zurecht. Gegen alle genannten SED-Oberstaatsanwälte wurden schließlich 1948/49 selbst Ermittlungsverfahren eingeleitet. Ausgerechnet das CDU-Mitglied Stargardt hielt sich als einziger - auf höherer Ebene - bis 1950103 .

Das Hauptproblem der frühen Personalpolitik bestand darin, die geflohenen, gestorbenen und entlassenen Richter und Staatsanwälte zu ersetzen. Kaum zu erwarten war dies von den Universitäten, die im Wintersemester 1945/46 wieder die Juristen-Ausbildung aufnahmen. Nahezu $80 \%$ aller Studenten waren zuletzt in NS-Organisationen gewesen. Die Personalsituation entspannte sich nicht etwa, vielmehr nahm das Problem immer größere Ausmaße an. Im März 1947 verglich sich das Justizministerium sogar mit „einem Schiffe in schwerer Seenot" ${ }^{\text {"104. Der }}$ DJV meldete die Behörde: „Die Zahl der Volljuristen sinkt von Woche zu Woche. "105 Immer mehr Richter kündigten ihren Dienst oder verließen Brandenburg aus politischen Gründen oder wegen der geringen Lebensmittelrationen ${ }^{106}$. Vereinzelt gerieten Richter selbst ins Visier der Justiz, meist unter dem Verdacht der Korruption. So wurden einige von ihnen unter dem Vorwurf der Bestechlichkeit und der Unterschlagung entlassen, teilweise auch verhaftet ${ }^{107}$. Obwohl die Stichhaltigkeit der Vorwürfe hier nicht im einzelnen überprüft werden kann, scheint es sich bis Anfang 1948 noch nicht um fabrizierte Beschuldigungen mit dem Ziel der Personalauswechslung gehandelt zu haben. Vielmehr bestand in der Justiz dasselbe Problem wie in der übrigen Verwaltung: Die massive Einsetzung neuen Personals ermöglichte es auch labilen Charakteren und Kriminellen, an höhere Positionen zu gelangen und sich unter den Bedingungen der Mangelwirtschaft zu bereichern ${ }^{108}$.

103 Die Angaben wurden einer Vielzahl von Sachakten entnommen, da Personalakten nicht ermittelt werden konnten.

${ }_{104}$ BLHA, Rep. 212, Nr. 41, Bl. 112-116, Runderlaß MdJ Brandenburg Nr. 72, 24. 3. 1947.

105 BLHA, Rep. 212, Nr. 313, Bl. 198, MdJ Brandenburg an DJV, 26. 8. 1947.

106 Richter in Brandenburg erhielten bis Mitte 1948, Lehrgangsteilnehmer bis Ende 1946 nur Lebensmittelkarte III (in Berlin I), vgl. Berichte Landes- und Provinzialverwaltungen, S. 296; BLHA, Rep. 212, Nr. 42, B1. 500, Rundverfügung MdJ Brandenburg Nr. 303, 27. 8. 1948. Vgl. BA, DP-1 VA 1024, Bl. 106, MdJ Brandenburg an DJV, 16. 9. 1947, betr. Ausscheiden von Richtern und StA.

107 Fälle: Richter k.A. Liebenwalde (Bestechlichkeit); AGR AG Potsdam (Lebensmittelkartenbetrug); Richter k.A. Storkow (Gewahrsamsbruch); AA Beeskow (Gefangenenbegünstigung); StA Eberswalde (Amtsanmaßung).

${ }_{108}$ Ein Richter k.A. in Lieberose wurde im Januar 1946 wegen schwerer Vorwürfe krimineller Natur verhaftet und starb nach Mißhandlung durch die Polizei in Haft. Ein beteiligter Polizist wurde im März 1947 deshalb nach sowjetischen Vorgaben wegen Körperverletzung verurteilt; BAK, 
Mit Improvisation wurde versucht, die drückende Personalknappheit zu mildern. Schon in den ersten Wochen nach Kriegsende hatten die Kommandanturen sogenannte Richter im Soforteinsatz ernannt. Es sollte sich bald erweisen, daß dies nicht nur ein Notnagel für kurze Zeit war. Richter, Staatsanwälte und vor allem Amtsanwälte „kraft Auftrages“ (k.A.) arbeiteten bis Anfang der fünfziger Jahre in der Justiz. Noch 1945 war dieses Personal bunt zusammengewürfelt und oftmals nach „antifaschistischer Gesinnung“ ausgesucht worden. Danach bot man diese Posten jedoch vor allem dem mittleren Justizpersonal - wie Rechtspflegern oder Inspektoren - und Rechtsanwälten an, die meist über langjährige Erfahrungen im Justizbereich verfügten. In der Regel wurden diese Justizjuristen in der Zivilrechtsprechung an den Amtsgerichten eingesetzt, manchmal auch als Beisitzer in den Landgerichten. Ihre Kollegen mit juristischer Vollausbildung sollten ein kontrollierendes Auge auf sie werfen. Für die Amtsanwälte existierte seit 1945 eine eigene kleine Schule in Potsdam ${ }^{109}$.

Ein Drittel aller brandenburgischen Richter und die Hälfte aller Staatsanwälte waren im September $1945 \mathrm{im}$ Soforteinsatz. Im Jahr darauf reduzierten sich diese Anteile, weil einige der Kurzzeit-Juristen in ihre alten Berufe zurückkehrten und andere auf Volksrichterschulen die Rechtsausbildung nachholten ${ }^{110}$. Gleichzeitig erfolgten die Ernennungen jetzt „kraft Auftrages“. 1947 wurden alle diejenigen Richter k.A. entlassen, die zwar Referendare gewesen waren, aber der Hitlerjugend angehört hatten. Hilde Benjamin zeigte sich insgesamt eher enttäuscht von den Richtern im Soforteinsatz: „In Brandenburg ist ein großer Teil wieder am Ausscheiden, da sie sich nicht bewährt haben" 111 . Wegen der sich verschärfenden Personalknappheit drängte Hoeniger aber Ende 1947 darauf, wieder mehr Richter und Staatsanwälte k.A. zu ernennen; zu diesem Zeitpunkt waren 32 Richter, ein Staatsanwalt und $21 \mathrm{Amtsanwälte} \mathrm{auftragsweise} \mathrm{tätig112.} \mathrm{So} \mathrm{wurden} \mathrm{im} \mathrm{Jahr} \mathrm{darauf}$ auch Schöffen gebeten, richterliche Funktionen wahrzunehmen ${ }^{113}$. Erst Ende 1949 begann die Justizverwaltung damit, die Bestellungen „kraft Auftrages“ aufzuheben. Obwohl sie eigentlich noch dringend gebraucht wurden, galten diese Juristen als politisch unzuverlässig und gerieten zusehends unter Druck. 1950 kündigten weitere von sich aus ${ }^{114}$. Danach waren solche nur noch an wenigen Amtsgerichten zu finden.

B 209/1, Anklage OStA Cottbus ./. W., 30. 9. 1946; OStA Cottbus an GStA Brandenburg, 5. 3. 1947; Löwenthal, Der neue Geist von Potsdam, S. 11-14.

109 Vgl. BA, DP-1 VA 1024, Bl. 108-109, Vermerk Benjamin über Gespräch mit Hoeniger am 16. 9. 1947.

110 Zur Geschichte der Rechtspflege 1945-1949, S. 49, 117.

111 SAPMO, NY 4182/1120, Bl. 3, Protokoll der Sitzung des Rechtsausschusses beim ZS der SED am 4. 1.1947.

112 BLHA, Rep. 212, Nr. 1072, Bl. 13-17, Vermerk MdJ Brandenburg (Schulze), 5. 11. 1947; BLHA, Rep. 212, Nr. 41, Bl. 517-520, Rundverfügung MdJ Brandenburg Nr. 332, 2. 12. 1947; BA, DP-1 VA 1054, Bl. 17-20, Schiffer an SMAD/RAbt., 12. 12. 1947.

113 BLHA, Rep. 201, Nr. 312, Bl. 14-15, MdJ (Stargardt) an Landtag Brandenburg, 24. 5. 1948; BLHA, Rep. 212, Nr. 6, Bl. 83-85, Tätigkeitsbericht MdJ Brandenburg für 3.3.-3.4.1948, 1. 4. 1948(!).

114 BA, DP-1 VA 1024, Bl. 409, MdJ Brandenburg an MdJ der DDR, 22. 11. 1949; BLHA, Rep. 212, Nr. 1482, Bericht über die Tätigkeit der Justizbehörden in Brandenburg im 2. Halbjahr 1949, 15. 1. 1950. 
Die Richter und Staats- bzw. Amtsanwälte k.A. waren in der zweiten Hälfte der vierziger Jahre ein wichtiges personelles Standbein der Justiz, in Brandenburg ebenso wie in Mecklenburg. Allerdings war ihre Fluktuation hoch; in vielen Fällen zeigten sie sich den Anforderungen nicht gewachsen ${ }^{115}$. Nur wenige von ihnen wurden auf Dauer in den höheren Dienst übernommen. Mit Verbesserung der Wirtschaftslage erwies sich eine Stellung als Jurist auf Abruf als immer weniger attraktiv, so daß kaum noch Personal geworben werden konnte. Die letzten Juristen k.A. wurden 1952 in die reguläre Laufbahn übernommen oder sie schieden aus.

\section{f. Die ersten Volksrichter}

Die Bedeutung der sogenannten „Volksrichter“ für die ersten Jahre der Justizentwicklung in der SBZ wird oftmals überschätzt ${ }^{116}$. Die ersten Absolventen traten nicht vor September 1946 als Richter und Staatsanwälte in die brandenburgische Justiz ein, sie blieben zahlenmäßig noch für einige Zeit hinter den Richtern „im Soforteinsatz" zurück; einige von ihnen verließen den Justizdienst bald wieder.

Die ersten Vorschläge zum Einsatz von Richtern, die aus der Bevölkerung angeworben und in Schnellkursen ausgebildet werden sollten, sind schon für Juni 1945 aus Sachsen nachweisbar. Ab September wurde diese Idee zwischen der DJV, der SMAD-Rechtsabteilung und vor allem der KPD-Spitze diskutiert. Nachdem die DJV hierzu ein Konzept entwickelt hatte, ordnete die SMAD am 17. Dezember 1945 die Einrichtung solcher Kurse an, was die DJV in ihrem Rundschreiben vom 28. Dezember konkretisierte117.

Obwohl die sowjetische Militärverwaltung lange keine eindeutige Linie bei der Ausbildung der Volksrichter verfolgte, hatte sie dennoch ein strenges Auge auf die Kurse. Nahezu alle Details mußten der SMA gemeldet werden; hin und wieder griff sie ein, so bei der Frage der Anerkennung von Prüfungen ${ }^{118}$. Die brandenburgische Provinzialverwaltung war an der frühen Diskussion nur peripher beteiligt. Präsident Steinhoff und Abteilungsleiter Hoeniger sind aber als dezidierte Vertreter des Volksrichter-Gedankens anzusehen. Gerade Hoeniger betrachtete Volksrichter nicht nur als Übergangserscheinung während der Personalnot, sondern als Dauereinrichtung, die erst allmählich durch Universitäts-Absolventen wieder abgelöst werden sollte ${ }^{119}$.

Die Ausbildung von Volksrichtern lief in Brandenburg parallel zu den anderen Ländern. Die brandenburgischen Lehrgänge spielten sich zunächst „in zwei kleinen, in einem alten Berliner Wohnhaus gemieteten Zimmern" ab und wurden

115 Vgl. BLHA, Rep. 212, Nr. 6, Bl. 74-76, Tätigkeitsbericht MdJ Brandenburg für 1.6.-1.7. 1948, 1.7. 1948 .

116 Das Referat Justiz des SED-LV sah den Volksrichter-Einsatz gar erst 1949 als bedeutsam an, BLHA, Rep. 332, Nr. 839, Bericht über die Tätigkeit des Referates Justiz, (31. 10. 1949).

117 BLHA, Rep. 212, Nr. 313, Bl. 1-7, DJV an Abt. Justiz Brandenburg, 28. 12. 1945. Zum folgenden bes. Wentker, Volksrichter, S. $14 \mathrm{ff}$. Mit Rücksicht auf die zahlreichen neuen Arbeiten zur Volksrichter-Ausbildung wird hier auf die Darlegung der Gesamtentwicklung weitgehend verzichtet.

118 Vgl. die Anweisung Scharows zur Einrichtung der Lehrgänge, ca. Ende 1945, in: Freundschaft Werden und Wachsen, S. 129; BLHA, Rep. 212, Nr. 313, Bl. 127, MdJ an Volksrichter-Lehrgang, 23. 1. 1947; BLHA, Rep. 203 MdI/LBdVP, Nr. 9, Bl. 12-15, Befehl Nr. 45 SMA, 10. 3. 1947.

119 BA, DP-1 VA 1024, Bl. 42-45, Rede Hoenigers bei Amtseinführung von Stargardt, 28. 12. 1946; Artikel Hoenigers „Juristen und Volksrichter“, in: Tägliche Rundschau, 24. 12. 1947. 
1946 auf Anordnung der SMA nach Potsdam verlegt. Trotz intensiver Bemühungen gelang es der Justizverwaltung bis 1948 nicht, ein Internat für die Volksrichterschule zu finden ${ }^{120}$. Erst 1949 konnte das Schloß Babelsberg, das ursprünglich für das Zentralarchiv der SBZ vorgesehen war, als Richterschule „Hans Litten“ bezogen werden. Seit 1949 plante die SMAD-Rechtsabteilung die Errichtung einer zentralen Richterschule für alle Länder der SBZ in Babelsberg, wozu ein Erweiterungsbau in Angriff genommen wurde ${ }^{121}$. Aber nicht nur die Unterbringung, sondern allein schon die Verpflegung der Lehrgangsteilnehmer war so schwierig, daß eine Ausdehnung der Kurse an Grenzen stieß. Noch im Winter 1947/48 mußte der dritte Lehrgang für vier Wochen unterbrochen werden, weil es an Kohle und Nahrungsmitteln fehlte ${ }^{122}$.

Der erste Volksrichter-Lehrgang in Brandenburg begann am 18. Februar 1946 mit 30 Teilnehmern, davon fünf Frauen ${ }^{123}$. Im Vergleich zu späteren Kursen war das Bildungsniveau der Volksrichter-Schüler noch ziemlich hoch. Die Parteizugehörigkeit war eindeutig: 26 Personen gehörten der KPD oder der SPD an. Von den 27 Teilnehmern, die den Lehrgang bis zum Schluß mitmachten, bestanden 23 die Prüfung und wurden Richter oder Staatsanwalt. Die vier durchgefallenen Kandidaten kamen in den mittleren Justizdienst ${ }^{124}$. Zwar brachte dies angesichts des Personalmangels eine erhebliche Verstärkung für die Justiz, erheblich waren aber auch die Probleme der im Schnellverfahren Ausgebildeten. Nur drei von ihnen machten dauerhaft Karriere in der brandenburgischen Justiz ${ }^{125}$. Die meisten anderen, vor allem solche mit den besseren Prüfungsabschlüssen, wanderten im Laufe der Zeit nach Berlin ab, Helmut Rehse kam zur DJV, wo er sich aber nicht bewährte.

Der zweite Lehrgang startete am 1. Oktober 1946. Schon unmittelbar nach Beginn der Schulung wurden drei Bewerber wegen ihrer Vorstrafen ausgeschlossen, zwei schieden freiwillig aus. Allerdings zeigte es sich nun, daß es immer schwieriger wurde, geeignete Personen zu finden. Von den anfänglich 40 VolksrichterSchülern (33 SED) schafften es schließlich nur 23, die Abschlußprüfung zu bestehen ${ }^{126}$. Aber auch die Ausbildung war anspruchsvoller geworden, sie wurde Mitte Juli 1947 abgeschlossen, dauerte nun also ein dreiviertel Jahr ${ }^{127}$. Erst im dritten Lehrgang wurde die Zahl der Schüler aufgrund des SMAD-Befehls Nr. 193 erheblich erweitert, und zwar auf 58 Personen. Inzwischen waren auch die neuen Parteien CDU und LDPD, die die ersten beiden Male nur je vier Aspiranten gewin-

120 Zur Geschichte der Rechtspflege 1945-1949, S. 99; A. Nikitin, Sowetskaja woennaja administrazija i justizija wostotschnoj Germanii 1945-1949. MS, Bl. 10. BLHA, Rep. 212, Nr. 313, Bl. 324327, Bericht DJV (Hartwig) über Besuch des 3. Lg., 27. 10. 1947.

121 BLHA, Rep. 212, Nr. 313, Bl. 543, MdJ an Ministerpräsident, 28. 7. 1948; Wentker, Volksrichter, S. $58 \mathrm{f}$.

122 BLHA, Rep. 212, Nr. 594, Bl. 57-66, MdJ an SMA, 29. 4. 1947; BA, DP-1 VA 20, Bl. 15, Löwenthal auf der Volksrichtertagung vom 7. 9. 1947 in Potsdam; Anders, Diss., Anhang Kap. II, S. 2.

123 Vgl. SAPMO, SgY 30/2077, Erinnerungen Elfriede Göldner (1984/87), die von ihrer Nachbarin Hilde Benjamin geworben wurde.

124 BLHA, Rep. 212, Nr. 313, Bl. 234-238, MdJ an SMA (Schipkow), 2. 10. 1947; ebenda, Bl. 16, Brief aus der Abt. Justiz Brandenburg, 8. 10. 1946.

125 Walter Dubberke, Max Junius und Heinz Wensierski.

126 BLHA, Rep. 212, Nr. 313, Bl. 222, MdJ an SMA (Oberstleutnant Podmoskowsky), 27. 8. 1947.

127 BLHA, Rep. 212, Nr. 320, HA Justiz Brandenburg an MdJ der DDR, 22. 10. 1951. 
nen konnten, an der Werbung für Kandidaten stärker beteiligt ${ }^{128}$. Diesmal stellten die „bürgerlichen“ Parteien 13 von 49 politisch organisierten Lehrgangsteilnehmern ${ }^{129}$.

In der Justizabteilung hatte der Stellvertreter Hoenigers, Horst Schulze (SED), die Oberaufsicht über die Lehrgänge; 1947 übernahm Götz Schlicht die unmittelbare Leitung. Schlicht war frisch promoviert und bekam hervorragende Beurteilungen: „ausgezeichneter Jurist, guter Pädagoge, nur etwas sarkastisch. Wird von allen begabten Schülern hoch geschätzt, die geistig schwächeren Teilnehmer haben es schwer mit ihm. politisch: ausgesprochener Antifaschist, fortschrittl. Denken“130. Was man im Justizministerium nicht kannte, war Schlichts Laufbahn als Polizeioffizier im Dritten Reich. In der besetzten Ukraine hatte Schlicht an der Verwischung der Spuren von Massengräbern von NS-Opfern teilgenommen. Der Großteil seiner damaligen Untergebenen stammte aus der Berliner Polizei und wurde Ende 1947 vom MGB verhaftet und verurteilt ${ }^{131}$. Erst 1952 ereilte ihn sein Schicksal, allerdings wurde er nicht wegen seiner NS-Vergangenheit, sondern wegen seines Widerstandes gegen die SED-Diktatur festgenommen ${ }^{132}$.

Nicht nur bei den Verantwortlichen in der Justizabteilung, auch unter den Kurs-Dozenten überwogen die SED-Mitglieder ${ }^{133}$; der dritte Lehrgang wurde sogar von einem der wenigen früheren KPD-Mitglieder unter Brandenburgs Juristen, Eberhard Greiff, geleitet ${ }^{134}$. Lediglich der Dozent Kurt Dittrich war in der LDP, August Lecreux parteilos. Die Lehrgänge hatten damit und mit der Auswahl der Teilnehmer zwar von Anfang an eine politische Ausrichtung, die Inhalte wurden bis 1948 dadurch aber nur teilweise bestimmt. Götz Berger und Hilde Benjamin reisten aus Berlin an, um Vorträge zur „Soziologie" zu halten; diese bildeten jedoch nur einen kleinen Teil des Ausbildungsprogramms und waren noch nicht von stalinistischer Marxismus-Dogmatik geprägt. Hilde Benjamin nahm auch an den Prüfungen des 2. Lehrgangs teil135.

Unmittelbar vor dem Amtsantritt der ersten Volksrichter erließ die Provinzialverwaltung am 23. September 1946 ohne Absprache mit der SMAD eine Verordnung über die Befähigung zum Richteramt ${ }^{136}$. Damit war die Rechtsgrundlage dafür geschaffen, daß auch Personen ohne zwei Staatsprüfungen im höheren Justizdienst tätig sein konnten, und verfahrensrechtliche Probleme beim Einsatz der Volksrichter waren a priori ausgeschaltet. Brandenburg nahm deshalb später als einziges Land die Institution der Volksrichter nicht in seine Verfassung auf. In al-

128 ACDP, III-033-051, Rundschreiben CDU KV Potsdam, 17. 6. 1946; ACDP, VII-011-1294, Rundschreiben CDU LV an KV Nr. 21/1946, 11. 12. 1946. Ähnlich für Mecklenburg: Bartusel, Politisierung der Justiz, S. 67.

129 BLHA, Rep. 212, Nr. 313, Bl. 324-327, Bericht DJV (Hartwig) über Besuch des 3. Lg. in Brandenburg, 27. 10. 1947.

130 BLHA, Rep. 212, Nr. 269, Bl. 53, MdJ an SMA-Rechtsabteilung, 2. 9. 1948.

131 Vgl. seine Vernehmung am 7. 2. 1964 durch die StA Hamburg 141 Js 204/60 und die MGB-Vernehmungen in Zentrale Stelle Ludwigsburg, 208 AR-Z 294/59, Band 21, Bl.4541-91. Zum Zusammenhang Pohl, Nationalsozialistische Judenverfolgung, S. 378-381.

132 Siehe unten S. 252.

133 Walter Beckmann, Helmut Bloch, Löwenthal, Rosenthal, Schlicht, Schoeps und Diether Schulze.

134 BLHA, Rep. 212, Nr. 313, Bl. 419, MdJ an DJV, 5. 4. 1948.

135 Ebenda, Bl. 234-238, MdJ an SMA (Schipkow), 2. 10. 1947.

136 Jakupow kritisierte später den Alleingang Brandenburgs, BA, DP-1 VA 22, Bl. 89-94, Konferenz der Länderjustizminister am 13. 12. 1946. 
len anderen Ländern der SBZ wurde dieser Schritt formal erst durch den SMADBefehl Nr. 193 im August 1947 vollzogen ${ }^{137}$.

Der Empfang der Neulinge durch die Volljuristen an den Gerichten gestaltete sich recht unterschiedlich. Nur relativ wenige Volksrichter konnten von uneingeschränkt positiven Erfahrungen berichten. Viele hatten Probleme mit der Rechtspraxis und wurden von ihren Kollegen als Juristen zweiter Klasse angesehen ${ }^{138}$. Die Justizabteilung forderte deshalb die Landgerichte auf, für die Fortbildung der Neulinge zu sorgen. Die Gerichte winkten jedoch mit Verweis auf ihre Arbeitsüberlastung $\mathrm{ab}^{139}$.

Die ersten zwei Volksrichtertagungen in Potsdam im September und November 1947 waren denn auch von den Schwierigkeiten bestimmt, die die Absolventen in der Praxis hatten. So berichtete der Volksrichter Heinz Wensierski über seinen Dienstantritt in Cottbus im Oktober 1946: „Der erste Empfang war der erschütterndste. Der Vertreter des Oberstaatsanwalts sagte: ,Meine Herren, wenn Sie sich Ihr Wohlwollen erhalten wollen, dann sorgen Sie dafür, daß ständig etwas zu rauchen da ist'. " 140 Andere Lehrgangsabsolventen hatten positivere Erfahrungen. Bemängelt wurde von allen aber die unzureichende Fortbildung.

Bei den Volksrichtertagungen handelte es sich bereits um reine SED-Veranstaltungen. Der Landesvorsitzende Friedrich Ebert formulierte die Ansprüche der Partei an die frischgebackenen Juristen: „Im übrigen bin ich der Meinung, daß Ihr als Richter die Gesetze so anzuwenden versteht, daß sie im Einklang stehen mit unseren Interessen. “ Sie hätten „sich immer und immer als Funktionäre der Partei zu fühlen " ${ }^{141}$. Bei der Novembertagung 1947 waren Hilde Benjamin und Oberstleutnant Jakupow von der SMAD anwesend. Letzterer zeigte sich über das Niveau der Veranstaltung enttäuscht, Hoeniger fügte hinzu: „Die Teilnehmer machten ausnahmslos einen müden und abgehetzten Eindruck." 142 Als der SMA unmittelbar nach der Tagung zu Ohren kam, daß die Volksrichter schlechter bezahlt würden als ihre anderen Kollegen, ordnete sie sofort die gleichwertige Entlohnung an ${ }^{143}$.

Anfang 1948 arbeiteten in Brandenburg 48 Lehrgangs-Absolventen, die zumeist an den Amtsgerichten tätig waren ${ }^{144}$. In der ganzen SBZ gehörten 1947 erst $20 \%$ der Richter und $28 \%$ der Staatsanwälte der SED an ${ }^{145}$. Dies sind keine hohen Anteile. Allerdings verschleiern diese Zahlen, daß einige SED-Mitglieder in Schlüsselpositionen der Justiz saßen. Besonders der Beginn der deutschen NSVerfahren nach Befehl Nr. 201 im Herbst 1947 brachte die Lehrgangsabsolventen in wichtige Stellen.

137 Feth, Volksrichter, S. 373; vgl. BLHA, Rep. 212, Nr. 40, Bl. 468, Runderlaß der Abt. Justiz Nr. 293, 16. 10. 1946.

138 Vgl. BLHA, Rep. 212, Nr. 313, Bl. 39, Vermerk Abt. Justiz Brandenburg, 14. 11. 1946.

139 Ebenda, Bl. 189-192, Rundschreiben MdJ Brandenburg, 31. 5. 1947, mit Antworten der LG-Präsidenten Eberswalde, Neuruppin und Cottbus.

140 BA, DP-1 VA 20, Bl. 8, Protokoll 3. Volksrichtertagung vom 7. 9. 1947 in Potsdam.

141 Ebenda, Bl. 1..

142 BLHA, Rep. 212, Nr. 295, Bl. 93-94, MdJ an DJV betr. Tagung am 22.11. 1947.

143 BLHA, Rep. 201, Nr. 212, Bl. 165, Befehlsschreiben Nr. 2679 SMA, 30.12. 1947.

144 SAPMO, DY 30/IV 2/1/38, Bl. 106, Fechner auf PV-Tagung zu Justiz, 14./15. 1. 1948.

145 Feth, Volksrichter, S. 369. 


\section{Die Entwicklung der Justiz im politischen Kräftefeld 1946/47}

Aus der Retrospektive wird sichtbar, daß eine eigenständige brandenburgische Politik innerhalb der SBZ nur in den Jahren bis 1947 und nur in eingeschränktem Maße möglich war. Welchen Weg die Justiz in der Provinz gehen würde, hing stark von den Machtverhältnissen und rechtspolitischen Vorstellungen der Akteure, aber auch von der Sondersituation nach dem Krieg ab. Insbesondere in der Zeit bis 1948 verschob sich das politische Koordinatensystem der SBZ nahezu ununterbrochen. Anfang des Jahres 1946 schienen die politischen Verhältnisse zunächst einigermaßen konsolidiert, die Verwaltungen und der Justizapparat waren in den Grundzügen aufgebaut.

\section{a. Die sowjetische Militärverwaltung}

Der entscheidende Ansprechpartner für die Justizabteilung war die sowjetische Militärverwaltung. Angesichts der eingeschränkten Kenntnisse, die bisher über die Struktur der SMAD und besonders der SMA vorliegen ${ }^{146}$, kann eine Rekonstruktion von deren Rechtspolitik erst in Ansätzen vorgenommen werden. Wie es scheint, hatte die SMA Brandenburg bis Anfang 1948 keine eigene Rechtsabteilung ${ }^{147}$. Dies dürfte ein wichtiger Grund dafür gewesen sein, daß Hoeniger und seine Angestellten des öfteren mit der Rechtsabteilung der SMAD in BerlinKarlshorst unter Jakow Karassjow verhandeln mußten ${ }^{148}$. Von dort kamen alle grundlegenden Anweisungen in Justizfragen. Die SMAD genehmigte die Länderkonferenzen der Justiz, hielt aber die Kompetenzverteilung zwischen DJV und den Länderjustizverwaltungen eher in der Schwebe. Sie war über alle Gesetzentwürfe rechtzeitig zu informieren; zu diesem Zweck besuchte Hoeniger Major Kurbatow in Berlin. Dieser ordnete auch die Vorlage von Stellenplänen an ${ }^{149}$. Allgemein drängte die Rechtsabteilung alle Provinzen und Länder dazu, sich eine einheitliche Struktur in der Justizverwaltung zu geben ${ }^{150}$.

Relativ selten waren Kontroll-Revisionen der SMAD-Rechtsabteilung in Brandenburg. Bald nach Erlaß des Befehls Nr. 49 schickte die Abteilung Mitarbeiter durch die Provinzen; Karassjow wertete diese Touren als vollen Erfolg151. Oberstleutnant Jakupow, der für Fragen der Gerichtsorganisation zuständig war, reiste

146 Vgl. dazu grundlegend: Foitzik, Sowjetische Militäradministration - Struktur. Ungeklärt ist etwa, inwieweit die SMAD-Rechtsabteilung nur Vollzugsorgan der Innenabteilung war, ebenda S. 29.

147 BA, DP-1 VA 116, Bl. 14, Präsident Provinzialverwaltung Brandenburg an Scharow, 13. 6. 1946, erwähnt eine Rechtsabteilung der SMA Potsdam. Wahrscheinlich wurde deren Existenz aber nur vermutet.

148 Vgl. BLHA, Rep. 212, Nr. 20, Bl. 1-5, 88-91, Bericht der Abt. Justiz an die SMA über die Rechtspflege in Brandenburg vom 20.7.-20. 8. 1946, 29.8. 1946; dasselbe, 30.10. 1946. Zur SMADRechtsabteilung vgl. Amos, Justizverwaltung, S. 17.

149 BA, DP-1 VA 120, Bl. 1, Abt. Justiz Brandenburg an DJV, 21. 2. 1946; BLHA, Rep. 212, Nr. 264, Bl. 8, Abt. Justiz Brandenburg an SMA, 6.11.1945.

150 Anders, Diss., Kap. III, S. 3; SAPMO, DY 30/IV 2/13/433, Protokoll der Konferenz der Länderjustizminister am 14./15. 6. 1946.

151 Bericht Karassjow an den stellv. Außenminister Wyschinski, 14. 11. 1945, abgedruckt bei Laufer, SSSR i germanskij wopros, Band 2 (iVb). 
im Juli 1946 zehn Tage lang durch die Provinz, besuchte zahlreiche Gerichte und ließ sich deren Urteile vorlegen; Major Nikolajew befand sich Ende November 1946 gleich für mehrere Tage zu Besprechungen in der Justizabteilung 152 .

Der Präsident des Oberlandesgerichts und der Generalstaatsanwalt waren direkt der SMAD berichtspflichtig ${ }^{153}$. Darüber hinaus forderte die SMAD-Rechtsabteilung von der Abteilung Justiz immer wieder Sonderberichte, so zur Jugendkriminalität oder zum Strafvollzug ${ }^{154}$. Die Anforderungen der SMAD erwecken hin und wieder den Eindruck, daß deren Rechtsabteilung über die brandenburgische Entwicklung nicht ganz auf dem laufenden war. So forderte sie im November 1946 über die DJV alle Gesetze und Verordnungen aus der Provinz an ${ }^{155}$.

Die Rechtspolitik der brandenburgischen Militärverwaltung (SMA) ist noch schwerer zu durchschauen. Die ersten Weisungen und Berichtsaufträge kamen im Sommer 1945 vom stellvertretenden Gerichtsoffizier der SMA, Oberleutnant Tschaikowski156. Ab September 1946 waren alle Eingaben der Justizverwaltung an den Leiter der Innenabteilung, Oberst Gami, zu richten. Monatsberichte hingegen gingen an Oberstleutnant Gofschtein ${ }^{157}$. Gami beschäftigte sich im allgemeinen mehr mit Polizeifragen, bei Einzelproblemen wie etwa Straftaten gegen die Ernährungswirtschaft beorderte er auch Vertreter der Justizabteilung zu sich ${ }^{158}$. Für die Überwachung der Generalstaatsanwaltschaft war der "Generalprokuror der Mark Brandenburg“ Major Fatow zuständig, der bis 1948 zu einem der wichtigsten Justizoffiziere für die Brandenburger wurde ${ }^{159}$.

Vom Sommer 1947 an wechselten offensichtlich die sowjetischen Ansprechpartner für die deutsche Justiz. Die Berichte wurden von nun an immer Major Schipkow übersandt, ab Ende 1947 auch an Leutnant Antschupan, der 1948 in der SMA-Rechtsabteilung als Fachberater (Ekspert-konsultant) die deutsche Justiz betreute ${ }^{160}$. Oberstleutnant Anochin führte zeitweise die Innenabteilung; er schaltete sich in alle Fragen von Polizei und Strafvollzug ein. Sporadisch ergaben sich auch Kontakte mit anderen Bereichen der SMA, so etwa mit der Finanzabteilung, die auch den Justizetat überwachte.

Die Weisungen der SMA ergingen auf verschiedenen Wegen ${ }^{161}$. Nur wenige grundlegende Justizfragen regelte die Militärverwaltung in Form von regulären SMA-Befehlen ${ }^{162}$. Erheblich häufiger waren sogenannte Befehlsschreiben, die ins-

152 BA, DP-1 VA 325, Bl. 283, Vermerk DJV (Stackelberg), 2. 8. 1946; BLHA, Rep. 212, Nr. 6, Bl. 170-177, Tätigkeitsbericht Abt. Justiz für 19. 11.-18. 12. 1946, 18. 12. 1946.

153 BLHA, Rep. 203, Nr. 21, Bl. 295, SMAD-Rechtsabteilung Nr. 15/24184 an OLG und GStA der Länder, 9. 3. 1946.

${ }^{154}$ BLHA, Rep. 212, Nr. 40, Bl. 289-292, Runderlaß der Abt. Justiz Nr. 205, 19. 6. 1946, und Nr. 209, 20.6. 1946.

155 BLHA, Rep. 202A, Nr. 136, Bl. 14, DJV an Abt. Justiz Brandenburg, 14. 11. 1946.

156 Foitzik, Sowjetische Militäradministration - Struktur, S. 453, führt Tschaikowski als Leiter der Rechtsabteilung an.

157 BLHA, Rep. 212, Nr. 313, Bl. 12, interne Anweisung Abt. Justiz, 30. 8. 1946.

158 BLHA, Rep. 203, Nr. 25, Bl. 120-134, Abt. Justiz an Gami, 27. 10. 1946.

159 Ab 19. 1. 1948 trat Fatow an die Stelle von Schipkow, BLHA, Rep. 212, Nr. 25, hdschr. Entwurf MdJ an SMA, 12. 12. 1947. Vgl. BLHA, Rep. 203, Nr. 21, Bl. 136, Militärstaatsanwalt Nr. 510160 an Justiz Brandenburg, 6. 2. 1946, das von einem Gardemajor Besfamilnow gezeichnet ist.

160 Der bei Geßner, Befehle der SMA Brandenburg, S. 21, erwähnte Major Sachwatow übernahm erst etwa im Mai 1948 die Rechtsabteilung. Siehe unten S. 107.

161 Vgl. dazu Foitzik, Sowjetische Militäradministration - Struktur, S. $301 \mathrm{ff}$.

$162 \mathrm{Vgl}$. Befehle der Sowjetischen Militäradministration, S. $25 \mathrm{ff}$. 
besondere für die Abstellung einzelner Mißstände genutzt wurden. Diese Befehlsschreiben waren für alle SMA-Abteilungen gemeinsam durchnumeriert, insgesamt belief sich ihre Zahl auf bis zu zehntausend jährlich (für alle Abteilungen) ${ }^{163}$. Oftmals richteten sie sich direkt an den Provinzialpräsidenten, auch wenn sie Justizfragen behandelten. Ein Weisungskanal, der kaum noch zu rekonstruieren ist, sind die vielen Telefonate der SMA mit der Justizabteilung. Insbesondere außerordentliche Berichtsaufträge wurden telefonisch erteilt ${ }^{164}$. In die andere Richtung lief die Berichterstattung der Justizabteilung, meist Monatsberichte und Sonderberichte zu Einzelfragen, wobei durch deren Übersetzung Verzögerungen eintraten.

Die SMA war zugleich die höchste politische und die höchste Rechtsinstanz in Brandenburg. Bis 1947 mußten alle Todesurteile der deutschen Justiz der Militärverwaltung zur Genehmigung vorgelegt werden. Ihr Hauptaugenmerk richtete die SMA aber auf das Personal in der Provinzialjustiz. Nach den ersten Personalerfassungen im Herbst 1945 wurden immer detailliertere Personalaufstellungen eingefordert. Ab März 1947 mußten darin unter anderem die Westverwandten der Justizangehörigen vermerkt werden ${ }^{165}$.

Anfang 1947 wies die SMA das Justizministerium an, eine Revision der gesamten Strafrechtspflege durchzuführen ${ }^{166}$. Erstmals wollten sich die Besatzungsbehörden einen umfassenden Überblick über die Gerichte verschaffen. Die Überprüfungen bei den Amtsgerichten Oranienburg, Bernau, Angermünde und Eberswalde vom Januar/Februar 1947 zeitigten aus Sicht der sowjetischen Verantwortlichen katastrophale Ergebnisse. Die Militärverwaltung sah gar eine „verbrecherische Tätigkeit" einiger Justizangestellter, insbesondere Unterschlagungen beim AG Oranienburg. Des weiteren beklagte sie schlechte Ermittlungen, zu milde Urteile und Berufungsurteile, zu lange Untersuchungshaft und Ausbrüche aus den Gerichtsgefängnissen. Die Vorwürfe mündeten in den harschen Befehl Nr. 45 der SMA vom 10. März 1947, der die Abstellung der Mißstände und die Festnahme des Oranienburger Amtsrichters Fandrich anordnete ${ }^{167}$. Fünf Wochen später konnte das Justizministerium über die Erfüllung des Befehls berichten: Man habe Strafverfahren gegen einen Richter und einen Amtsanwalt eingeleitet und das Personal bei Revisionen an 43 Orten überprüft. Noch verbliebene Personen mit $\mathrm{Zu}$ gehörigkeit zu NS-Organisationen seien entlassen oder auf tägliche Kündigung eingestellt worden. Die Masse der Mängel sei aber auf äußere Umstände wie die schlechte Ermittlungsarbeit der Kripo zurückzuführen ${ }^{168}$.

Besonders in Verfahren wegen Wirtschaftsstrafsachen griff die SMA des öfteren ein. Sie forderte Akten an, drängte auf schnelle und harte Aburteilung und ord-

163 Vgl. BLHA, Rep. 202A, Nr. 90-134. Die Schreiben sind nur zum Teil erhalten, vermutlich unterlagen sie oft der Rückgabepflicht.

16+ Dies geht aus den Bezugsvermerken vieler Schreiben an die SMA hervor.

165 BLHA, Rep. 240 Eberswalde, Nr. 11, Bl. 9, Rundschreiben LG Eberswalde an alle AGe, 14. 3. 1947.

166 BA, DP-1 VA 14, B1. 9, Protokoll der Konferenz der GStA am 25.-26. 4. 1947.

167 BLHA, Rep. 203 MdI/LBdVP, Nr. 9, Bl. 12-15, SMA-Befehl Nr. 45, 10. 3. 1947.

168 BLHA, Rep. 212, Nr. 594, Bl. 57-66, MdJ an SMA, 29. 4. 1947. Zum Fall Fandrich: Löwenthal, Der neue Geist von Potsdam, S. 18-23. 
nete in vielen Fällen schriftlich die Bestrafung bestimmter Personen an ${ }^{169}$. Auf diesem Feld dominierten bis 1947 die Kommandanturen. Die Gerichte mußten in der Regel wöchentlich beim Kommandanten Bericht erstatten. In den sowjetischen Kreisbehörden saß in der Regel ein Gerichtsoffizier. Die Eingriffe ins deutsche Justizleben unterschieden sich von Ort zu Ort. Der Kreiskommandant von Neuruppin und sein Wirtschaftsoffizier beispielsweise setzten das Amts- und Landgericht immer wieder unter Druck ${ }^{170}$. Die SMA untersagte den Kommandanturen mehrfach die eigenmächtige Intervention in Justizfragen, besonders ab 1947171 . Anscheinend gelang es der Rechtsabteilung in Potsdam ab 1948, die Kompetenzen weitgehend an sich zu ziehen. An vielen Orten entwickelte sich die Zusammenarbeit der Gerichte aber auch ohne Friktionen. Ab August 1947 wurde die Zahl der lokalen sowjetischen Vertretungen allmählich reduziert; damit ließ auch die Kontrolle vor Ort nach ${ }^{172}$.

Sehr diffus ist das Bild der sowjetischen Geheimpolizei in der Justizpolitik, die im gesamten Bereich der Innenpolitik inklusive der Justiz ein gewichtiges Wort mitzureden hatte. Während in anderen Ländern die Einflußnahme von NKWD und MGB auf den Justizapparat klar nachweisbar ist ${ }^{173}$, bleibt sie für Brandenburg weitgehend im dunkeln. Sicher ist, daß die Operativen Gruppen in den einzelnen Städten unmittelbaren Zugriff auf die Volkspolizei hatten. Vor Ort behielten sich Dienststellen des NKWD die Genehmigung von Verhaftungen vor ${ }^{174}$, griffen öfters in Verfahren ein, zogen Akten an sich oder untersagten deutsche Ermittlungen. Die SMA selbst versuchte die lokalen Eingriffe wenn nicht zu verhindern, so doch zu kontrollieren. Offiziell waren Aktenabgaben an Kommandanten und Operative Gruppen von der SMA und dem Generalstaatsanwalt zu genehmigen. Im Mai 1948 ordnete der Operative Sektor in Potsdam an, daß alle Einmischungen der Operativen Gruppen in Rechtssachen der SMA zu melden seien ${ }^{175}$. Zeigte sich die Operative Gruppe an Verfahren desinteressiert, die in ihre eigene Kompetenz fielen, so gingen sie an die deutschen Gerichte über ${ }^{176}$. Beim Landgericht Neuruppin forderte die Operative Gruppe des MGB nicht nur Personalaufstellungen des Gerichts an, sondern legte auch den Termin für die Hauptverhandlung in einer

169 SAPMO, DY 30/IV 2/13/109, Bl. 43, Protokoll der Innenministerkonferenz am 1. 6. 1947; BLHA, Rep. 202A, Nr. 420, Bl. 104-105, Hoeniger an Scharow, Juni 1947, mit Bezug auf SMA-Befehl Nr. 71 vom 19. 4. 1947; BLHA, Rep. 201, Nr. 212, Bl. 54, Befehlsschreiben Nr. 3872 SMA, 6. 6. 1947.

170 SAPMO, DY 30/IV 2/13/407, Notiz über Gespräch Hoeniger mit Max Berger, 5.11. 1947; BLHA, Rep. 212, Nr. 595, Bl. 109-113, Bericht MdJ Brandenburg über Besuch bei LG und StA Neuruppin, 17. 1.1948.

171 Vgl. BLHA, Rep. 212, Nr. 1072, Bl. 18-19, Vermerk Hoeniger, 6. 11. 1947; BLHA, Rep. 212, Nr. 43, Rundverfügung MdJ Brandenburg Nr. 100, 9. 4. 1949.

172 Foitzik in: Inventar der Befehle, S. 9.

173 Weber, Rechtsstaat Thüringen, S. 121. Für Außenstehende waren NKWD/MWD und NKGB/ MGB ab Ende 1946 nicht genau abgrenzbar, während das MGB immer mehr exekutive Befugnisse an sich zog, vgl. Murphy/Kondrashev/Bailey, Battleground Berlin, S. 461. Deshalb wird im folgenden in der Regel die Bezeichnung aus der zeitgenössischen deutschen Sicht übernommen.

174 BA, DO-1/7/146, Bl. 225, Abt. K DVdI an Mielke, 4. 11. 1947.

175 BLHA, Rep. 212, Nr. 29, Bl. 14, Vermerk MdJ über Gespräch mit Major Moisejew von der „Zentrale der operativen Gruppe“, 14. 5. 1948.

176 BLHA, Rep. 212, Nr. 43, Rundverfügung MdJ Brandenburg Nr. 100, 9. 4. 1949; BLHA, Rep. 212, Nr. 41, Bl. 375, Rundverfügung MdJ Brandenburg Nr. 233, 7.9. 1947, mit Bezug auf eine neue Weisung der SMA. 
Waffenbesitz-Sache fest und ordnete einen Schauprozeß an ${ }^{177}$. In mindestens einem Fall griff die Geheimpolizei direkt in die Gesetzgebung ein: „Den Text der Verordnung hat s.Zt. der Leiter der NKWD Potsdam mündlich festgelegt. ${ }^{\text {" }} 178 \mathrm{Da}$ neben übernahm die sowjetische Geheimpolizei Überprüfungen von Justizpersonal, insbesondere wenn ein Verdacht auf NS-Belastung auftauchte. Das NKGB/ MGB versuchte, in der ganzen SBZ ein Spitzelnetz zu etablieren. Anscheinend war dieses Unternehmen aber nicht so erfolgreich, wie man bisweilen annimmt. Geplant waren wohl 50 Informanten auf 1000 Einwohner, angeworben werden konnten 1949 aber nur etwa 3000 Personen in der ganzen Besatzungszone ${ }^{179}$. Es ist anzunehmen, daß die zuständige Dritte Abteilung des MGB sich bemühte, einzelne Justizfunktionäre an wichtigeren Stellen wie dem Justizministerium oder den Landgerichten als Informanten zu verpflichten. Mit ziemlicher Sicherheit läßt sich dies aber erst ab 1949/50 nachweisen ${ }^{180}$.

Die massivste Intervention der Besatzungsmacht in den Justizapparat waren die Verhaftungen von Angestellten. Von Ende 1945 bis Sommer 1947 betraf dies mindestens drei Justizangehörige ${ }^{181}$. Das NKWD scheute sich nicht einmal, Anfang 1946 KPD-feindliche Richter aus den Westsektoren Berlins zu entführen und im Lager verschwinden zu lassen ${ }^{182}$. Im September 1947 geriet ein mecklenburgischer Richter in die Fänge des MGB. Über ein Jahr später, im Dezember 1948, nahm das MGB den Cottbusser Landgerichtsrat Bruno Goll fest. Ursache dafür waren anscheinend sein Verhältnis zum SED-Kreisverband und einige politische Äußerungen ${ }^{183}$. Im gleichen Jahr ereilte die Sekretärin von Hoenigers Stellvertreter dieses Schicksal ${ }^{184}$. Es folgte im Mai 1949 die Verhaftung eines weiteren Richters aus Cottbus, der sogar selbst an politischen Verfahren beteiligt gewesen war ${ }^{185}$. Die

177 BA, DP-1 VA 412, Bl. 113, LG Neuruppin an MdJ Brandenburg, 25. 9. 1947; BLHA, Rep. 212, Nr. 595, Bl. 90e-d, Vermerk Ostmann über Besuch in Neuruppin am 10. 12. 1947; BLHA, Rep. 240 Neuruppin, Nr. 12, LG-Präsident Neuruppin an Chef der operativen Gruppe, 24. 1. 1948.

178 BA, DP-1 VA 116, Bl. 100, Hoeniger an DJV, 31. 5. 1947; gemeint ist die VO zur Bestrafung von Sterilisationen, siehe unten S. 160 f.

179 Foitzik, Organisationseinheiten und Kompetenzstruktur, S. 131; Sacharov/Filippovych/Kubina, Tschekisten in Deutschland, S. 310 f. Am 1. 1. 1946 waren 2304 Informanten in der SBZ registriert, Semiryaga, Wie Berijas Leute, S. 748.

${ }_{180}$ Murphy/Kondrashev/Bailey, Battleground Berlin, S. 38. Siehe unten, S. 120; zur Verpflichtung von Antifa-Kadern für das MWD/MGB vgl. Foitzik, Die stalinistischen Säuberungen, S. 415. Ein Amtsanwalt beim LG Potsdam gab einem Kollegen gegenüber lediglich einmal an, 1945/46 „für die SMA“ gearbeitet zu haben, BStU ZA AIM 609/53, Bl. 39; vgl. den Fall Albrecht, siehe S. 250.

181 IfZ, OMGUS 2/99-2/12, „Report on Disappearences of Judges in the Russian Zone“, o.D., zum Verschwinden eines Richters auf der Polizei in Teltow am 26. 12. 1945; BA, DP-1 VA 76, Bl. 1422, Liste der Justizangehörigen in Brandenburg, die vom 1.1.1946 bis 10.8. 1947 entlassen wurden.

182 Berlin 1945-1946, S. 335, 371 (25. 1. 1946); Filippovych, Sowetskaja woennaja administrazija, S. 55 (damit brüstete sich Serow später gegenüber Stalin).

183 Bartusel, Politisierung der Justiz, S. 45; BA, DP-1 VA 1024, Bl. 118, 227, MdJ Brandenburg an DJV, 13. 10. 1947, Vermerk DJV, 28. 12. 1948; BLHA, Rep. 212, Nr. 494, B1. 278, Hoeniger an LG Cottbus, 10. 1. 1949; AdsD, Ostbüro 0048a, Bericht über Cottbusser Justizbehörden, 8. 6. 1949. Es ist nicht klar, ob es sich hierbei um Auseinandersetzungen mit der SED handelte oder ein $\mathrm{Zu}$ sammenhang mit den Verhaftungen von SED-Funktionären besteht.

184 Erwähnt in BStU, ASt. Potsdam, AOP 192/55, Band 2, Bl. 37, Bericht Abt. VI LVerw., 26. 5. 1951. Ein Hinweis auf die MGB-Verhaftung eines Volksrichter-Schülers im 3. Lehrgang 1948 befindet sich in BAK, B 209/257, Informationen zur richterlichen Besetzung des BG Potsdam zum 20. 11. 1952.

185 BA, DP-1 VA 687, Revision DJV (Reuter) bei StA und LG Cottbus, 9. 6. 1949. 
breitere Kriminalisierung von Justizpersonal setzte aber erst Ende 1949 ein und wurde dann vom SED-Apparat betrieben.

Wie sich die sowjetische Militäradministration konkret den Aufbau und die Entwicklung der Justiz vorstellte, läßt sich nur indirekt erschließen. Zunächst einmal ist anzunehmen, daß nur ein sehr geringer Teil der Offiziere auch Rechtserfahrung hatte. Dies waren an erster Stelle SMA-Zivilchef Scharow, der Jura studiert hatte ${ }^{186}$, und vor allem Militärjuristen wie Fatow. Darüber hinaus hatten wohl nur einzelne detaillierte Kenntnisse vom sowjetischen Justizsystem. Inwieweit das deutsche Rechtswesen bekannt war, ist nicht zu rekonstruieren. Für mehr als Schnellkurse war hier wohl kaum Zeit; zudem hatten anfangs nur wenige deutsche Sprachkenntnisse ${ }^{187}$. Also orientierten sich die Militärstellen in Brandenburg an den SMAD-Weisungen und an den Bedürfnissen der Nachkriegszeit. Die grundlegenden SMAD-Weisungen aber zielten zunächst auf eine formale Wiederherstellung der Justiz der Weimarer Republik, mit der Beseitigung der organisatorischen und der meisten rechtlichen Neuerungen des NS-Regimes.

Die Prärogative der sowjetischen Militärjustiz stand außer Diskussion. Dies umfaßte alle Verfahren gegen Sowjetsoldaten, bei Straftaten, in die sowjetische Staatsbürger verwickelt waren, bei Waffenbesitz und zunächst bei allen politischen Ermittlungen. Daran erinnerte die SMA wiederholt ${ }^{188}$.

Allerdings setzte die sowjetische Justizverwaltung schon frühzeitig einige Akzente, die auch vom eigenen Rechtssystem beeinflußt waren: Dies betraf die explizite Förderung der Volksrichter, die Durchführung von Schau- bzw. Lehrprozessen im lokalen Rahmen, oder die Führung von Kriminalitätsstatistiken nach sozialen Herkunfts-Merkmalen ${ }^{189}$. Im großen und ganzen ging dies jedoch mit der Haltung der deutschen Justizverwaltung konform.

\section{b. Begrenzte Einflußnabme der DJV 1946/47}

Während die Militärverwaltung praktisch unbegrenzte Eingriffsmöglichkeiten in die brandenburgische Justiz hatte, mußte die Deutsche Zentralverwaltung für Justiz (DJV) darum kämpfen, allmählich auch ein Mitspracherecht in Brandenburg zu erlangen. Nachdem erste derartige Bestrebungen Ende 1945 von der SMAD abgeblockt worden waren, etablierte sich die DJV 1946 zunehmend als Koordinationsinstanz für die Länder.

Im Februar 1946 verschärfte sich die Debatte um das Statut der DJV. Während der thüringische Ministerpräsident Paul dieses rundweg ablehnte, erhob Steinhoff zwar auch „ernstesten Protest“, äußerte aber vorwiegend einzelne sachliche Einwände gegen das Vorläufige Statut, das die Kontrolle und Lenkung der Justiz durch die DJV vorsah, insbesondere die Aufsicht über das Personalwesen. Gerade wegen der Finanzierung des Justizapparates durch die Provinzen und Länder sei

186 SAPMO, SgY 30/1307, Bl. 23, Erinnerungen Karl Steinhoff; Steinhoff, In der Mark Brandenburg, S. 548.

${ }_{187}$ Vgl. Naimark, Russians, S. 40: Im März 1946 ordnete die SMAD obligatorische Sprachkurse an.

188 Beispielsweise BLHA, Rep. 212, Nr. 41, Bl. 187, Rundschreiben MdJ Brandenburg Nr. 119, 1. 6. 1947.

189 BLHA, Rep. 203, Nr. 21, Bl. 295, SMAD-Rechtsabteilung Nr. 15/24184 an OLG und GStA der Länder betr. Monatsberichte, 9. 3. 1946. 
dies unerträglich. Insgesamt nannte Steinhoff die Zentralisierung eine „höchst unglückliche Maßnahme" und kündigte Protest bei der Besatzungsmacht an ${ }^{190}$. Eine Neufassung des Statuts kam jedoch nicht zustande. Noch im Oktober 1947 beschwerte sich Schiffer, daß Brandenburg die Rechtsvereinheitlichung ablehne und dies mit der fehlenden Rechtsgrundlage hierfür wie mit der eigenen Rechtsprechung des Oberlandesgerichts begründe. Im übrigen habe Potsdam den nachgeordneten Dienststellen jeglichen direkten Schriftverkehr mit der DJV untersagt und verhindere somit die Kontrolle ${ }^{191}$.

Allerdings hatte die DJV gegenüber den Landes- und Provinzialjustizverwaltungen den Vorteil, daß sie direkten Kontakt zur Rechtsabteilung der SMAD besaß. Deshalb war sie nicht nur besser über die sowjetische Justizpolitik informiert, sondern konnte auch einen begrenzten Einfluß auf die Entscheidungsbildung in der zuständigen SMAD-Abteilung nehmen. Kein Zweifel bestand in Brandenburg an der Berichtspflicht der Justizabteilung gegenüber der DJV.

Während eine Weisungsgebung 1946/47 nicht durchsetzbar war, mußte sich die DJV mit einem anderen Forum behelfen, den Länderjustizkonferenzen. Ein erstes Treffen der Oberlandesgerichtspräsidenten und Leiter der Justizabteilungen hatte am 15./16. Februar 1946 stattgefunden. Schon die Zusammenkunft vom 11. März 1946 zeigte aber, daß sich diese Konferenzen auf die Parallelisierung der Gesetzgebung konzentrierten. Unter Aufsicht von Nikolajew und Lyssjak von der SMAD-Rechtsabteilung wurden dabei die brandenburgischen Alleingänge bei den Amnestien, bei der Bestrafung von Zwangssterilisationen und sogenannter Gerüchtemacherei durch die DJV kritisiert. Beim Folgetreffen am 3. Mai nahm die Provinz keine so exponierte Position mehr ein. Am 14./15. Juni 1946 drängte die SMAD auf eine stärkere Vereinheitlichung, diesmal in der Struktur der Justizabteilungen ${ }^{192}$. Die vierte Länderjustizkonferenz am 16. August 1946 markierte einen weiteren Vorstoß der DJV in die Struktur der Justizapparate. Schiffer schlug vor, Personalfragen der Richter und die Revision der Rechtsprechung - wie vor 1933 und wie in Teilen der britischen Zone - auf die Oberlandesgerichte zu verlagern. Die Vertreter der Länder und Provinzen winkten ebenso wie die SMAD ab. Der Druck der DJV blieb jedoch bestehen ${ }^{193}$. Im November/Dezember 1946 rückte das Problem der Lenkung und Kontrolle in den Hintergrund. Allerdings verlagerte sich die Diskussion nun auf die Personalfragen, die der DJV ja besonders am Herzen lagen ${ }^{194}$. Auf der Siebten Länderkonferenz im April 1947 erklärte der SMAD-Vertreter die DJV zum Leitungs- und Kontrollorgan für das Gerichtswesen: „Die Anweisungen der DJV sind von allen Justizministerien der Länder

190 BA, DP-1 VA 2, Bl. 6-8, Präsident Provinzialverwaltung Brandenburg an DJV, 14. 2. 1946. Lorenz, Deutsche Zentralverwaltung der Justiz, S. 148.

191 BA, DP-1 VA 3, Bl. 103-113, Denkschrift DJV (Schiffer) zur Rechtseinheitlichkeit, 16. 10. 1947.

192 SAPMO, DY 30/IV 2/13/433, Protokoll der Konferenzen der Länderjustizminister, 11.3., 3.5., 14./15.6. 1946 .

193 BA, DP-1 VA 22, Bl. 45-52, Konferenz der Länderjustizminister am 16. 8. 1946. Benjamin, Zur Leitung der Rechtsprechung, S. 788, 791, interpretiert dieses Treffen allerdings als Durchbruch zur Justizleitung. Heilbronn, Aufbau der nordrhein-westfälischen Justiz, S. 5 ff., spricht für diese Zeit vom „Regiment“ der Oberlandesgerichtspräsidenten im späteren Nordrhein-Westfalen.

194 BA, DP-1 VA 22, Bl. 53-88, 89-94, Konferenz der Länderjustizminister am 1./2.11. und 13.12. 1946. 
und Provinzen zu erfüllen." ${ }^{195}$ Aber dies war lediglich ein Wechsel auf die $\mathrm{Zu}$ kunft. Denn erst auf dem Treffen der Länderjustizminister am 29. August 1947 war eine neue Grundlage für DJV-Weisungen gegeben, nämlich der Befehl Nr. 201196. Alle diese Treffen zeigen, wie zögerlich die SMAD 1946/47 an die Zentralisierung - genauer: Zonalisierung - der Justiz ging. Nur bei wenigen Essentials wurden der DJV frühzeitig zentrale Kompetenzen übertragen.

Die Personalpolitik war das eigentliche Feld, auf dem Schiffer und seine Personalleiter mit den Ländern haderten. Zwar hatte die DJV die Aufgabe, die Durchführung der Entnazifizierung nach Befehl Nr. 49 zu überwachen, darüber hinaus stieß sie immer wieder an Grenzen. Die Zentralverwaltung konnte keine Stellen besetzen, ja hatte in einigen Bereichen nicht einmal einen Überblick über die Personalpolitik außerhalb Berlins. Schiffer protestierte nicht nur gegen die Ernennung Löwenthals zum Oberlandesgerichts-Präsidenten, sondern auch gegen die Besetzung des Landgerichts Potsdam durch Kurt Regel, von der er erst im nachhinein erfahren hatte ${ }^{197}$. Die DJV mahnte etwa die Meldung aller Dienstaufsichtsverfahren gegen Richter und aller Entlassungen aus politischen Gründen an ${ }^{198}$. Nur in Ausnahmefällen wie dem Korruptionsskandal am Oranienburger Amtsgericht konnte die DJV konkrete Anweisungen in der Personalpolitik geben ${ }^{199}$. Erst bei den Problemen, die mehrere Länder bzw. Provinzen gleichzeitig berührten, gelang es der Zentralverwaltung, sich auch durchzusetzen. Beispielsweise dämmte sie die Abwanderung von Richtern aus Brandenburg in den Sowjetsektor Berlins ein. Ebenso wies sie Potsdam an, Kündigungen von Justizpersonal zu verhindern 200 .

Der eigentliche Hebel für die DJV war jedoch die Volksrichterschule. Nachdem die interne Debatte um die Volksrichter zwischen den DJV-Mitgliedern beendet war, versuchte die Zentralverwaltung möglichst großen Einfluß auf deren Ausbildung und Einsatz zu gewinnen. Grundsätzlich wollte die DJV die Richtlinien zur Auswahl der Anwärter und den Lehrplan herausgeben sowie auf die Berufung der Dozenten Einfluß nehmen. Die Länder wiederum waren für Organisation und Finanzierung zuständig. Jeder Volksrichter-Lehrgang wurde von einem DJV-Vertreter mindestens einmal besucht. Außer der schlechten räumlichen Unterbringung hatte er dabei meist nur wenig auszusetzen ${ }^{201}$.

Die DJV sah nicht nur für die Volksrichter, sondern auch für die verbliebenen Volljuristen die Notwendigkeit zu weiterer Information. Deshalb ordnete sie im April 1946 die Abhaltung monatlicher politischer Fortbildungsveranstaltungen an. Tatsächlich fehlten dafür aber die organisatorischen Voraussetzungen. Wegen der Arbeitsüberlastung und der schlechten Verkehrswege war es nicht möglich, einmal im Monat alle Richter und Staatsanwälte eines Landgerichtsbezirks zu ver-

195 Zur Geschichte der Rechtspflege 1945-1949, S. 186.

196 BA, DP-1 VA 19, Konferenz der DJV vom 29. 8. 1947.

197 BA, DP-1 VA 1024, Bl. 26-27, Schiffer an SMAD, 14. 1. 1947 (Entwurf).

198 Ebenda, Bl. 52, 62, Runderlaß DJV, 26. 2. 1947; Runderlaß DJV (Melsheimer), 18. 4. 1947.

199 BA, DP-1 VA 1024, Bl. 71, DJV (Melsheimer) an MdJ Brandenburg, 29. 5. 1947.

200 BLHA, Rep. 212, Nr. 269, Bl. 15, 16a, DJV an MdJ Brandenburg, 30. 5. 1947; DJV an MdJ Brandenburg, 11.7. 1947.

201 BLHA, Rep. 212, Nr. 313, Bl. 184-187, 324-327, DJV-Bericht über Revision des Lehrgangs Potsdam (Hartwig), 30. 4. 1947; Bericht DJV (Hartwig) über Besuch des 3. Lg., 27. 10. 1947. 
sammeln, schon gar nicht über mehrere Tage hinweg. Deshalb blieben Richtertagungen bis 1948 eher sporadisch ${ }^{202}$.

Nicht nur beim führenden Gerichtspersonal verlangte Schiffer ein Mitspracherecht, sondern auch im Strafvollzug. Die DJV strebte ein Bestätigungsrecht für alle Anstaltsleiter an, ohne damit bei der SMAD durchzudringen ${ }^{203}$. Sie arbeitete zudem zentrale Referendars- und Assessorenprüfungsordnungen sowie eine $\mathrm{Zu}$ lassungsordnung für alle Rechtsanwälte aus und sandte sie den Ländern und Provinzen $\mathrm{zu}^{204}$.

Im Bereich der Rechtsprechung erlangte die DJV erste Kompetenzen durch den SMAD-Befehl Nr. 160 über Sabotage vom 3. Dezember 1945. Die DJV regelte mit ihrer Durchführungsverordnung die Zuständigkeit der Landgerichte bei der Anwendung des Befehls und war von der SMAD mit der Kontrolle der einschlägigen Rechtsprechung beauftragt ${ }^{205}$. Eine ähnlich grundsätzliche Ermächtigung der DJV gab es erst wieder beim Befehl Nr. 201/1947 über die NS-Verfahren.

Die Kontrolle der Justiz lief nicht nur über die Berichterstattung an die DJV, sondern auch - trotz der Bedenken von Steinhoff - über Revisionen einzelner Gerichte durch DJV-Angehörige. Dabei sollten im Idealfall alle Urteile durchgesehen werden. Tatsächlich konnten die Überprüfungen oft nur recht oberflächlich gehalten werden, was zu harscher Kritik seitens der SMAD führte ${ }^{206}$. In den Revisionsberichten der DJV werden die unterschiedlichen Positionen innerhalb der Zentralverwaltung deutlich. Hilde Benjamin revidierte im Oktober/November 1946 die Landgerichts-Bezirke in Brandenburg, nämlich Cottbus, Eberswalde und Neuruppin. Zwar galten Revisionen im allgemeinen dem Geschäftsgang, der Einhaltung von Fristen und ähnlichen formalen Anforderungen. Benjamin monierte jedoch darüber hinaus die Strafurteile wegen mangelnder Ablieferung von Agrarprodukten als viel zu milde ${ }^{207}$.

Letztendlich konnte die DJV bis Anfang 1948 aber keinen direkten Einfluß auf die Justizpolitik und die Rechtsprechung in Brandenburg nehmen. Aus der Sicht Berlins schien das Land daher immer weiter abzudriften. Hoeniger mußte sich im November 1947 eine heftige Schelte bei der DJV abholen: „Vizepräsident Melsheimer betonte insbesondere, daß sogar das insoweit früher besonders ,radikale Land Thüringen in letzter Zeit seine Politik in dieser Hinsicht völlig geändert habe. Ich habe nicht geglaubt, auf diese spitze Bemerkung etwas Positives erwidern zu wollen." 208

202 BLHA, Rep. 212, Nr. 295, Bl. 1-2, 5, 70, DJV an Abt. Justiz Brandenburg, 6. 4. 1946; Abt. Justiz Brandenburg an DJV, 3. 9. 1946; MdJ an DJV, 27. 8. 1947.

${ }^{203}$ BLHA, Rep. 212, Nr. 1195, Bl. 1-2, 6-7, Rundschreiben DJV, 4. 10. 1945; Vermerk Abt. Justiz Provinzialverwaltung (Fähnrich?), 23. 10. 1945 über Besprechung mit Gentz am 20. 10. 1945.

204 18. 6. 1946 Zulassungsordnung für RA der DJV, am 12. 7. 1946 den Provinzialverwaltungen zugeleitet.

205 Zur Geschichte der Rechtspflege 1945-1949, S. 243; BLHA, Rep. 212, Nr. 251, Bl. 6-7, Runderlaß DJV, 19. 12. 1945; Anleitung der DJV zum SMAD-Befehl Nr. 160, 23. 8. 1946.

206 BA, DP-1 VA 12, Bl. 3-14, Zusammenfassender Bericht DJV/II über Revision, 31.12. 1946, auch zum folgenden.

207 BLHA, Rep. 212, Nr. 495, Bl. 138-150, Kontrollbericht Benjamin Justizbehörden Eberswalde am 6./7.11.1946.

${ }^{208}$ BLHA, Rep. 212, Nr. 1072, Bl. 18-19, Vermerk Hoeniger, 6. 11. 1947. 
Trotz der Differenzen zwischen Zentrale und Land sollte nicht unterbelichtet bleiben, daß der inhaltliche Konsens überwog. Auch die brandenburgische Justizverwaltung wurde nicht müde zu betonen, daß es zu keiner Rechtszersplitterung kommen dürfe. Die DJV war lange Zeit keineswegs kommunistisch dominiert. Noch im Oktober 1947 arbeiteten dort lediglich zehn SED-Mitglieder, von denen sechs jedoch auf wichtigen Stellen saßen.

\section{c. Justiz in der Provinzialpolitik 1946}

In der Provinzialregierung nahm 1945 die KPD mit Bechler die Schlüsselstellung ein, auf regionaler Ebene teilten sich KPD und SPD die Posten weitgehend. Die Provinzialverbände beider Parteien traten unmittelbar nach dem Krieg nicht mit einer expliziten rechtspolitischen Linie auf. Zwar enthielten die ersten Aufrufe allgemeine Formulierungen wie das Bestreben zur Wiederherstellung der Rechtssicherheit und zur Bestrafung der NS-Verbrecher, genauere Vorstellungen sind aber 1945 nicht sichtbar ${ }^{209}$. Typisch waren Äußerungen wie die von Friedrich Ebert: „Wir wollen nicht die Wiederkehr einer blutlosen formalen Gerechtigkeit in der Justiz!" 210 Grundsätzlich ging die SPD aber von einer Kontinuität des Rechtssystems aus. Provinzialpräsident Steinhoff kam selbst aus der Justiz und hatte ihre Pervertierung im Dritten Reich mitverfolgt.

Konkreter beschäftigten sich seit Ende 1945 die Zonenverbände von KPD und SPD mit Fragen der Justizpolitik. Der Referent für Justiz und Polizei in der kommunalpolitischen Abteilung der KPD in Berlin, Erich Mielke, legte Ulbricht einen Plan zur Justizreform vor, der u.a. „Volksgerichte zur Aburteilung aller Straftaten, die sich gegen die demokratische Ordnung richteten" enthielt. Damit sollte an die Volksgerichts-Pläne auf lokaler Ebene angeschlossen werden. Die SMADJustizabteilung lehnte Sondergerichte jedoch $a b^{211}$.

Die Zonenverbände von KPD und SPD tauschten sich des öfteren über Justizfragen aus, so etwa über die Bestrafung der NS-Verbrecher, was allerdings bis 1947 kaum in deutsche Kompetenzen fiel212. Im Oktober 1945 begannen beide Parteien, jeweils einen Justizausschuß zu bilden. Bei einer Tagung Berliner KPDJuristen im Januar 1946 forderte Ulbricht bereits, die Einheitsfront mit der SPD in jedem Gericht herzustellen. Tatsächlich gab es fast nirgends KPD-Richter und nur wenige aus der SPD. Auch waren die Vorstellungen in beiden Parteien durchaus unterschiedlich; auf den Treffen der KPD- und SPD-Juristen im Dezember 1945 und Februar 1946 zeichnete sich ein gewisser Dissens ab²13.

Bereits im März 1946, einen Monat vor der Vereinigung von KPD und SPD, wurde der Nukleus für die Justizabteilung der SED gelegt, zunächst als Abteilung für Rechtsfragen unter Karl Polak. Diese war anfangs noch mit allgemeinen Fragen der Bodenreform und der Verfassungsgebung beschäftigt. Erst am 4. August

${ }^{209}$ Vgl. zur KPD: Schöneburg, Kriminalwissenschaftliches Erbe der KPD, S. 39 ff. Eine Übernahme konkreter Vorstellungen aus der Zeit der Weimarer Republik ist nur sehr begrenzt sichtbar.

210 Urban, Vereinigung von KPD und SPD, S. 65.

211 Kubina, In einer solchen Form, S. 356.

212 SAPMO, NY 4036/631, Auszug Notizkalender Pieck, 18. und 23. 7. 1945.

213 SAPMO, DY 30/IV 2/13/404, Protokoll über Sitzung der KPD in der Berliner Justiz mit Ulbricht, 19. 1.1946. 
1946 richtete sie eine erste Besprechung der SED-Juristen aus den Provinzen und Ländern aus. Dort sollte die Formulierung eines SED-Justizprogramms eigentlich erst vorbereitet werden. Die dabei vorgestellten „Grundsätze zur Erneuerung der Justiz“ waren noch sehr allgemein gehalten, ihre Endfassung wurde erst 1948 veröffentlicht. Konkretere Formen nahm die Justizpolitik der SED Anfang 1947 mit der Installation eines Rechtspolitischen Ausschusses beim Zentralsekretariat an. Der bereitete die Erste Juristenkonferenz der SED am 1./2. März 1947 vor, auf der unter den 100 Parteijuristen für Brandenburg Hoeniger, Ostmann und der Volksrichter Kurt Megelski vertreten waren. Dort wurde vor allem die Frage der Ausbildung neuer Richter diskutiert. Eindeutig war die Tendenz, mittels der Volksrichter die soziale Zusammensetzung der Justiz zu verändern und den Einfluß der SED zu vergrößern. Eine Kontrolle der gesamten Rechtsprechung sei angestrebt, aber noch kaum machbar ${ }^{214}$. Auf der nächsten Beratung der Parteijuristen in Berlin spiegelte sich dann vor allem die Auseinandersetzung zwischen den Vertretern der Länder und der DJV wider. Über die Koordinierung der einzelnen Landesverbände hoffte man jedoch eine Zentralisierung in einigen wichtigen Punkten erreichen zu können ${ }^{215}$.

Im Anschluß an die erste Tagung wurden auch in den Ländern rechtspolitische Ausschüsse der SED installiert, die die Spitzenjuristen der Partei versammeln sollten. In Brandenburg führte dieses Gremium aber anscheinend nur ein Schattendasein. Die SED-Vertreter in der brandenburgischen Justiz wie der stellvertretende Abteilungsleiter Schulz sahen allerdings kaum noch Handlungsbedarf in Richtung auf eine Umwälzung: „In Brandenburg jedenfalls ist in der Justiz ganz gründlich aufgeräumt worden, und es sind nicht nur die ausgesprochenen Nazis, sondern darüber hinaus die reaktionären Militaristen entfernt worden. "216 Auch Ulbricht selbst hoffte, bis April 1947 die „Säuberung“ des Justizapparates abschließen zu können ${ }^{217}$. Diese Einstellung sollte sich Anfang 1948 gründlich ändern.

Im Rahmen der SED-Justizpolitik sind auch die vielfältigen Presseangriffe der SED-Zeitung Märkische Volksstimme zu sehen. Allerdings zeigten die ersten beiden Jahre ihrer Existenz, daß die Parteiführung sie durchaus noch nicht voll im Griff hatte. Freilich konnte auch die Märkische Volksstimme nur wenig veröffentlichen, was nicht von der sowjetischen Zensur geprüft worden war ${ }^{218}$. Besonders 1947 verschärften sich die Attacken der Zeitung auf einzelne Richter und Staatsanwälte. Die Redaktion hatte im März eine eigene „juristische Sprechstunde“ eingerichtet ${ }^{219}$. Mit diesen Beschwerden gegen angeblich zu lasche Urteile mußte sich

${ }^{214}$ SAPMO, DY 30/IV 2/1.01/37, Protokoll der Ersten Juristenkonferenz der SED am 1./2.3. 1947.

Vgl. Amos, Justizverwaltung, S. 55-57.

215 SAPMO, DY 30/IV 2/1.01/51, Protokoll der Sitzung des Ausschusses für Rechtsfragen am 21./ 22. 6. 1947 .

216 SAPMO, DY 30/IV 2/13/445, Abt. Justiz Brandenburg an Abt. Justiz im ZS der SED, 11. 9. 1946 (gez. Schulz).

217 SAPMO, NY 4182/1120, Bl.1-6, Protokoll der Sitzung 4.1. 1947. Amos, Justizverwaltung, S. $58 \mathrm{ff}$., sieht die justizpolitische Offensive der SED dagegen vor allem im Frühjahr 1947 und weniger die Zäsur Januar 1948.

218 Vgl. Strunk, Zensur und Zensoren, S. 72, $92 \mathrm{ff}$.

${ }^{219}$ SAPMO, NY 4182/907, Bericht zum II. Parteitag der SED Landesverband Brandenburg. 
zeitweise auch der Rechtsausschuß des Landtages beschäftigen ${ }^{220}$. Besonders aber das Justizministerium wehrte sich immer wieder gegen die Presseangriffe, die sie fast durchweg für verfehlt hielt. Einige Richter kündigten nach Pressekampagnen, die somit noch zur Verschärfung der Personalknappheit führten. Bis 1947/48 monierte auch die SED-Führung die rüden Angriffe der Märkischen Volksstimme auf die Justiz. In der Folge traf das Justizministerium eine Absprache mit der Märkischen Volksstimme, vor solchen Veröffentlichungen informiert zu werden ${ }^{221}$. Zunächst entspannte sich das Verhältnis der Justiz zur Presse; ab Ende 1948 starteten dann allerdings Kampagnen, die von der SED-Führung gezielt lanciert wurden.

Insgesamt ergibt sich für die Jahre 1946/47 der Eindruck, daß die SED zwar fortwährend Kritik am Justizwesen übte, diese jedoch nicht zu den zentralen Bereichen ihrer Politik zählte. Vor allem aber glaubte man damals offensichtlich noch, durch die bereits eingeleiteten Veränderungen bald zu einer „Volksjustiz“ zu kommen. Erst Ende 1947 zeichnete sich ab, daß ein völliger Neuaufbau der Justiz in Erwägung gezogen wurde.

Mit dem Zusammenschluß von KPD und SPD in Brandenburg war nicht nur ein Parteieintritt auch für Juristen attraktiver geworden, sondern auch die Justizpolitik erhielt eine festere Form. Formell übernahm Max Homa als SED-Sekretär den Aufgabenbereich Justiz, genauso wie Ulbricht und Fechner in der Zentrale. Im Landesvorstand wurde innerhalb der Abteilung Landespolitik ein Referat für Justiz und Polizei eingerichtet, das von Josef Leininger übernommen wurde 222 . Leininger kam aus der KPD und konnte immerhin ein abgebrochenes Jura-Studium vorweisen. Er hatte eine bewegte Vergangenheit hinter sich, von der Universität bis zum arbeitslosen Landarbeiter in der Weimarer Republik, danach im Saarland und schließlich inhaftiert in Vichy-Frankreich. Im April 1945 befreite ihn die Rote Armee aus dem Zuchthaus Luckau, wo er unmittelbar danach zum stellvertretenden Landrat avancierte, bevor ihn die Partei nach Potsdam rief223.

Leiningers Aufgaben waren vielfältig: Er sollte ständigen Kontakt zur Justizverwaltung halten, sich aber in erster Linie um die SED-Mitglieder unter den Juristen kümmern. Dazu berief er hin und wieder SED-Juristentreffen ein, die vorzugsweise rechtliche Fragen behandelten. In politischer Hinsicht sah man sich vor unlösbare Probleme gestellt, wenn Leininger auch vollmundig verkündete: „Die Träger des neuen Apparates sind wir." Nur fünf der elf Kreisleitungen - so Leininger - hätten überhaupt Justiz- und Polizeireferate, die Auswahl der Volksrichter und deren Betreuung sei völlig unzulänglich 224 .

220 BLHA, Rep. 201, Nr. 162, B1. 197-199, Sitzungsprotokoll des Rechtsausschusses am 13. 3.1947 (betr. Artikel in der Märkischen Volksstimme vom 23. 1. 1947)

221 SAPMO, NY 4182/1120, Bl. 140-144, Schäfermeyer an Märkische Volksstimme, 12. 11. 1947; Märkische Volksstimme an Justizabt. ZS, 17. 11. 1947; BLHA, Rep. 212 Nr. 21, Bl. 7-11, Bericht der Abt. Justiz an die SMA über die Rechtspflege in Brandenburg im Jahre 1947, 17. 1. 1948.

222 BLHA, Rep. 332, Nr. 22, Bl. 7-11, Protokoll der ersten Sitzung des Sekretariats SED Brandenburg, 10. 4. 1946.

223 BStU, MfS AIM 4950/71, Bl. 29-31, Lebenslauf Leininger, 25. 5. 1956.

224 BLHA, Rep. 332, Nr. 829, Bl. 4-9, Protokoll Juristensitzung Abt. Justiz LV Brandenburg, 24. 1. 1947; Zitat ebenda, Bl. 114, Bericht über SED-Juristen- und Polizeitagung im Bezirk Cottbus, 6. 3. 1947; ebenda, Bl. 36, Protokoll Juristentagung der SED Brandenburg, 7. 9. 1947. 
Auch das Zentralsekretariat ließ kein gutes Haar an der Justizarbeit der brandenburgischen SED. Auf einem Treffen von SED-Juristen am 4. Januar 1947 griff Personalchefin Hilde Benjamin zu drastischen Worten, besonders in der Frage der Volksrichter:

„Zu kritisieren ist, daß die Partei restlos versagt hat. Es ist entscheidend, daß die neuen Richter die richtige Position bekommen. Dafür ist nötig, daß sie lebendig in der Partei verwurzelt bleiben und daß die Partei sich um sie kümmert. Es ist bisher nichts geschehen, um in Neu-Ruppin, Kottbus, Eberswalde usw. den Volksrichtern zu helfen. Die Partei in Brandenburg und Mecklenburg kann das nicht bewältigen."

Wenig besser stehe es um die wenigen Volljuristen in der brandenburgischen SED: „Die Gefahr, die gerade in Brandenburg besteht, ist, daß unsere Genossen im Alkohol versaufen." 225 Ulbricht zeichnete bereits das SED-Justizprogramm der Zukunft: Aufbau von Parteigruppen überall in der Justiz, Registrierung aller Richter und Überprüfung ihrer Urteilspraxis usw. 226 Davon waren die Justizabteilungen der SED jedoch noch meilenweit entfernt. So kündigte das Zentralsekretariat den Landesvorständen erst einmal an, die Justizarbeit vor Ort selbst zu überprüfen. Am 5. März 1947 war eine Delegation in Potsdam. Als Schwerpunkt gab das Zentralsekretariat Personalfragen und die Rekrutierung bzw. Betreuung der Volksrichter an ${ }^{227}$.

Das Zentralsekretariat unternahm im Laufe des Jahres 1947 immer wieder Versuche, die Justizreferate in den Ländern zu aktivieren. Doch außer den Volksrichtertagungen und Vorträgen zur SED-Justizpolitik war von dort nicht viel zu hören. Am 31. Oktober schied Leininger schließlich aus dem Landesvorstand aus, offiziell aus gesundheitlichen Gründen. Ab 1948 war er als Justitiar im Finanzministerium, danach als Leiter der Abteilung Schulden- und Vermögensverwaltung der DWK in Berlin. Wie viele Funktionäre der ersten Jahre ereilte ihn dort sein Schicksal. Unter dem Verdacht der Sabotage von Gesetzesentwürfen wurde er 1951 vom Landgericht Potsdam zu fünf Jahren Zuchthaus verurteilt. Retrospektiv sollte dieses Verfahren auch zur Anklage gegen die brandenburgische Justiz dienen, obwohl es damit nichts zu tun hatte 228 .

Angesichts dieser Schwierigkeiten blieb die Einflußnahme des Parteiapparats auf die Justiz bis Ende 1947 sehr fragmentarisch. Der eigentliche Einfluß der SED auf die Justiz lag in den Händen Walther Hoenigers. Die Justizabteilung wurde zwar offiziell dem Vizepräsident Schleusener (seit November 1945 CDU) 229 zugeordnet, ab 1946 faktisch aber allein von Hoeniger geleitet.

225 SAPMO, NY 4182/1120, Bl. 4, Protokoll der SED-Justizbesprechung, 4. 1. 1947.

226 Vgl. SAPMO, NY 4182/1120, Bl. 7-9, Rundschreiben Nr. 3/47 des ZS der SED an Landesvorstände, 21. 2. 1947.

227 Anders, Diss., II, S. 80, 105; SAPMO, NY 4182/1120, Bl. 100-106, Arbeitsbericht der Abt. Justiz, 30. 5.1947.

228 BStU, MfS, AIM 4950/71, Bl. 29-31, 64-80, Lebenslauf Leininger, 25. 5. 1956; Urteil LG Potsdam, 29. 6. 1951; Stellungnahme Abt. XIII MfS, 2. 5. 1961; SAPMO, NY 4090/420, B1. 99-109, Bericht der ZKK für Januar 1951, 19. 2. 1951; BAC, DC-1, 5248, Bericht ZKK, 27.6. 1951. Leininger wurde Anfang 1954 aus der Haft entlassen und 1956 inoffiziell rehabilitiert. 1961 ließ er sich als IM vom MfS anwerben.

${ }_{229} \mathrm{Zu}$ Schleusener vgl. Richter, Ost-CDU, S. 417. 
Wie gering die Einwirkung des SED-Apparates in Brandenburg auf die Justiz bis 1947 insgesamt war, zeigt besonders ein Vergleich mit dem Aufbau der Polizei, der auf sowjetische Wünsche und Anweisungen zurückging230. Zu einem Zeitpunkt, in dem das NKWD in der Sowjetunion eine enorme politische Rolle spielte, maßen die Besatzungsoffiziere auch der Polizei in der SBZ eine vorrangige Rolle bei. Aus der Polizei vor 1945 stammten nur 3,3\% des Personals der ganzen Zone ${ }^{231}$, einerlei ob Parteigenosse oder nicht. Fast $90 \%$ der ad hoc angeworbenen neuen "Volkspolizisten" kamen aus der Arbeiterschaft; Polizisten waren - wegen der geringeren Anforderungen - ungleich leichter zu rekrutieren als Justizmitarbeiter. Die Polizeireferenten in den Stadtverwaltungen wurden fast durchweg von der KPD gestellt. Die Abteilung IX der Provinzialverwaltung (Polizei) leitete zuerst Artur Dorf, KPD-Funktionär seit 1929. Im April 1946 übernahm auf Beschluß des KPD-Sekretariats Richard Staimer diesen Posten, Moskau-Emigrant und Schwiegersohn von Wilhelm Pieck ${ }^{232}$.

Diese radikale Polizeipolitik zeitigte aber auch ihre unbeabsichtigten Folgen: In der Polizei tummelten sich viele Kommunisten, die - im Parteijargon als „linkssektiererisch" bezeichnet - sich nicht an die Generallinie der Partei halten wollten. Wegen des großen Personalbedarfs wurde zunächst jeder akzeptiert, der sich KPD/SPD-nah gab. So sickerten unkontrolliert auch Kriminelle ein. Hinzu kam, daß viele Polizisten mehr oder weniger zwangsrekrutiert worden waren. Freilich war das Personal völlig unzureichend ausgerüstet und ausgebildet. Die enorme Nachkriegs-Kriminalität stellte die Polizisten oft vor nahezu unlösbare Aufgaben $^{233}$. Die Fluktuation in der frühen Volkspolizei war enorm, allein 1946 schieden $57 \%$ der Angestellten in der SBZ wieder aus. Das hieß, daß statistisch gesehen nach ein paar Jahren das Personal komplett ausgewechselt wurde. Insgesamt wurde die Polizei von der KPD/SED immer als ihr ureigenstes Terrain angesehen, ganz im Gegensatz zur Justiz.

Dagegen blieben die beiden anderen Parteien CDU und LDP weit zurück. Sie hatten in Brandenburg erhebliche Anlaufschwierigkeiten, wurden faktisch von den Berliner Parteizentralen geführt und konnten sich auf Provinzialebene erst Ende 1945 in die Justizpolitik einschalten. In erster Linie machten die sowjetischen Kommandanturen den „bürgerlichen“ Parteien Schwierigkeiten bei der Anmeldung. Noch 1946 drohte die CDU wegen der harten Wahlkampfführung der SED mit Selbstauflösung, woraufhin Vizepräsident Bechler auf die Auswechslung ihrer Parteiführung drängte234.

So kam in Brandenburg am 22. November 1945 der letzte der Blockausschüsse in den Ländern und Provinzen der SBZ zustande. Innerhalb des Blocks war der Umgang der Parteien miteinander etwas versöhnlicher, allerdings war die Einwirkungsmöglichkeit auf die Provinzialregierung gering. In der Justizpolitik beließ es

2.30 Bisher am umfassendsten: Naimark, Russians in Germany, S. $355 \mathrm{ff} .$, mit der These vom „Polizeistaat"; dagegen Bessel, Grenzen des Polizeistaates; Foitzik, Der sowjetische Terrorapparat, S. $27 \mathrm{f}$.

231 Bessel, Polizei zwischen Krieg und Sozialismus, S. 523. Lediglich ehrenamtlich wurde der Polizeioberst Willi Neese beschäftigt, der seit 1932 im Ruhestand war, vgl. BStU, Allg. S 240/66, Bl. 373.

232 Protokolle des Sekretariats des Zentralkomitees der KPD, S. 207-211 (11. 4. 1946).

233 Vgl. Arlt, Zur Aufstellung, S. 218, 226.

${ }^{23+}$ Hurwitz, Stalinisierung der SED, S. 231. Das Datum dieser Äußerung ist nicht ganz klar, vermutlich der 7. 8. 1946. 
der Block dann auch bei Proklamationen ${ }^{235}$. Die Blocks auf Kreis- und Lokalebene konnten hingegen manchmal früher gegründet werden und vereinzelt recht aktiv ins Rechtsleben eingreifen, wenn sie eine starke Stellung vor Ort hatten. Noch weniger bedeutsam war das Vor-Parlament der Provinz, die sogenannte Beratende Versammlung, die seit Juni 1946 bestand. Sie tagte nur dreimal und diente mehr als Akklamationsgremium für die von der KPD durchgesetzten Enteignungsmaßnahmen ${ }^{236}$.

Eine echte Meinungsvielfalt brachte erst der Wahlkampf 1946. Hier wurden die gegensätzlichen Positionen von SED, CDU und LDP ausgetragen. Dabei spielte auch das Thema Rechtsstaat und Rechtssicherheit ein wichtige Rolle. Allerdings untersagte die SMAD die Behandlung der Frage der Ostgrenze, und sie verstand es, die Ausgangsposition der SED-Gegner von vorneherein zu schwächen. Durch restriktive Lizenzierungspolitik, Einschränkung der Publikationsmöglichkeiten, aber auch durch Einschüchterungen wurden CDU und LDP massiv behindert ${ }^{237}$. Wahlleiter Bechler tat ein übriges, indem er beispielsweise kurzerhand den LDPVorsitzenden Falk von der Wahlliste strich ${ }^{238}$. Obwohl man aus diesen Gründen nur von halbfreien Wahlen sprechen kann, gelang es CDU und LDP, eine absolute Mehrheit der SED bei den Landtagswahlen am 20. Oktober zu verhindern. Im Landtag, der am 22. November 1946 zum ersten Mal zusammentrat, waren die SED und die ihr nahestehende Vereinigung der gegenseitigen Bauernhilfe VdgB numerisch in der Minderheit ${ }^{239}$.

In der Landtagsdebatte vom 18. Dezember 1946 äußerten sich die Parteienvertreter erstmals ausführlicher öffentlich zu ihrer Justizpolitik. Während Ministerpräsident Steinhoff vor allem die nationalsozialistische Durchsetzung der alten Justiz betonte, entwickelte der CDU-Provinzialvorsitzende Wolf Vorstellungen für die Zukunft. Das wichtigste sei die Wiederherstellung der Rechtssicherheit; auch für Ansprüche aus der Vergangenheit müßte der Rechtsweg offenbleiben. Wolf trat offensiv gegen eine neue Einseitigkeit der Justiz auf, „wie es so manche wünschen“. Die Dominanz der SED in den Sequesterausschüssen und der Polizei sei ein warnendes Beispiel. In diese Kerbe schlug auch der LDP-Sprecher Koerber. Zwar sei eine Justizreform dringend nötig; die Volksrichter seien aber nur als Übergangserscheinung zu sehen, eine Parteibuch-Justiz tunlichst zu vermeiden ${ }^{240}$.

\section{d. Die Bildung des Justizministeriums}

Die Wahlniederlage der Sozialisten am 20. Oktober 1946 war für SMA und SED ein Schock; unmittelbar danach setzten dort Überlegungen zur Aushebelung der Mehrheitsverhältnisse ein. Scharow plädierte für eine Reaktivierung des Blocks. Der brandenburgischen CDU und LDP blieb nichts anderes übrig, als im Februar

${ }^{235}$ Reinert in: Protokolle Landesblockausschuß, S. XXIII; ausführlich ders., Brandenburgs Parteien, S. $57 \mathrm{ff}$.

${ }^{236}$ Koch, Beratende Versammlungen, S. 324; Warning, Bildung und Tätigkeit.

237 Creuzberger, Die sowjetische Besatzungsmacht, S. 55-71.

${ }^{238}$ Vgl. Protokolle Landesblockausschuß, S. 62 f. (Sitzungsprotokoll, 8. 11. 1946).

$239 \mathrm{Vgl}$. Schreckenbach/Künzel, Geschichte der brandenburgischen Landtage, S. $18 \mathrm{ff}$.

${ }^{240}$ Stenographische Berichte Brandenburg, 3. Sitzung, 18. 12. 1946. 
1947 dem sowjetischen Drängen nachzugeben und den Parteienausschuß als Instanz neben dem Landtag beizubehalten ${ }^{241}$. Der Landesblock sollte durch die Vorbereitung von Plenarsitzungen Einfluß auf die Landtagsarbeit nehmen und wurde somit zu einem wichtigen Hebel der SED gegen die Mehrheitsverhältnisse ${ }^{242}$.

Gleichzeitig verlangte die SMAD die Bildung von Allparteienkoalitionen. Welche Stellung dabei das Justizressort in der Regierung haben sollte, wurde erst in langwierigen Verhandlungen um den Parteienproporz entschieden. Gemessen am Wahlergebnis waren die Verhältnisse eigentlich klar: Die SED würde danach in einer Koalitionsregierung die meisten Minister stellen, aber weniger als CDU und LDP zusammen. Um diesen Verhältnissen Rechnung zu tragen, schlugen CDU und LDP in den Koalitionsverhandlungen ab dem 27. November die Einrichtung von fünf Ministerien inklusive Ministerpräsidenten vor ${ }^{243}$. Die SED konterte mit dem Vorschlag von sechs Posten, von denen sie drei selbst besetzen wollte. Erst auf diesen Vorstoß hin unterbreitete die CDU eine Variante von sieben Ministerien, die erstmals auch ein eigenständiges Justizressort ins Spiel brachte.

Der SED-Landesvorsitzende Sägebrecht drohte den „bürgerlichen“ Parteien nun mit Druck von oben und dem Abbruch der Verhandlungen. So lenkte die CDU-Führung auf ein Modell ein, das neben dem Ministerpräsidenten sechs Ministerien vorsah, wobei die Justiz einem CDU-geführten Innenministerium unterstellt und die strategischen Posten der Abteilungsleiter proportional verteilt werden sollten. Mehrfach intervenierte Oberstleutnant Milcheker von der SMAPropagandaabteilung direkt, der einen CDU-Innenminister ablehnte. Nach Absprache mit Tjulpanow legte die Militärverwaltung nun eine härtere Gangart vor ${ }^{244}$. Sägebrecht bot der CDU zunächst lediglich die Besetzung des Abteilungsleiters Justiz und des stellvertretenden Abteilungsleiters Inneres an. Am 4. Dezember schließlich gab die CDU dem Druck nach und erklärte sich mit einem eigenen Justizministerium unter ihrer Führung einverstanden.

Diese Auseinandersetzungen zeigen zweierlei: Erstens war die SED-Führung zu keinem Zeitpunkt bereit, die Mehrheit in der Provinzialregierung abzugeben. Ulbricht hat seine Geringschätzung für echte Wahlverfahren intern klar geäußert, Sägebrecht ignorierte das Wahlergebnis eher verklausuliert „mit dem Hinweis, daß die Wählerschaft nicht immer in der Lage sei, die Arbeit der einzelnen Amtsinhaber in der vergangenen Zeit zu überblicken. “245 Zweitens fällt bei den Verhandlungen die geringe Bedeutung des Justizressorts auf. Es wurde quasi als Verhandlungsmasse hin- und hergeschoben. Nicht zu unterschätzen ist schließlich das Kalkül der SED-Führung, angesichts der öffentlichen Justizkritik dieses Mi-

24: Creuzberger, Dic sowjetische Besatzungsmacht, S. $115 \mathrm{f}$.

242 Reinert in Protokolle Landesblockausschuß, S. XLIII.

243 Zum folgenden: SAPMO, NY 4182/1084, Bl. 119-121, 126-128, Rundschreiben Nr. 26/46 des ZS der SED, 21. 11. 1946; undatierte Notiz über Sitzung der Ministerpräsidenten und Vizepräsidenten im ZS der SED am 26. 11. 1946; ACDP, III-033-091, Besprechung über Regierungsbildung (ab 28. 11. 1946); Blocksitzungen vom 29.11. und 3. 12. 1946, Protokolle Landesblockausschuß, S. 6971.

244 Ausführlich Creuzberger, Die sowjetische Besatzungsmacht, S. 119-122, teilweise auf Basis der sowjetischen Akten.

${ }^{245}$ Zitat in: ACDP, III-033-091, Besprechung über Regierungsbildung (ab 28. 11. 1946). Vgl. auch die retrospektive Darstellung in Sägebrecht, Nicht Amboß, S. 366. 
nisterium offiziell den „Bürgerlichen“ zuzuschieben. So wollten weder CDU noch LDP den Abteilungsleiter für Justiz stellen ${ }^{246}$.

Nachdem feststand, daß es ein eigenes Justizministerium und einen Justizminister aus der CDU geben würde, mußten Personalfragen geklärt werden. Die CDU-Führung verfügte über mehrere ausgewiesene Juristen. Zuerst wäre natürlich an Frank Schleusener zu denken gewesen, der formal im Provinzialpräsidium für die Justiz zuständig war. Schleusener zog es anscheinend aber mehr in seinen erlernten Beruf als Rechtsanwalt. Als er die Finanzabteilung der Provinz aufbauen sollte, stellte er sein Amt wegen der großen Schwierigkeiten, die sich dabei ergaben, zur Verfügung. Offiziell schied Schleusener erst im Dezember aus der Provinzialregierung aus ${ }^{247}$. Er blieb der Rechtspolitik jedoch als Vorsitzender des Rechtsausschusses im Landtag erhalten. Ein weiterer Jurist, Gerhard Schütze, war Rechtsanwalt und Notar aus Brandenburg a.d.H., er hatte von 1943-1945 im KZ Sachsenhausen gesessen. Doch seine Partei sah ihn als CDU-Fraktionsvorsitzenden für andere Aufgaben vor ${ }^{248}$.

So fiel die Wahl auf Ernst Stargardt, den Oberstaatsanwalt von Potsdam. Dieser stammte selbst aus einer Juristenfamilie und war bis 1920 Rechtsanwalt gewesen, seit 1922 Staatsanwalt in Potsdam. Trotz seiner jüdischen Eltern wurde er 1933 auf seinem Posten belassen, weil er Frontkämpfer des Ersten Weltkrieges und vor 1914 Beamter gewesen war. Stargardt selbst war Protestant, er engagierte sich bald in der Bekennenden Kirche. Im Oktober 1935 traf ihn die Kündigung, von da an mußte er sich als Privatlehrer durchschlagen und wurde mehrfach von der Gestapo zu Verhören vorgeladen. Stargardt verlor im Krieg zahlreiche seiner Verwandten, die in Konzentrationslagern ermordet wurden. Seine Frau trug von Zwangsarbeiten bei Kriegsende schwere gesundheitliche Schäden davon ${ }^{249}$.

So galt Stargardt als Antifaschist und wurde nach Kriegsende bald wieder eingestellt, nachdem er im Mai/Juni 1945 den Antifa-Ausschuß in Potsdam juristisch beraten hatte: „1920-1935 im staatsanwaltschaftlichen Dienst, dann als Angehöriger der jüdischen Rasse entlassen. [...], entschiedener Antifaschist. Seit dem 3.7. 1945 auf Empfehlung des sozialrevolutionären Elferausschusses Potsdam als Oberstaatsanwalt in Potsdam tätig. " ${ }^{250}$ Aus der Sicht der SED und der SMA hatte Stargardt allerdings einen Makel: Er war Mitglied der Deutschnationalen Volkspartei gewesen. Da man ihn aber den Gegnern Hugenbergs im sogenannten Westarp-Flügel zurechnete, wog dieses Faktum nicht so schwer. Darüber hinaus hatte Stargardt auch einen kleineren Zusammenstoß mit dem Potsdamer Polizeichef Staimer gehabt, als dieser Gefangene für kommunale Arbeiten anforderte, aber nicht bekam ${ }^{251}$.

246 ACDP, III-033-091, Besprechung im CDU-LV mit LDP am 2. 1. 1947.

${ }_{247}$ ACDP, I-297-200, Rechtsanwaltszulassung für Schleusener, 15. 1. 1946; BLHA, Rep. 202A, Nr. 20, Bl. 7, 11, Ministerpräsident an MdI, 23. 12. 1946; Schleusener an Steinhoff, 24. 6. 1946. Im Jahre 1949 bot die SMA Schleusener einen Ministerposten an, falls er sich öffentlich für eine Verschiebung der Wahlen äußern würde, Richter, Ost-CDU, S. 202.

248 Vgl. Bloch, Politiker, S. 83.

249 BLHA, PA Rep. 212, Nr. ST/9909, Personalakte Ernst Stargardt.

250 BLHA, Rep. 212, Nr. 264, Bl. 1-6, Abt. Justiz Brandenburg an SMA, (Oktober 1945).

251 BLHA, PA Rep. 212, Nr. ST/9909, Vermerk Hoeniger, 6. 7. 1946; Abt. Justiz an Polizei Potsdam, 14. 9.1946 . 
Dennoch hatte Stargardt für die SMA auch eine Reihe von Meriten: Auf seine Initiative hin wurde im Mai 1945 der nationalsozialistische Oberbürgermeister in Potsdam verhaftet. In der Vereinigung der Verfolgten des Naziregimes (VVN) wurde Stargardt 1948 zum Mitglied des Zentralvorstandes gewählt. Als Oberstaatsanwalt vertrat er in Wirtschaftsverfahren durchaus eine harte Linie ${ }^{252}$.

Anscheinend hat sich Stargardt nicht nach dem Posten des Justizministers gedrängt, vielmehr mußte er vom CDU-Landesverband, dessen Rechtsauschuß er bereits angehörte, gebeten werden ${ }^{253}$. Der Landesvorstand begründete seinen Personalvorschlag wie folgt: „Seine politische Haltung war stets maßgeblich beeinflußt durch seine positive Einstellung zu den sozialen Fragen. Diese soziale Gesinnung und sein starkes Rechtsbewußtsein sind maßgebend für die ChristlichDemokratische Union gewesen, Oberstaatsanwalt Stargardt als Justizminister vorzuschlagen." 254

Im großen und ganzen erwies sich Stargardt aus sowjetischer Sicht als geeigneter Kandidat, weil man ihn zu den „fortschrittlichen“ Persönlichkeiten im Kabinett rechnete ${ }^{255}$. Nach außen hin verfügte er über alle Merkmale einer politischen Integrationsfigur: sehr kompetent, Antifaschist, engagiert in der evangelischen Kirche und trotzdem in guter Zusammenarbeit mit der SED. Allerdings war er kein exponierter CDU-Mann, der sich etwa öffentlich für die beiden zwangsweise abgelösten Führungsduos der Partei, Hermes/Schreiber bzw. Kaiser/Lemmer, aussprach. Und wie sich erweisen sollte, legte Stargardt den Schwerpunkt seiner Tätigkeit in Landtag und Kabinett, und nicht in das Justizministerium selbst. In seiner Amtsausübung war Stargardt stark durch seinen schlechten Gesundheitszustand beeinträchtigt. Schon aus dem Ersten Weltkrieg trug er eine 20prozentige Kriegsbeschädigung davon, die Verfolgung im Dritten Reich tat ein übriges. 1934/ 35 mußte er für sieben Monate beurlaubt werden. Als Oberstaatsanwalt in Potsdam schickte ihn sein Arzt 1946 auf Kur und verbot ihm zeitweilig jede berufliche Tätigkeit. Die Kuraufenthalte mußten nun jedes Jahr angetreten werden; Stargardts Gesundheit verschlechterte sich jedoch weiter, so daß er schließlich monatelang ausfiel256. Im Endeffekt konnte Walther Hoeniger unter Stargardt seine Position nahezu ungebrochen beibehalten und die brandenburgische Justiz faktisch allein verwalten. Auch in der DJV war bekannt, daß Hoeniger einen „außerordentlich großen" Einfluß auf seinen Minister hatte257. Nur so ist es auch zu erklären, daß sich Stargardt bis in den August 1950 als Justizminister halten konnte,

252 Reuter/Hansel, Das kurze Leben der VVN, S. 258; BLHA, Rep. 212, Nr. 465, B1. 38, Protokoll der Justiztagung am 11. 8. 1949.

${ }^{253}$ So in sciner Antrittsrede, BA, DP-1 VA 1024, Bl. 41, Runderlaß Nr. 8 MdJ Brandenburg, 4. 1. 1947. Vgl. ACDP, III-033-001, Protokoll Vorstandssitzung CDU Brandenburg, 28. 5. 1946.

25. BLHA, Rep. 202A, Nr. 20, Bl. 101, Charakteristik CDU-Landesvorstand über Stargardt, 12. 12. 1946.

${ }_{255}$ Creuzberger, Die sowjetische Besatzungsmacht, S. 122.

${ }^{256}$ BLHA, Rep. 202A, Nr. 20, Bl. 104, Stargardt an Steinhoff, 21. 4. 1947; BLHA, PA Rep. 212, Nr. ST/9909, Beurteilung MdI über Stargardt, 20. 10. 1948; BLHA, Rep. 332, Nr. 27, Bl. 60-71, SEDSekretariatsvorlage zur Justiz (ohne Deckblatt), ca. März 1949.

257 BA, DP-1 VA 3, Bl. 45-46, Bemerkungen über Justizpersonal in Ländern, o.D. (1947). 
während in den anderen Ländern die erste Generation der Justizminister bereits abgelöst worden war258.

Im Ministerium begann der Anteil der CDU- und LDP-Mitglieder allmählich zu schrumpfen. Zwar war er Anfang 1948 noch der größte aller Ministerien; die Anzahl der SED-Mitglieder hatte sich im Vergleich zu 1946 aber verdoppelt ${ }^{259}$.

\section{e. Die Stellung der Justiz in der brandenburgischen Verfassung}

Als vornehmste Aufgabe des neugewählten brandenburgischen Provinziallandtages sollte sich die Ausarbeitung einer Verfassung erweisen. Nach der faktisch verfassungs- und rechtlosen Zeit der NS-Diktatur kam dem Erlaß von Verfassungen schon allein eine hohe symbolische Bedeutung zu. Im September 1945 hatte die Provinzialverwaltung eine erste Landesordnung erlassen, die ausschließlich ihre eigene Arbeit regelte 260 . Erst nach der Konstituierung des Parlaments stand die richtige Verfassungsgebung an. Eigentlich signalisierte dies einen niemals zuvor gegebenen föderalen Freiraum, zumal Preußen im Februar 1947 von den Alliierten formal aufgelöst wurde.

Allerdings waren dem Parlament durch die Besatzungsmacht noch engere Grenzen gesetzt, als man lange vermutet hat ${ }^{261}$. Im folgenden interessieren vor allem die Verfassungsregelungen, die sich unmittelbar auf das Rechtssystem auswirkten. Im Grunde lagen zwei konkurrierende Entwürfe für die ganze Zone vor, einer von seiten der SED und einer von der CDU. Die LDP formulierte zwar verfassungspolitische Essentials, einen eigenen Entwurf brachte die Partei aber nicht in die Landtage ein. Die stärkste parteipolitische Kraft, die SED, hatte durchaus eigene Vorstellungen, die es mit Hilfe der Besatzungsmacht durchzusetzen galt. Intern lehnte Pieck, der offiziell auch im brandenburgischen Verfassungsausschuß saß, ebenso eine Volksabstimmung über die Verfassung ab. Er fürchtete eine Ablehnung wegen der virulenten Frage der Ostgrenze262. Das galt besonders für Brandenburg mit seiner langen Grenze zu den Ostgebieten und seinem hohen Anteil an Vertriebenen. Pieck äußerte sich bei einer Besprechung mit den Ministerpräsidenten und Landtagspräsidenten auch düster über die Juristen. So dürfe es kein Zurück zum Ideal des überparteilichen Richters geben. Auf einer ähnlichen Linie lag Ministerpräsident Steinhoff, der darauf drängte, die Rechte des Landtages in Polizeifragen möglichst gering zu halten und sich eine Regelung dieser Frage durch die SMAD wünschte263.

Anfang August 1946 präsentierte Ulbricht der SMAD den Entwurf einer „Lan-

${ }^{258}$ Amos, Justizverwaltung, S. 46-48. In Sachsen-Anhalt wurde erst 1948 ein eigener Leiter der Justizverwaltung eingesetzt, bis dahin verwaltete Ministerpräsident Hübener das Ressort.

${ }^{259}$ Statistik zum 9. 2. 1948, Meinicke, Zur Entnazifizierung in der sowjetischen Besatzungszone Band 2, S. LI ff. (von 32 Beschäftigten waren 10 in der SED, 3 in der LDP und 2 in der CDU).

260 "Verfassung der Provinz Mark Brandenburg“ vom 26.9. 1945; vgl. Ribbe, Land Brandenburg, S. 695.

${ }^{261}$ Das hat jetzt Creuzberger, Die sowjetische Besatzungsmacht, S. $127 \mathrm{ff}$. auf der Grundlage sowjetischer Akten herausgearbeitet. Ansatzweise schon bei Braas, Entstehung der Länderverfassungen, S. $90 \mathrm{ff}$.

262 SAPMO, NY 4036/747, Bl. 98, Klarschrift Notiz Pieck, ca. Dezember 1946.

263 SAPMO, NY 4036/747, Bl. $106 \mathrm{ff}$., Klarschrift Notiz Pieck über Besprechung mit Ministerpräsidenten und Landtagspräsidenten am 12.1.1947. 
desordnung " für alle Länder. Das SED-Papier lehnte sich weitgehend an die Weimarer Verfassung an, enthielt jedoch eine Reihe markanter Neuerungen: Mit der Aufhebung der Gewaltenteilung war die Unabhängigkeit der Judikative eingeschränkt, die obersten Justizjuristen sollten gewählt werden, die Justiz sollte nicht das Recht zur Überprüfung von Gesetzen erhalten. Daneben war die Rechtsprechung möglichst volksnah zu gestalten: Die Institution der Volksrichter sollte in der Verfassung verankert werden, Laien waren an der Rechtsprechung zu beteiligen, die wiederum sozialen Gesichtspunkten folgen sollte ${ }^{264}$.

Die brandenburgische CDU äußerte sich kritisch zu diesem Entwurf. Sie wandte sich gegen die Aufhebung der Gewaltenteilung. Mit Blick auf die Erfahrungen aus der NS-Zeit forderte sie, Gesetze müßten auf ihre Verfassungsmäßigkeit überprüft werden können. Die Laienrichter hätten sich bisher nur in Strafgerichten bewährt, in der Ziviljustiz würden sie die Rechtssicherheit gefährden ${ }^{265}$. Deshalb enthielt der CDU-Länderverfassungsentwurf Bestimmungen über die Einrichtung eines Staatsgerichtshofes, die Unabhängigkeit von Gerichten und Richtern, und er sah die Festschreibung eines Widerstandsrechtes vor. Aus gesamtdeutschen Rücksichten sollten noch keine zu genauen Festlegungen zur Rechtspflege erfolgen; von der Wiedererrichtung eines Reichsgerichts ging man aus ${ }^{266}$. Unter dem Eindruck eines gesondert von der CDU in Mecklenburg-Vorpommern entwickelten Entwurfs wurde die Anstellung der Richter auf Lebenszeit und die Beschränkung der Laienrichter auf Kollegialgerichte hinzugefüg ${ }^{267}$.

Im Zentral-Sekretariat der SED, wo die Verfassungspolitik der SED federführend bearbeitet wurde, sah man die CDU-Entwürfe als unzureichend an, wartete jedoch die ersten Debatten in den Landtagen ab268. Am 6. Dezember 1946 trat die SED mit einem richtigen - jetzt zweiten - Verfassungsentwurf in die politische Arena, der erheblich detaillierter war, in Fragen der Rechtspflege aber die bisherigen Forderungen enthielt.

Weder der Landesblock noch das neue Justizministerium wurden in die Verfassungsberatungen in größerem Ausmaß einbezogen ${ }^{269}$. Das tatsächliche Verfahren in Potsdam lief weitgehend im Rechts- und Verfassungsausschuß des Landtages ab. Unter Frank Schleusener saßen dort elf Abgeordnete, davon fünf von der SED

${ }^{264}$ Ausführlich: Braas, Entstehung der Länderverfassungen, S. $51 \mathrm{ff}$.

265 ACDP, III-033-003, Stellungnahme zum SED-Entwurf für eine Landesverfassung (Brandt), 4. 12. 1946.

266 Braas, Entstehung der Länderverfassungen, S. $72 \mathrm{ff}$.; der Entwurf der brandenburgischen CDU enthielt noch keinen Abschnitt „Rechtspflege“: ACDP, III-033-003, CDU-Entwurf für Landesverfassung.

${ }^{267}$ Braas, Entstehung der Länderverfassungen, S. 79.

268 SAPMO, NY 4036/746, Bl. 86-91, Polak an Pieck/Grotewohl, 21. 12. 1946; SAPMO, DY 30/IV 2/13/405, Grundsätzliches zum Länderverfassungs-Entwurf der CDU.

${ }^{269} \mathrm{Im}$ Ministerium war für das Staatsrecht zu diesem Zeitpunkt Wolfgang Abendroth zuständig, später einer der profilierten Staatsrechtler der Bundesrepublik. Abendroth, „der stets politisch klar und überzeugt auftrat" (Ostmann), hatte sich schon in Potsdam kritisch zur SMAD geäußert und wollte nicht in die SED eintreten (er war seit 1. 1. 1947 Mitglied der SPD in Berlin). Im Januar 1949 flüchtete er aus Thüringen in den Westen; vgl. Heil, Verwaltungsgerichtsbarkeit in Thüringen, S. 273; BStU, AU 255/56, Bl. 364-396, Notiz aus DVdI, 8. 2. 1949; Charakteristik DVdI, HA K, Ref. C 2 über Abendroth, 22. 3. 1949; BA, DP-1 VA 6832, Bl. 54, Beitrag Ostmann zur BenjaminFestschrift, 1962. In den fünfziger und sechziger Jahren entwickelte die DDR ein ambivalentes Verhalten zu Abendroth, vgl. BStU, PA 2671 und HA IX 9728; Abendroth, Ein Leben in der Arbeiterbewegung, S. 197 ff.; Fricke, Akten-Einsicht, S. 80. 
und einer von der $\mathrm{Vdg} \mathrm{B}^{270}$. In diesem Gremium wurde auf der Basis des SEDEntwurfs diskutiert. Die CDU brachte ihren Verfassungsentwurf in Brandenburg gar nicht formell ein, vielmehr diente er nur im Ausschuß als Arbeitsmaterial271. Die CDU-Mitglieder versuchten, möglichst viele Modifikationen am Papier der SED anzubringen. Insbesondere wandten sie sich gegen die Bestimmungen zur Festschreibung der bisherigen Enteignungen. Während zwei Anträge der LDP zum Verfassungsabschnitt „Rechtspflege“ abgelehnt wurden ${ }^{272}$, konnte die CDU ihre Ideen zur Eigentumsfrage mit Hilfe zweier SED-Abgeordneter, Paul Szillat und Werner Lufft, zunächst durchsetzen.

Die SMA, die über die Diskussionen ständig im Bilde war, reagierte prompt und ablehnend ${ }^{273}$. Auf ihre Anweisung kam diese „Panne“ auf die Tagesordnung des SED-Landessekretariats, wo man die Arbeit der Genossen im Verfassungsausschuß heftig kritisierte. Sägebrecht vermißte die ausführliche Behandlung von Wirtschaftsfragen und wollte auf jeden Fall die Festschreibung privater Eigentumsansprüche verhindern, um die Enteignungen nicht zu gefährden. Wichtig war die Politik und nicht die Verfassung: „Unsere Verfassung muß so formuliert werden, daß wir auch in Zukunft keine Schwierigkeiten haben." ${ }^{274}$ Daraufhin trat Pieck mit der Landtagsfraktion zusammen. Nun sollten die Ergebnisse der Bodenreform wieder festgeschrieben und weitere Änderungen vorgenommen werden. Der Landtagsausschuß sollte noch einmal zusammentreten und Nachbesserungen vornehmen ${ }^{275}$.

Offensichtlich erst kurz vor dem Tag der Landtagsdebatte, dem 31. Januar 1947, legte die SED einen neuen Entwurf vor, der in einigen Teilen wieder ihrer ersten Fassung glich 276. Dieser wurde nun im Plenum diskutiert. Neben den Fragen der Eigentumsordnung kam dabei erneut die Wahl von Oberlandesgerichts-Präsident und Generalstaatsanwalt zur Sprache. Während der LDP-Sprecher Schwoche für die Streichung des einschlägigen Artikels plädierte, betonte Ernst Lemmer von der CDU die entscheidende Stellung des Landtages als höchstem Organ; die umstrittene Frage der lebenslangen Anstellung von Richtern wollte er - wie sein Vorredner Lufft von der SED - vertagen ${ }^{277}$. Am Tag darauf wurde die Verfassung in zweiter Lesung vom Parlament einstimmig verabschiedet, am 6. Februar 1947 trat sie in $\mathrm{Kraft}^{278}$.

270 SAPMO, NY 4036/746, Bl. 117, Besetzung der Ausschüsse im brandenburgischen Landtag. Auf die Führung des Rechtsausschusses legte die SED keinen großen Wert: SAPMO, NY 4182/1084, Bl. 119-121, Rundschreiben Nr. 26/46 des ZS der SED, 21. 11. 1946.

271 ACDP, III-033-003, Webersinn an Meissner, 27. 9. 1948.

272 BLHA, Rep. 201, Nr. 163, Aufstellung an den Rechtsausschuß überwiesene Anträge, Bl. 232-236. Gemeint sind die Streichung der Richterwahl und die lebenslange Anstellung der Juristen.

${ }^{273}$ Creuzberger, Die sowjetische Besatzungsmacht, S. $127 \mathrm{f}$.

274 BLHA, Rep. 332, Nr. 23, Bl. 8-9, Protokoll der Sekretariatssitzung SED-LV, 20. 1. 1947.

275 SAPMO, NY 4182/1103, Bl. 443-444, Hausmitteilung Plenikowski an Ulbricht, 22. 1. 1947; BLHA, Rep. 332, Nr. 23, Bl. 14-21, Protokoll der Sekretariatssitzung SED-LV, 27. 1. 1947.

276 ACDP, III-033-091, Protokoll CDU-Fraktionssitzung 30.1.1947 (Mitteilung Bloch); Creuzberger, Die sowjetische Besatzungsmacht, S. 129. Allerdings wurden nicht alle Wünsche der SED erfüllt, so daß diese später im Block Nachbesserungen forderte, insbesondere die Gewährleistung der Betriebs-Enteignungen; Protokolle Landesblockausschuß, S. 178f. (24. 11. 1947).

${ }^{277}$ Stenographische Berichte Brandenburg, 5. Sitzung, 31.1. 1947; Der brandenburgische Landtag, S. 89-98; vgl. Schreckenbach/Künzel, Geschichte der brandenburgischen Landtage, S. 25 f.

278 Abdruck u.a. in: Künzel, Brandenburgs Landesverfassung, S. 25-33. 
Trotz der Intervention von SMA und SED gelang es vor allem den CDU-Abgeordneten, eigene Akzente in der brandenburgischen Verfassung zu setzen ${ }^{279}$. Besonders hervorzuheben ist hier der Grundrechtsteil der Konstitution. Einzig in Brandenburg gab es ein - wenn auch abgeschwächtes - Widerstandsrecht.

Unmittelbare Auswirkungen auf die Justiz hatten die Bestimmungen über die Wahl von Oberlandesgerichts-Präsident und Generalstaatsanwalt durch den Landtag. Dennoch traten dadurch faktisch keine Änderungen ein. Schon Ende 1946 hatte das Zentral-Sekretariat der SED festgelegt, daß in Brandenburg beide Posten mit Genossen zu besetzen seien ${ }^{280}$. Also blieb alles beim alten. Als Innenminister Bechler am 29. Mai 1947 die Vorschläge Löwenthal und Ostmann begründete, erwähnte er beider Mitgliedschaft in der SED nicht ${ }^{281}$. Daß er an Generalstaatsanwalt Ostmann nicht so sehr fachliche Qualitäten, sondern andere Eigenschaften schätzte, bekamen die Abgeordneten im Plenum von Bechler ebenfalls nicht zu hören: „Ein festes politisches Auftreten hat er nicht. Er wird jedoch alle Maßnahmen so durchführen, wie sie ihm von Seiten der Partei oder seiner Vorgesetzten angewiesen werden. [...] Wenn ich trotzdem dafür eintrete, daß er weiterhin auf dieser Stelle belassen wird, so nur aus dem Grund, weil sowohl ich als Minister des Innern als auch die Partei einen starken Einfluß auf ihn ausüben, und er bisher alle Weisungen unsererseits zufriedenstellend befolgt hat." 282 Interessanterweise erhielt Ostmann bei der Wahl auch nur die Zustimmung von 66 der 100 Abgeordneten, bei Löwenthal waren es 70 Stimmen $^{283}$.

Von langfristiger Bedeutung für die Justizjuristen war ein Prinzip, das mit der Wahl der obersten Juristen zusammenhing, in der Verfassung aber nur implizit enthalten war: die Abschaffung des Berufsbeamtentums. Gerade bei den Richtern hatte die lebenslange Anstellung auch deren Unabhängigkeit unterstreichen sollen. Waren es in den Westzonen vor allem die Alliierten, die eine Abschaffung des Berufsbeamtentums - vergeblich - forderten, so setzte sich in der SBZ die SED mit dieser Idee durch. Vor allem die brandenburgische LDP äußerte dagegen schwere Bedenken. Anders als die Westalliierten hatten viele Einheitssozialisten allerdings revolutionäre Umwälzungen im Staatsapparat im Sinn ${ }^{284}$. So stand den Entlassungs

wellen in der Justiz, die bis Mitte der fünfziger Jahre anhielten, keine Verfassungsbestimmung entgegen.

Der für unseren Zusammenhang entscheidende Artikel 40 lautet: „Die Richter sind bei Ausübung ihres Richteramtes unabhängig und nur dem Gesetze unterworfen. “ Entsprechend hieß es in den Verfassungen der übrigen Länder ${ }^{285}$. Diese

279 So auch das zeitgenössische Selbstverständnis: ACDP, III-033-195, Bl. 47, Protokoll CDU-Landesparteitag 3.-5.5.1947 (Beitrag Schütze).

280 Amos, Justizverwaltung, S. 45.

281 Stenographische Berichte Brandenburg, 12. Sitzung, 29. 5. 1947; ebenso in Adamy/Hübener, Geschichte der brandenburgischen Landtage, S. 260.

282 BLHA, PA Landesreg. Brandenburg Abgabe 1991, Bdl. 25, Nr. O/7219, Charakteristik MdI Brandenburg über Ostmann, ca. Ende 1946. In einer späteren Beurteilung wird ein „schwieriger u. komplizierter" Entwicklungsweg Ostmanns konstatiert, BStU, ZA AP 3578/65, Bl. 21, Beurteilung MdJ, 31.7. 1959.

${ }^{283}$ Stenographische Berichte Brandenburg, 12. Sitzung, 29. 5. 1947.

284 Vgl. allgemein Müller, Ersetzung des Berufsbeamtentums.

${ }^{285}$ Dort hieß es aber unisono „in ihrer Rechtsprechung“ statt „bei Ausübung ihres Richteramtes“. 
Bestimmung war schon angesichts der sowjetischen Vorrechte eingeschränkt und sollte ab 1949 systematisch von der SED verwässert werden. Ganz und gar nicht im Sinne der SED war die Tatsache, daß im Gegensatz zu den Verfassungen der anderen Länder die Institution der Volksrichter konstitutionell nicht fixiert war. Dies führte allerdings keineswegs zu einem brandenburgischen Sonderweg in dieser Frage. Vielmehr reichte dort die Verordnung vom 23. September 1946 aus, um die Volksrichter dauerhaft in der Justiz zu installieren.

Wie der Abschnitt über die Grundrechte, so waren auch die Bestimmungen zur Rechtspflege stark an das Weimarer Vorbild angelehnt; ähnliche Bestimmungen finden sich auch in den neuen Verfassungen der Länder in den Westzonen. Festgenommene mußten innerhalb von 24 Stunden einem Richter vorgeführt werden. Es galt das Prinzip des gesetzlichen Richters, also die Zuweisung der Beschuldigten nach vorher festgelegten Geschäftsplänen, um die spezielle Auswahl der Richter zu verhindern. Laienrichter, also Schöffen und Geschworene, seien an der Rechtsprechung "weitgehend zu beteiligen" 286 . Gerichtsverfahren waren öffentlich zu führen außer bei "Gefährdung der öffentlichen Ordnung oder Sittlichkeit“. Delikte sollten nur bestraft werden, wenn sie zum Tatzeitpunkt gesetzlich geregelt waren. Allein in Brandenburg und Sachsen wurde der SED-Vorschlag übernommen, Sondergerichte bei entsprechenden gesetzlichen Regelungen zuzulassen ${ }^{287}$.

Eine Gesamtbeurteilung der Verfassung ist schwierig. Zwar wurde sie zweieinhalb Jahre später in Teilen von der DDR-Verfassung abgelöst. Doch schon zuvor hatte die SED die Länderbestimmungen ausgehöhlt, ab 1949/50 systematisch durchbrochen. Deshalb hat man sie aus der Retrospektive als "Scheinexperiment“ (Lemmer) bezeichnet. Noch zutreffender formulierte Peter Bloch, daß „deren Wortlaut sich sehen lassen konnte. Daß sie später in der Praxis nur ,ein Fetzen Papier' blieb - wie Hitler die Weimarer Verfassung zu bezeichnen pflegte -, steht auf einem anderen Blatt. "288 In der damaligen Situation der Jahre 1946 bis 1948 war die Verfassung jedoch nach den Jahren der Diktatur ein wichtiger demokratischer Bezugspunkt, dessen Symbolkraft man nicht unterschätzen sollte. Besonders ab Mitte 1948 repräsentierte die Verfassung ein justizpolitisches Argument gegen die Aspirationen der SED 289. In Brandenburg gab es zwar eine Reihe von Parallelen zu den Länderkonstitutionen der Westzonen, aber auch markante Unterschiede, so besonders das Fehlen der Gewaltenteilung und deshalb das Fehlen eines Verfassungsgerichts, oder die Wahl der obersten Juristen ${ }^{290}$. Vor allem aber war es die Verfassungswirklichkeit, die Ost und West in den folgenden Jahren zunehmend voneinander trennte.

286 Nur in Brandenburg war der Vorschlag der Schöffen den Parteien vorbehalten.

${ }_{287}$ Braas, Entstehung der Länderverfassungen, S. 200 f. Gemeint waren damals vor allem Arbeitsgerichte.

288 Lemmer, Manches war doch anders, S. 277; Bloch, Zwischen Hoffnung und Resignation, S. 84. Vgl. Künzel, Brandenburgs Landesverfassung, S. 9, der nur noch eine „konstitutionelle Fixierung“ der neuen Machtverhältnisse sieht.

289 Vgl. BLHA, Rep. 212, Nr. 129, Bl. 21, Arbeitsminister Schwob an Ministerpräsident, 21. 11. 1947; ACDP, III-033-168, Entschließung des CDU-LV, o.D. (ca. Juni 1948); ein Richter sah die WStVO im Widerspruch zur Verfassung: BLHA, Rep. 212, Nr. 296, Protokoll über die Richtertagung in Potsdam am 19. 1. 1949.

290 Vgl. Abendroth, Die Justiz in den Länderverfassungen; vgl. zur hessischen Verfassung: Gosewinkel, Adolf Arndt, S. $128 \mathrm{f}$. 


\section{f. Die Auseinandersetzung um das Verwaltungsgericht}

Noch vor der Verfassungsgebung stand die Wiederherstellung einer Verwaltungsgerichtsbarkeit auf der Liste der Aufgaben, die unmittelbar nach dem Dritten Reich auf die Tagesordnung gesetzt wurden ${ }^{291}$. Die Verwaltungskontrolle durch Gerichte, wie es sie bis 1933 gegeben hatte, war im Dritten Reich zwar nicht abgeschafft, aber völlig ausgehöhlt worden. Deshalb hatte die Wiedereinsetzung, in Brandenburg die Neuerrichtung der Verwaltungsgerichtsbarkeit eine Signalfunktion für die Entwicklung demokratischer Strukturen. In Berlin schritten die Westalliierten dabei schon 1946 schnell zur Tat, bevor das verwässerte Kontrollratsgesetz Nr. 36 erlassen wurde 292.

Auf der Basis des alliierten Konsenses drängte die SMAD nun auf Schritte in ihrer eigenen Zone. In der SED-Führung, insbesondere bei den alten KPD-Funktionären, wurde die Verwaltungsgerichtsbarkeit dagegen als notwendiges Übel betrachtet ${ }^{293}$. Lehnte man schon grundsätzlich die Gewaltenteilung ab, so wurde die Kontrolle der Verwaltung durch die Justiz als Störfaktor eingestuft ${ }^{294}$. Zwar wollte die SED auf jeden Fall das Heft in der Hand behalten und trat als erste Partei mit der generellen Forderung nach solchen Gerichten auf; deren Einrichtung ließ aber auf sich warten. Unter den brandenburgischen SED-Juristen herrschte keine einhellige Meinung über Besetzung, Kompetenzen und Organisation dieser Gerichtsbarkeit ${ }^{295}$.

In Brandenburg ergaben sich zunächst eine Reihe organisatorischer Probleme. Vor allem war unklar, woher - bei allgemeiner Personalknappheit - qualifizierte Richter zu bekommen waren. Die Verwaltungsgerichtsbarkeit sollte als eigener Senat dem OLG angegliedert sein. Dafür plädierte vor allem OLG-Präsident Löwenthal. Ebenso wie in den anderen Ländern wurde schließlich jedoch ein eigenständiges Verwaltungsgericht projektiert. Das MdJ sah sich hier in der Tradition des Preußischen Oberverwaltungsgerichts ${ }^{296}$.

Mit einem zweiten Vorschlag drang der OLG-Präsident jedoch durch: Das Verwaltungsgericht sollte nicht dem Justiz-, sondern dem Innenressort zugeordnet werden. Angesichts der Kräfteverteilung in der brandenburgischen Regierung war dies keine reine Organisationsfrage. Der CDU-Vorsitzende Wolf vermutete zurecht: „Es seien Kräfte am Werk, die die Verwaltungsgerichte für eigene Inter-

291 Vgl. BA, DP-1 VA 2, Bl. 9-11, Niederschrift über Besprechung Abt. 1 DJV am 3. 9. 1945. Vgl. zum folgenden Janke, Verwaltungsgerichtsbarkeit in der SBZ.

292 Loewenstein, Reconstruction of the Administration of Justice, S. $426 \mathrm{f}$.

${ }^{243}$ SAPMO, NY 4182/1192, Bl. 193, Protokoll einer Beratung Fechners/Ulbrichts mit DVdI und Länderinnenministern, 20. 12. 1946: „Es ist der Plan, diese Gerichte möglichst ungefährlich zu machen." (Polak); ähnlich Melsheimer: SAPMO, DY 30/IV 2/1.01/37, Bl. 190, Protokoll der Ersten Juristenkonferenz der SED am 1./2. 3. 1947. Zum Verlauf der Debatte: Müller, Parteiministerien, S. $396 \mathrm{ff}$.

${ }^{294}$ Vgl. SAPMO, NY 4182/1119, Bl. 50-61, Stellungnahme der Abt. Justiz beim ZS zu den Verwaltungsgerichten, 26.11.1946.

295 BLHA, Rep. 332, Nr. 829, Bl. 4-9, Protokoll Juristensitzung Abt. Justiz SED-LV Brandenburg, 24. 1. 1947. Am 26.7. 1947 besprach sich das ZS der SED mit den Ländervertretern über diese Frage, vgl. SAPMO, DY 30/IV 2/13/109, Bl. 49, Plenikowski an Ulbricht/Fechner, 4. 8. 1947.

296 BLHA, Rep. 212, Nr. 487, B1. 18-22, 33, 42-43, Entwurf Präsident Prov. Brandenburg an DJV, Mai 1946; Vermerk MdJ Brandenburg, Mai 1947; MdJ an MdI Brandenburg, 16. 7. 1947. 
essen in Anspruch nehmen wollen und dagegen müsse Sicherung getroffen werden." 297

Die SED-Landtagsfraktion arbeitete mit dem zentralen SED-Gesetzesentwurf für alle Länder, der von vorneherein nur beschränkte Kompetenzen für das $\mathrm{Ge}$ richt enthielt: Das Hauptanliegen der SED-Spitze war es, die Generalklausel im Verwaltungsgerichtsgesetz zu vermeiden, die grundsätzlich die Überprüfung aller Verwaltungsakte ermöglicht hätte. Statt dessen sollten diese Fälle nach dem Enumerationsprinzip eng umgrenzt sein. Die Regierung sollte bestimmte Beschlüsse a priori von einer Prüfung ausschließen können ${ }^{298}$. Ebenso konnte alles Verwaltungshandeln aus der Zeit vor dem Erlaß des Gesetzes nicht mehr angefochten werden. In der CDU plädierte man dagegen für eine voll ausgebildete Verwaltungsgerichtsbarkeit, wenn auch über einige Fragen wie die Wählbarkeit der Richter Meinungsverschiedenheiten bestanden ${ }^{299}$. Am 9. Oktober 1947 wurde der Gesetzentwurf der SED im Landtag diskutiert. Die Sprecher von LDP und CDU stimmten schließlich dem Enumerations-Prinzip mit der offiziellen Begründung zu, daß dies einfach praktikabler sei. In Wirklichkeit war der Druck der SMA dafür verantwortlich, daß das Thema Generalklausel ad acta gelegt wurde: „Die Besatzungsmacht sehe es nicht gern, daß in den Ausschüssen über diese Frage diskutiert werde. " 300 Immerhin erreichte die CDU im Rechtsausschuß des Landtages einige Modifizierungen des SED-Entwurfs, mit denen dann am 12. Oktober 1947 das Gesetz über die Verwaltungsgerichtsbarkeit erlassen wurde. Die Enumeration ging der CDU jedoch nicht weit genug 301 .

Nachdem die Einrichtung dieser Gerichte in den Ländern - bis auf Thüringen $^{302}$ - schleppend, in Sachsen-Anhalt gar nicht vor sich gegangen war, ordnete schließlich die SMAD, deren Rechtsabteilung schon länger den Aufbau der Verwaltungsgerichtsbarkeit plante, mit Befehl Nr. 173 deren Eröffnung für den 1. Oktober $1947 \mathrm{an}^{303}$. Doch dieser Termin konnte in Brandenburg nicht eingehalten werden. Nicht nur war das einschlägige Gesetz - wie in Sachsen - noch nicht erlassen worden, sondern es entwickelte sich zudem die Besetzung des Postens des Verwaltungsgerichtspräsidenten zum Dauerproblem. In der Verfassung war dafür noch keine Regelung vorgesehen, erst das Verwaltungsgerichtsgesetz schrieb die Wahl der Richter durch den Landtag vor ${ }^{304}$. Nachdem die Posten des Oberlandesgerichts-Präsidenten und des Generalstaatsanwalts bereits an die SED gegangen waren, sahen sich nun die anderen Parteien an der Reihe, mit der Be-

297 ACDP, III-033-091, Protokoll CDU-Fraktionssitzung 30.1. 1947.

298 BLHA, Rep. 216, Nr. 1, Bl. 3-7, Erläuterungen zum Entwurf einer DVO über die Ausgestaltung der Verwaltungsgerichte.

${ }^{299}$ ACDP, III-033-003, Tagung der Landtagsabgeordneten der Union 26.-27. 10. 1946; ACDP, III033-091, Protokoll der ersten CDU-Landtagsfraktionssitzung 7.11. 1946 (Beitrag Schulze).

300 Stenographische Berichte Brandenburg, 20. Sitzung, 9. 10. 1947, S. 1-5; ADL, LDPD 2509, Protokoll Rechts- und Verfassungsausschuß des LDPD-Vorstands, 23.10.1947 (Zitat Koerber).

301 ACDP, III-033-120, Protokoll Sitzung Rechts- und Verfassungsausschuß Landtag Brandenburg am 8./9. 10. 1947; ACDP, III-033-171, Bl. 91, Protokoll CDU-Landesparteitag 7.-9.5.1948 (Redebeitrag Schütze). Gesetz abgedruckt in: Unrecht als System, S. 165.

${ }_{302}$ Dazu ausführlich Heil, Verwaltungsgerichtsbarkeit in Thüringen, S. 23 ff., mit der These eines thüringischen Sonderwegs.

303 BLHA, Rep. 212, Nr. 487, Bl. 40, SMAD-Befehl Nr. 173, 8. 7. 1947.

304 Der thüringische Staatsrechtler Schultes vermutete, dies sei „vergessen“ worden, SAPMO, DY 30/ IV 2/1.01/37, Bl. 174, Protokoll der Ersten Juristenkonferenz der SED am 1./2. 3. 1947. 
gründung, „daß es mit einer Blockpolitik nicht zu vereinbaren ist, wenn bei der Besetzung der führenden Positionen innerhalb des Gerichtswesens des Landes Brandenburg nicht die gleichen Grundsätze zur Anwendung gelangen wie es bei der Zusammensetzung des Kabinetts und der leitenden Positionen der Verwaltung der Fall war." 305 Die CDU schlug ihr Mitglied Franz Krause vor, einen Richter am Oberlandesgericht, die LDP wartete ebenfalls mit einem eigenen Kandidaten auf 306 .

Auf den Sitzungen des Landesblocks im Oktober machte die SED aber klar, daß sie als stärkste Fraktion auch diesen Posten zu besetzen gedachte. Schon acht Monate zuvor war Walter Lufft, der Oberlandrat von Cottbus, intern als der geeignete Kandidat im Gespräch ${ }^{307}$. Schließlich wurde von der SED der alte SPD-Jurist Walter Beckmann auserkoren, der überparteiliches Ansehen genoß308. Da keine Einigung erzielt werden konnte und die sowjetischen Termine bereits überschritten waren, beauftragte Innenminister Bechler den Oberlandesgerichts-Präsidenten Löwenthal mit der Führung der Geschäfte eines Verwaltungsgerichts. Ihm wurden Krause und Beckmann als Verwaltungsgerichtsräte und 15 Laienrichter, davon sechs aus CDU und LDP, zugeordnet ${ }^{309}$.

So konnte mit zweimonatiger Verspätung am 1. Dezember 1947 der brandenburgische Verwaltungsgerichtshof eröffnet werden. Bechler und Löwenthal machten auf der Eröffnungssitzung sogleich klar, daß das Gericht nur ganz begrenzt in die Verwaltung eingreifen sollte ${ }^{310}$. Angesichts vollendeter Tatsachen erklärten sich CDU und LDP im Januar 1948 mit der Besetzung des Präsidentenpostens durch Beckmann zunächst einverstanden und wollten nun die Führung der beiden Senate mit eigenen Kandidaten besetzen. Doch Bechler konterte sogleich, daß zwei Senate wegen des geringen Arbeitsanfalls nicht nötig seien. Bei Streitfragen zwischen dem Präsidenten und dem Senatspräsidenten war schließlich die Stimme des Präsidenten ausschlaggebend ${ }^{311}$. Als dann im Frühjahr 1948 doch die Besetzung eines zweiten Senats anstand, bezeichnete die SED den LDPKandidaten als untragbar ${ }^{312}$. So kam es letztendlich weder zur offiziellen Wahl eines Verwaltungsgerichtspräsidenten noch zur Bildung der zweiten Kammer. Als

305 BLHA, Rep. 201, Nr. 127, Bl. 1, CDU-Fraktion an Präsidium Landtag Brandenburg, 10. 10. 1947.

306 Protokolle Landesblockausschuß, S. 172 (Sitzungsprotokoll 20. 10. 1947). Krause war von 1922-

1945 Richter am Reichsversicherungsgericht, 1945/46 Organisationsreferent in der Abt. Justiz, BLHA, PA Rep. 212, Nr. K/6292, Personalakte Franz Krause. Der von der LDP vorgeschlagenc Dr. Brandt konnte nicht näher identifiziert werden.

307 BLHA, Rep. 332, Nr. 23, Bl. 27-29, Protokoll der Sekretariatssitzung, 6. 2. 1947; BLHA, Landesreg. Brandenburg Abgabe 1988, Bdl. 47, Nr. L 14951, Personalakte Lufft; SBZ-Handbuch, S. 971; als Schumacher-Anhänger wurde Lufft bezeichnet von Sägebrecht, Nicht Amboß, S. 329.

308 Protokolle Landesblockausschuß, S. 169, 172f.; ADL, LDPD/L5-45, Protokoll der erweiterten Landesvorstandssitzung der LDPD am 5. 2. 1948. Zeitweise waren Walter Schmeißer und Max Masius im Gespräch, BLHA, Rep. 332, Nr. 23, Bl. 167-173, 182-185, Protokolle der Sekretariatssitzungen SED-LV 15.9. und 6. 10. 1947.

309 BLHA, Rep. 216, Nr. 2, Bl. 6, 58, Bechler an Löwenthal, 3. 11. 1947 (nach Kabinettsbeschluß vom 28. 10. 1947); Richterverzeichnis Verwaltungsgerichtshof.

310 BLHA, Rep. 216, Nr. 2, Bl. 59-81, Protokoll der Eröffnungssitzung des Verwaltungsgerichtshofes am 1. 12. 1947.

311 Protokolle Landesblockausschuß, S. 187-190 (Sitzungsprotokolle 20. und 29. 1. 1948).

312 BLHA, Rep. 203, Nr. 170, Bl. 10-11, MdI an Block, 22. 5. 1948; Protokolle Landesblockausschuß, S. 201-203 (Sitzungsprotokoll, 1. 9. 1948). 
kommissarische Richter fungierten Beckmann, Krause und später der NDPDLandesvorsitzende Koltzenburg ${ }^{313}$.

Wie von der SED-Spitze beabsichtigt, blieb die Verwaltungsgerichtsbarkeit in einem embryonalen Zustand. Einen Teil der Klagen von Bürgern gegen Verwaltungsmaßnahmen ließen die Regierung und das Gericht gar nicht erst zu. Stattdessen beschäftigten sich die Juristen mit einigen wenigen Auseinandersetzungen von Kirchen und Gemeinden um Eigentum bei der Trennung von Schul- und Kirchämtern ${ }^{314}$. Die Geschäfte des Verwaltungsgerichts wurden zusehends vom Oberlandesgericht nebenbei erledigt. 1951 fielen noch ganze neun Sachen an, im folgenden Jahr nur noch eine, die Klage eines Bauern gegen eine wasserschutzpolizeiliche Anordnung; im April 1952 wurde die Auflösung der Institution eingeleitet ${ }^{315}$.

Die Idee der Verwaltungsgerichte war vor allem von den Westalliierten propagiert und in deren Zonen auch durchgesetzt worden. In der Rechtskonzeption der SED-Führung gab es dafür jedoch keinen Platz. Deshalb wurden die Gerichte zwar formell eingerichtet, aber ohne dieselben Kompetenzen und ohne den Instanzenzug wie in den Westzonen. Während die DDR-Verfassung im Oktober 1949 vom Weiterbestehen dieser Gerichte ausging 316 , reduzierte sich ihre Bedeutung in der sich rasch wandelnden Verfassungswirklichkeit noch weiter. Mit der Umstrukturierung der Justiz im Jahre 1952 verschwanden die Verwaltungsgerichte letztendlich geräuschlos. Erst über 35 Jahre später machte die SED hier einen zaghaften Neuanfang ${ }^{317}$.

Die Jahre 1946/47 brachten die zeitweise Konsolidierung der brandenburgischen Landesjustiz. Trotz der schweren materiellen und personellen Probleme gab es nun eine funktionierende Provinzial- bzw. Landesjustizverwaltung; die Aufwertung zum Justizministerium im Oktober 1946 war unter anderem den Auseinandersetzungen um die Regierungsbildung zu verdanken, als das Justizressort Verhandlungsmasse war. Zwar wurde mit dem Potsdamer Oberstaatsanwalt Ernst Stargardt ein CDU-Mitglied zum Justizminister berufen, dieser blieb jedoch relativ einflußlos. Generell unterlag das Justizwesen einer allgemeinen Kontrolle durch die sowjetische Besatzungsmacht, die weder eine eigene Rechtsabteilung auf Landesebene hatte noch ein eigenes Justizkonzept aufzeigte. In Macht- und Wirtschaftsfragen griff sie allerdings konsequent ein.

Auch der Landesverband der SED beschäftigte sich nur am Rande mit der Justiz. Probleme von grundsätzlicher Bedeutung regelte das Zentral-Sekretariat in Berlin; aus Sicht der SED-Zentrale galt die brandenburgische Justiz zunächst als vergleichsweise konform. Der Einfluß der Partei im Justizsektor war an die SED-

313 BLHA, Rep. 332, Nr. 37, Bl. 92-95, Sekretariatsvorlage der Abt. Staatl. Verwaltung, 18. 10. 1950. Krause wurde im Juni 1949 wegen seines Westberliner Wohnsitzes gekündigt, BA, DP-1 VA 1024 , Bl. 377, DJV an SMAD/RAbt., 21.6. 1949. Zu Koltzenburg, der seit Oktober 1948 Richter am OLG war: Kotsch, Karriercwege, S. 164 f.; Reinert, Parteien, S. 280.

314 BLHA, Rep. 201, Nr. 310, Übersicht über Tätigkeit des VerwGH, o.D. (vermutl. 7. 5. 1949).

315 BLHA, Rep. 203, Nr. 140, Bl. 4-5, 8, Löwenthal an MdI Brandenburg, 25. 4. 1952; MdI Brandenburg an OLG-Präsident, 24. 4. 1951; Protokolle Landesblockausschuß, S. 202. Beckmann entzog sich 1951 der Richtertätigkeit aus gesundheitlichen Gründen, 1952 flüchtete er in den Westen; BStU, ASt. Potsdam, AOP 130/55, Bl. 67f., Dzida an ZK der SED, 21. 4. 1953.

$316 \mathrm{Vgl}$. noch im Februar 1952: Löwenthal, Zur Frage der Zulässigkeit des ordentlichen Rechtsweges. 317 Janke, Verwaltungsgerichtsbarkeit in der SBZ, S. 431. 
Mitglieder in der Justizverwaltung, insbesondere den Hauptabteilungsleiter Walther Hoeniger, gebunden. Dieser hatte jedoch weit mehr mit der DJV als mit seiner Parteiorganisation zu tun. Allein in der Phase von 1946 bis Anfang 1948 entwickelte sich eine von SED-Führung und Zentralinstanzen weitgehend eigenständige, also föderale brandenburgische Justiz.

\section{Rechtspolitik und Rechtsprechung 1945-1947}

Der brandenburgische Justizapparat sah sich unmittelbar nach dem Krieg vor allem mit zwei Aufgaben konfrontiert: Das eine war die juristische Bewältigung der enormen Kriegsfolgen, das andere die Gestaltung eines Rechtssystems, welches durch den Nationalsozialismus stark gestört war. Während die erste Aufgabe die Justiz sozusagen unfreiwillig in Atem hielt, war der Handlungsspielraum bei der Gestaltung der Rechtsordnung zunächst größer. Bis 1948 verfügte die Provinzialbzw. Landesjustiz über eine Gesetzgebungsabteilung ${ }^{318}$, die durchaus eigene Akzente gegenüber den anderen Ländern der SBZ setzen konnte.

\section{a. Justiz und Nachkriegsprobleme}

Die Auflösung staatlicher Strukturen und die in Brandenburg ganz besonders ausgeprägte, von materieller Not und dem Verlust ethischer Wertmaßstäbe gekennzeichnete Zusammenbruchsgesellschaft führten zu einer explosionsartigen Zunahme der Kriminalität ${ }^{319}$. Typische Merkmale dieser Nachkriegsentwicklung war die Vervielfachung der Eigentumsdelikte und Kapitalverbrechen. Von August bis Dezember 1945 registrierte man in Brandenburg allein 301 Morde, d.h. fast jeden Tag zwei. Im Jahr darauf waren es 461, 1947 dann 510 Fälle 320.

Hinzu kam die "Hungerkriminalität" in ihren vielfältigen Erscheinungsformen. Wie in allen Besatzungszonen entwickelte sich aber immer mehr der Schwarzmarkt zum zentralen Problem von Polizei und Justiz. Die Verwaltungen versuchten, den Schwarzmarkt mit administrativen Mitteln zu bekämpfen. Landräte und Oberbürgermeister konnten bei Preisüberschreitungen Geldstrafen bis zu 5000 RM verhängen ${ }^{321}$. Einzelne Landräte wie der in Teltow gingen dazu über, selbst Strafverordnungen zu erlassen, wozu allerdings die Rechtsgrundlage fehlte ${ }^{322}$. Erst die schwereren Fälle landeten vor den Amtsgerichten. Die Richter wußten oftmals nicht genau, wie sie Schwarzhändlern juristisch beikommen sollten $^{323}$. Angesichts der katastrophalen Versorgungssituation waren viele Urteile ge-

318 Zunächst unter Löwenthal, dann unter Conrad; BLHA, Rep. 212, Nr. 158, GVPl. Abt. VI Justiz Brandenburg, 15. 3. 1946; GVPl. MdJ Brandenburg, 28. 10. 1947.

319 Anschaulich für Potsdam 1945: Kasack, Dreizehn Wochen, S. $19 \mathrm{ff}$.

320 Errichtung des Arbeiter- und Bauernstaates, S. 232; BLHA, Rep. 212, Nr. 22, Bl. 8, Übersicht Geschäftsentwicklung Justiz Brandenburg 1947.

321 BLHA, Rep. 212, Nr. 40, Bl. 127-129, Runderlaß der Abt. Justiz Nr. 99, 22. 2. 1946 (zur Preisregelungs-VO vom 5. 12.1945).

322 BLHA, Rep. 212, Nr. 406, Bl. 4, 19, Landrat Teltow an Abt. Justiz Brandenburg, 12. 12. 1945, Abt. Justiz an Landrat Teltow, 17. 12. 1945 (betr. Verbot der Ausfuhr landwirtschaftlicher Erzeugnisse).

323 BLHA, Rep. 240 Potsdam, Nr.9, Bl. 220-222, Runderlaß Abt. Justiz Provinzialverwaltung 
gen Schwarzhändler, Hamsterer, Lebensmittelkartenbetrüger und sogenannte Schieber heftiger Kritik von Öffentlichkeit und Presse ausgesetzt, weil die Strafmaße unangemessen niedrig erschienen. Solche Justizschelte war kein spezifisch brandenburgisches Problem, sondern in Berlin noch ausgeprägter ${ }^{324}$. Die SMA beschwerte sich, die deutschen Behörden würden ihren Pflichten bei der Bekämpfung des Schwarzhandels nicht nachkommen. Die Kommandantur in Potsdam beispielsweise rekrutierte ertappte Schieber an Ort und Stelle für $\mathrm{Z}$ wangsarbeitsKommandos ${ }^{325}$. Die Justizverwaltung selbst forderte von den Gerichten schnellere Verfahren und ein härteres Vorgehen in den Wirtschaftsverfahren ${ }^{326}$. Daß sie sich dabei auf einem schmalen Grat bewegte, war ihr durchaus bewußt:

„Die Provinzialverwaltung ist weit entfernt von der Absicht, von ihren Gerichten Bluturteile nazistischer Prägung zu verlangen, aber andererseits ist ohne abschreckende Strafen der moralisch unsicher gewordenen Bevölkerung nicht das nötige Gefühl für die Unantastbarkeit gewisser Rechtsgüter im Interesse des demokratischen Neuaufbaus beizubringen." 327

Ein ganz anders gelagertes Rechtsproblem war die Verbreitung von Geschlechtskrankheiten. Sie war oft eine Folge der Vergewaltigungen. Schiere Not trieb viele Frauen in die Gelegenheits-Prostitution; die miserablen hygienischen Verhältnisse und die hohe Mobilität der Bevölkerung taten ein übriges. Schon am 30. August 1945 erließ die Provinzialverwaltung eine Verordnung, die Zwangsmaßnahmen enthielt ${ }^{328}$. Die Sowjetische Militäradministration griff zu harschen Mitteln. Im Befehl Nr. 0194 vom 19. Juli 1946 ordnete die SMAD die Einrichtung von ein bis zwei Arbeitskolonien für als rückfällig eingestufte Prostituierte in jeder Provinz und jedem Land an. In schweren Fällen sollten Gerichtsverfahren gegen Frauen nach Befehl Nr. 030 und nach einem Gesetz von 1927 eingeleitet werden. Die Provinzialverwaltung folgte mit einer entsprechenden Verordnung ${ }^{329}$. Zunächst wurden die betroffenen Frauen in ein Fürsorgeheim oder in ein Lager eingewiesen, das „Arbeits-Sanitätshaus“ Heidekrug in Brandenburg/Havel. Aber auch im Gefängnis Luckau und im Gerichtsgefängnis von Guben waren entsprechende Abteilungen für Geschlechtskranke einzurichten. Allein im Juli 1947 veranstaltete die Polizei 241 Razzien wegen Prostitution, 2370 Frauen und 471 Männer wurden dabei festgenommen; 354 Frauen saßen zu dieser Zeit in Heidekrug ein. Zunächst war die Kriminalpolizei für Ermittlungen in diesem Bereich allein zuständig, ab April 1947 übernahmen die Gesundheitsämter den größten

Nr. 163, 3. 5. 1946, mit der Aufforderung zur Anwendung von Preisstraf-VO, KWStVO und Verbrauchsregelungstraf-VO.

324 Vgl. den Bericht des Berliner GStA Kühnast, 30. 3. 1946, Berlin 1945-1946, S. 402.

325 SAPMO, DY 30/IV 2/13/433, Konferenz der Länderjustizminister am 3. 5. 1946, S. 15.

326 Vgl. Stenographische Berichte Brandenburg, 4. Sitzung, 19. 12. 1946; BLHA, Rep. 212, Nr. 40, Bl. 280, Runderlaß der Abt. Justiz Nr. 199, 8.6.1946.

327 BA, DP-1 VA 7, Bl. 82, Abt. Justiz Brandenburg an DJV, 15. 7. 1946: Bericht über II. Quartal 1946.

328 Polizeiverordnung zur Bekämpfung der Geschlechtskrankheiten, 30. 8. 1945, VOBl. 1945, S. 23;

Inventar der Befehle, S. 68, vermerkt außerdem den SMAD-Befehl Nr. 25 vom 7. 8. 1945, der am 5. 1.1946 in Brandenburg bekanntgemacht wurde.

329 BLHA, Rep. 203, Nr. 26, Bl. 3-4, SMAD-Befehl Nr. 0194, 19. 7. 1946; BLHA, Rep. 212, Nr. 382 , Bl. 1-5, VO zur Änderung und Ergänzung des Gesetzes zur Bekämpfung von Geschlechtskrankheiten von 1927, 17.9. 1946. Vgl. BLHA, Rep. 201, Nr. 212, Bl.300, Befehlsschreiben SMA Nr. 5782, 23.11. 1948. Zur deutschen Tradition vgl. Ayass, Die "korrektionelle Nachhaft“, S. $184 \mathrm{ff}$. 
Teil dieser Arbeit ${ }^{330}$. Die Justizabteilung forderte als besonders drastisches Mittel die Durchführung von Schauprozessen gegen geschlechtskranke Frauen. Während die Mehrheit der Richter und Staatsanwälte dies ablehnte, führte etwa das Amtsgericht Potsdam zwei Schauprozesse gegen 19 Frauen vor Angehörigen eines Fürsorgeheims durch 331 !

Als spezifische Problemlage der Zeit nach dem Zweiten Weltkrieg erwies sich auch die Anwesenheit von Bevölkerungsgruppen, die nicht aus Brandenburg stammten. Aus der Einwohnerschaft kamen immer wieder Klagen über eine angeblich überdurchschnittliche Kriminalität der Vertriebenen und Flüchtlinge. In der Berichterstattung wurden hingegen Straftaten von Displaced Persons oftmals hervorgehoben. Dabei waren auch durchaus antisemitische Töne zu hören, so etwa im Zusammenhang mit den Insassen des UNRRA-Lagers in Klein-Machnow, von denen angeblich eine besondere Gefahr ausging 332 . Die nichtjüdischen DPs wurden hingegen bald nach Kriegsende fast ausnahmslos repatriiert. Auch um die alteingesessenen brandenburgischen NS-Opfer hatte sich die Justiz zu kümmern. Zunächst waren durch SMAD-Befehl Nr. 66 vom 17. September 1945 die NS-spezifischen Gesetze außer Kraft gesetzt. Personen, die aus politischen Gründen im Dritten Reich verurteilt worden waren, konnten nach SMAD-Befehl Nr. 228 um Annullierung der Urteile nachsuchen. Die Vereinigung der Verfolgten des Naziregimes (VVN) ermittelte, daß es in Brandenburg 252 Todesopfer des Nationalsozialismus gegeben habe, davon 66 Hingerichtete. Insgesamt waren im Herbst 19472613 sogenannte Opfer des Faschismus im Lande registriert ${ }^{333}$. Die Zahl der Rehabilitierungsanträge hielt sich aber in engen Grenzen, bis Jahresende 1946 waren es ganze 23 Fälle. Deshalb ordnete die SMAD eine breite Publizierung ihres Befehls an. Das Justizministerium in Potsdam vermutete, daß wohl die meisten der Betroffenen das Dritte Reich nicht überlebt hätten ${ }^{334}$. Für die Überlebenden brachte der Landesverband der VVN im August 1947 den Entwurf eines Wiedergutmachungsgesetzes ein. Innerhalb von SED und VVN entbrannte jedoch bald eine Debatte darüber, ob eine gesonderte Regelung für Juden getroffen werden sollte. Gerade in der SED war dabei das Argument anzutreffen, daß mit der

330 BLHA, Rep. 202A, Nr. 39, Bl. 172-174, 177-196, Tätigkeitsbericht LKPA Brandenburg, 7. 8. 1947; Tätigkeitsbericht LKA Brandenburg für Dezember 1947, 6. 1. 1948; vgl. BLHA, Rep. 212, Nr. 42, Bl. 575, Rundverfügung MdJ Brandenburg Nr. 367, 21. 10. 1948. Als Rechtsgrundlage für die Internicrungen diente das Polizeiverwaltungsgesetz vom 1.6. 1931. Dagegen tituliert Müller, Parteiministerien, S. 368 f., die Einführung von Haftlagern schon als „Einführung von Polizeistrafrecht".

331 BLHA, Rep. 212, Nr. 40, Bl. 505, Runderlaß der Abt. Justiz Nr. 308, 4. 11. 1946; BLHA, Rep. 212 Nr. 40, Bl. 557, Runderlaß der Abt. Justiz Nr. 333, 12. 12. 1946.

${ }_{332}$ Christopeit, Herkunft und Verteilung, S. 99, 103; über Neusiedler: BLHA, Rep. 212, Nr. 9, Bl. 130 , Bericht über die Tätigkeit der Justizbehörden des Landes Brandenburg im 1. Halbjahr 1950, 15. 7. 1950; Timm, Hammer, Zirkel, Davidstern, S. $102 \mathrm{f}$. Abfällige Zeitungsartikel über das Lager erschienen auch im CDU-Organ „Neue Zeit“ und in westlichen Zeitungen.

333 BA, DP-1 VA 326, Bl. 335-342, VVN-Statistik zum 1. 10. 1947; Liste von 73 Ermordeten der KPD (davon 13 Hingerichtete) aus dem Bezirk Frankfurt/Oder in: Wir waren damals 19, S. 29-36. Im Mai 1946 gab es in Brandenburg ca. 800 anerkannte „Kämpfer gegen den Faschismus“, Reuter/ Hensel, Das kurze Leben der VVN, S. 95.

${ }_{334}$ BA, DP-1 VA 318, Bl. 262, 335, 339, MdJ Brandenburg an SMAD, 30. 12. 1946; MdJ Brandenburg an DJV, 17. 5. 1947; MdJ Brandenburg an DJV, 19.6. 1947. In Brandenburg lebten nur noch wenige Juden, 1946 waren es 424 Einwohner, 1950 nur noch 107 Personen, Timm, Hammer, Zirkel, Davidstern, S. 77. 
Restitution von Eigentum, das Juden geraubt worden war, Kapitalisten unterstützt würden. Nicht zuletzt wegen dieser ideologischen Scheuklappen kam es allein in Thüringen, nicht dagegen in Brandenburg zum Erlaß eines Wiedergutmachungsgesetzes. Die entsprechende spätere Rechtsregelung in der DDR klammerte Vermögensfragen aus ${ }^{335}$.

Die Hauptlast der Justiztätigkeit in den ersten Nachkriegsjahren fiel aber nicht auf die Kriminalität, sondern auf zivilrechtliche Probleme. Das betraf vor allem das Familienrecht. Nie in der deutschen Geschichte hatte es so viele Scheidungen wie unmittelbar nach dem Zweiten Weltkrieg gegeben. Grundsätzliche Regelungen traf das Ehegesetz des Kontrollrates von 1946. Wegen der inflationären $\mathrm{Zu}$ nahme der Scheidungen mußten diese von den Landgerichten an die Amtsgerichte delegiert werden, da allein letztere bei der katastrophalen Verkehrssituation noch zu erreichen waren. Erst 1950/51 reduzierte sich die Scheidungsquote allmählich wieder auf das Vorkriegsmaß336. Auch das Vormundschaftsrecht mußte den Anforderungen der Zeit angepaßt werden. Belastete Nationalsozialisten konnten in Brandenburg von der Vormundschaft ausgeschlossen werden; eine Regelung, die unter den Ländern nicht unumstritten war und 1948 modifiziert wurde ${ }^{337}$.

\section{b. Anforderungen der Besatzungsmacht}

Rechtsfragen, die die sowjetische Besatzungsmacht nicht in eigener Regie behandelte (wie Waffenablieferung, Widerstand gegen die SMA, NS-Verbrechen), aber trotzdem für wichtig erachtete, wurden an die Provinzialregierung delegiert. Bei der Bodenreform und Sequestrierung geschah dies unauffällig im Hintergrund, bei Verstößen gegen wirtschaftliche Anordnungen der Besatzungsverwaltung aber offen.

Als besonders neuralgischer Punkt erwies sich die Ernährungswirtschaft. Die Militärbehörden hatten in Brandenburg ein „System gestaffelter Pflichtabgabenormen" für die Bauern verordnet, nicht unähnlich den Regelungen in der Sowjetunion, aber gemäßigter als im Dritten Reich. Mittels der teilweisen Zwangsabgabe landwirtschaftlicher Produkte sollten die Besatzungstruppen versorgt werden, vor allem aber die deutsche Bevölkerung. Und deren Ernährungssituation war in den ersten Nachkriegsjahren außerordentlich kritisch. Nicht nur durch die großen Zerstörungen landwirtschaftlicher Anbauflächen und Gebäude bzw. Geräte, sondern auch durch den enormen Bevölkerungszuwachs an Vertriebenen bestand hier ein großes Nahrungsmitteldefizit ${ }^{338}$. Dramatisch wurde die Lage im harten Hungerwinter 1946/47, nach den Überschwemmungen im Oder-

335 Reuter/Hensel, Das kurze Leben der VVN, S. 424 f.; Timm, Hammer, Zirkel, Davidstern, S. 66 f.

336 Tätigkeitsbericht der Abteilung Justiz der Provinzialverwaltung Mark Brandenburg für die Zeit von Mitte 1945 bis 5. Juli 1946, (Juli 1946), in: Berichte der Landes- und Provinzialverwaltungen, S. $294 \mathrm{f}$; Mertens, Ehescheidungen in der Ära Ulbricht, S. $174 \mathrm{f}$.

337 BLHA, Rep. 212, Nr. 40, Bl. 122, Runderlaß der Abt. Justiz Nr. 92, 19. 2. 1946; SAPMO, DY 30/ IV 2/13/433, Konferenz der Länderjustizminister am 3.5. 1946, S. 11; BLHA, Rep. 212, Nr. 42, Bl. 328, Rundverfügung MdJ Nr. 188, 22. 5. 1948.

338 Gries, Rationen-Gesellschaft, S. 82 f.; vgl. beispielsweise den Bericht der brandenburg. Provinzialabt. Handel und Versorgung, 13. 5. 1946, Berichte Landes- und Provinzialverwaltungen, S. 226232. 
bruch vom März 1947 und wegen der schlechten Ernte nach der Dürre im Sommer 1947339 .

Seit Juni 1945 war das Ablieferungssoll durch eine Vielzahl von SMAD-Befehlen geregelt ${ }^{340}$. Für die Durchführung der Pflichtablieferung zeichneten vor allem die Landräte und ihre Verwaltungen verantwortlich, die wiederum einer Kontrolle durch die Kommandanten unterlagen. Die Kommunen konnten die genaue Veranlagung der Abgabepflichten - gemessen an der Leistungsfähigkeit der Bauern - festlegen. Einige Landräte und Bürgermeister versuchten, manchmal gemeinsam mit Kommandanten ${ }^{341}$, das schematisch festgesetzte Ablieferungssoll zu unterlaufen, wenn die Lage der Bauern besonders schlecht war. In diesen Fällen drohte strafrechtliche Verfolgung, besonders auf Intervention der SMA ${ }^{342}$.

Hauptsächlich waren natürlich die Bauern selbst von solchen Verfahren betroffen. In der Masse der Fälle verhängten die Landräte Polizeistrafen, ohne ein Gerichtsverfahren einzuleiten. Kam es zu Prozessen, so liefen diese zunächst noch auf der Grundlage der Kriegswirtschafts-Strafverordnung in der Fassung von 1942. Am 3. Dezember 1945 erließ die SMAD jedoch ihren Befehl Nr. 160 gegen Sabotage- und Diversionshandlungen vor allem in der Wirtschaft. Dieser sah Prozesse bei den Landgerichten vor und hatte einen Strafrahmen bis hin zur Todesstrafe. Allerdings setzte die Anwendung des Befehls den Nachweis der „Böswilligkeit" voraus, was zu erheblichen Diskussionen führte. Der damalige Oberstaatsanwalt von Potsdam, Stargardt, drängte darauf, den Begriff Böswilligkeit möglichst weit auszudehnen, z. B. auf jede Schwarzschlachtung ${ }^{343}$. Ergänzt wurde der Befehl Nr. 160 durch eine Vielzahl von Durchführungsbestimmungen, die seine Handhabung nicht unbedingt erleichterten. Zeitweise erwog der Chef des MWD in der SBZ, Serow, alle Verfahren wegen Befehls Nr. 160 vor sowjetischen Militärgerichten führen zu lassen. Das Ergebnis wäre sicher katastrophal gewesen. Doch in Moskau lehnte man dieses Ansinnen offenbar $\mathrm{ab}^{344}$. So kamen die Verfahren meist vor Schöffengerichte.

Ab Sommer 1946 übte die SMA verstärkt Druck in der Frage der Abgabendisziplin aus. Sie konstatierte besonders im Bezirk Cottbus große Fehlmengen bei den Ablieferungen und ordnete Gerichtsverfahren auf der Basis des Befehls Nr. 160 an $^{345}$. Im Herbst 1946 spitzten sich die Dinge zu: „Von der SMA Potsdam sei festgestellt worden, daß ganze Dörfer unter Billigung ihrer Bürgermeister ihr Ablieferungssoll bewußt nicht erfüllt hätten."346 Einzelne Kommandanten for-

${ }^{339} \mathrm{Vgl}$. Die antifaschistisch-demokratische Umwälzung, S. $261 \mathrm{ff}$., $276 \mathrm{ff}$.; ausführlich zur britischen und amerikanischen Zone: Trittel, Hunger und Politik, S. $87 \mathrm{ff}$, $213 \mathrm{ff}$.

340 Unnumerierter Befehl vom 18. 6. 1945, Befehle Nr. 18 (29. 7.), Nr. 21 (3. 8.), Nr. 55 (8. 9.), Nr. 121 (29. 10.), Nr. 133 (3. 11.) 1945 usw., Inventar der Befehle, S. 65 ff.; des weiteren Gries, RationenGesellschaft, S. 357.

${ }^{3+1}$ Naimark, Russians, S. 15, erwähnt eine entsprechende Rüge von Scharow.

${ }^{342}$ So Bechler: SAPMO, DY 30/IV 2/13/109, Bl. 43, Protokoll der Innenministerkonferenz am 1. 6. 1947.

${ }^{343}$ BLHA, Rep. 212, Nr. 596, Bl. 70, Stargardt an OStA Eberswalde, 23. 1. 1946; vgl. die Diskussion in BA, DP-1 SE 2221, Löwenthal an Rosenthal, 23. 2. 1950.

${ }^{344}$ Nikitin, Die sowjetische Militäradministration und die Justiz, Bl. 14.

${ }^{345}$ BA, DP-1 VA 325, Bl. 145, Befehlsschreiben Nr. 3319 SMA, 9. 7. 1946; vgl. BLHA, Rep. 212, Nr. 595, Bl. 33, Landrat Westhavelland an Abt. Justiz, 29. 7. 1946.

${ }_{346}$ BA, DP-1 VA 22, Bl. 83, Konferenz der Länderjustizminister am 1./2.11. 1946 (Zitat Hoeniger). 
derten die Landräte und die Gerichte auf, Massenverfahren gegen die gesamte Bauernschaft einzelner Dörfer zu führen. Daraufhin brachte ein Landrat allein an die 400 Sabotagesachen ein ${ }^{347}$.

Der Anstieg der Prozesse und die teilweise drakonische Bestrafung riefen in der ländlichen Bevölkerung, die schon durch die Plünderungen von Rotarmisten verunsichert war, erhebliche Unruhe hervor ${ }^{348}$. Die Vereinigung der gegenseitigen Bauernhilfe glaubte unter den Kleinbauern schon eine starke Verängstigung zu spüren und drängte die DJV dazu, vor der Einleitung von Verfahren informiert zu werden ${ }^{349}$. Gerade im Vorfeld der Wahlen vom Oktober 1946 fürchtete die SED, die Massenprozesse könnten ihrem Image auf dem Lande schaden ${ }^{350}$. Auch danach, im Dezember 1946, dem Monat mit den meisten Verurteilungen, übernahm die SED die Initiative, die Massenabstrafungen einzudämmen ${ }^{351}$. Im Februar 1947 richteten die Landräte deshalb Ausschüsse zur Überprüfung der Urteile gegen Bauern ein. Diese befürworteten meist eine „Bauernamnestie“. Verurteilten Bauern konnte für die Frühjahrsbestellung 1947 Strafaufschub gewährt werden ${ }^{352}$.

Allerdings blieben diese Maßnahmen zur Abmilderung der Strafpolitik Episode. Nach Oderhochwasser und Mißernte im Jahre 1947 verstärkte sich der Druck auf die Bauern erneut, zunächst durch administrative Beschlagnahmen bei säumiger Erfüllung. Die SMA monierte nun auch die unzureichende Ablieferung von Milch und Schweinefleisch und ordnete an, alle Bauernprozesse gegenüber anderen laufenden Strafverfahren vorzuziehen ${ }^{353}$. Noch im November 1947 legte die SMA eine massive Kritik an der Justiz nach, weil ihre Befehle offensichtlich nicht befolgt würden ${ }^{354}$. Auf Drängen der SMA sollte mit einem brandenburgischen Gesetz über die Verletzung der Abgabepflicht von landwirtschaftlichen Produkten vom 13. Oktober 1947 eine neue Handhabe zur Bestrafung gegeben werden; nun könnten bis zu zehn Jahren Haft verhängt werden. Der Entwurf mußte von der Landesregierung - offensichtlich auf Anordnung der SMAD jedoch zurückgezogen werden, es galten weiter die KWStVO und die SMAD-Befehle ${ }^{355}$. Noch im Herbst 1947 wurden 800 Bauern in Brandenburg wegen Nichtablieferung zu harten Strafen verurteilt ${ }^{356}$. Nun griff die SMAD zu einem drasti-

347 Ebenda.

348 Vgl. SAPMO, NY 4036/684, Bl. 1-10, Vorläufiger Bericht der Landwirtschaftsabt. der brandenburg. Provinzialverwaltung, 9. 8. 1945 (gez. Hoernle).

349 BA, DP-1 VA 325, Bl. 121, VdgB-Zentralsekretariat an DJV, 26. 7. 1946.

350 Vgl. den Artikel „Agrarkrise in Brandenburg“ in: Der Sozialdemokrat, 15. 11. 1946.

351 Stenographische Berichte Brandenburg, 4. Sitzung, 19. 12. 1946; vgl. auch ACDP, VII-011-1286, Mitteilungen der CDU, 16. 12. 1946, mit der Kritik an den Massenbestrafungen.

$352 \mathrm{Vgl}$. die Einzelfallakten in BLHA, Rep. 217, Nr. 146, Überprüfung Nichtablieferungsverfahren 1947/48; BLHA, Rep. 212, Nr. 1195, Bl. 27, Runderlaß MdJ Brandenburg Nr. 61, 5. 3. 1947.

353 BLHA, Rep. 212, Nr. 41, Bl. 424, 472 f., Befehlsschreiben Nr. 7101 SMA Brandenburg, 30. 9. 1947; Rundverfügung MdJ Brandenburg Nr. 300, 6. 11. 1947 (mit Bezug auf Befehl Nr. 181 SMA Brandenburg, 31. 10. 1947).

354 BLHA, Rep. 203 MdI/LBdVP, Nr. 9, Bl. 66, Befehlsschreiben der SMA Nr. 8174, 6. 11. 1947.

355 Stenographische Berichte Brandenburg, 17. Sitzung, 11. 9. 1947; BLHA, Rep. 212, Nr. 375, Gesetzentwurf zur Sicherung der Ablieferung landwirtschaftlicher Produkte; MdJ an Kanzlei des Ministerpräsident, 6. 9. 1947; vgl. BLHA, Rep. 201, Nr. 163, Bl. 82-90, Übersicht der vom Rechtsund Verfassungsausschuß bis Dezember 1947 behandelten Vorgänge.

356 SAPMO, SgY 30/2077, Bl. 7, Erinnerungen Elfriede Göldner, 1984/87; z. B.: BLHA, Rep. 212, Nr. 820, Urteil AG Lübben, 17. 10. 1947: fünf Jahre Gefängnis wegen Nichtablieferung von $7 \mathrm{dz}$ Getrcide. 
schen justizpolitischen Mittel: Alle Urteile wegen Nichtablieferung waren sofort, also ohne Abwarten der Rechtskraft, zu vollstrecken. Erst danach konnte eine Berufungsverhandlung stattfinden. Diese Anordnung führte zu erheblicher Unruhe unter den Juristen. Hoeniger und Stargardt beschwerten sich bei der DJV, die jedoch keinen Handlungsspielraum sah ${ }^{357}$. Manche Landräte veranstalteten ein regelrechtes Kesseltreiben gegen Amtsgerichte, die in ihren Augen zu niedrige Urteile verhängten. In Luckenwalde mußten die Richter zu einer „Besprechung“ antreten:

„Dort sahen wir zu unserem Erstaunen, daß eine Unmenge von Verbänden mobil gemacht war, sogar ein Mitglied der Besatzungsmacht vorhanden war und wir wurden dann von dem Landrat mit den entehrendsten Ausdrücken belegt. Wir wurden als Verbrecher bezeichnet, die auf die Anklagebank gehörten und dergleichen mehr.“358

Allerdings bestrafte man bei weitem nicht alle Bauern, die vor Gericht standen. Vielfach intervenierten Kommunalverwaltung und VdgB zugunsten der Landwirte ${ }^{359}$. Im Januar und Februar 1948 griff auch die SMA erneut ein. Die Verfahren würden viel zu langsam laufen, die Berichterstattung sei schlecht, und auch der Ausgang der Prozesse befriedigte die Militärverwaltung nicht. Deshalb seien alle Verhandlungen bis Ende Februar abzuschließen und „auf diejenigen Gerichte einzuwirken, die Schuldige freisprechen" 360 .

Seit Ende 1947 mußten die Staatsanwälte durch die Dörfer ziehen und die Bauern in Versammlungen über die strafrechtlichen Folgen der unzureichenden Ablieferung aufklären. SMA und Justizverwaltung erhofften sich von dieser Maßnahme eine Einwirkung auf die regionalen "Schwerpunkte" bei der Nichtablieferung. Die Veranstaltungen endeten aber gerade in solchen Dörfern oftmals in einem Fiasko:

„Die sture Gleichgültigkeit der Sielower Landwirte - Sielow ist ein großes Dorf von ca. 2000 Einwohnern - versetzte den Landrat Saisowa so sehr in Erregung, daß er erklärte, unter diesen Umständen von der Abhaltung der Versammlung Abstand zu nehmen und nunmehr gegen diejenigen Landwirte Strafverfahren zu veranlassen, bei denen Böswilligkeit in Bezug auf ihre rückständigen Ablieferungen festgestellt wird, und zwar soll dies in einem Schauprozeß in Sielow stattfinden. ${ }^{\circ 361}$

Erst ab Ende 1948 ging die Zahl der Ermittlungsverfahren wegen Nichtablieferung deutlich zurück ${ }^{362}$. Doch dies hielt nicht lange vor. Schon Ende 1950 war ein erneutes Ansteigen zu verzeichnen. Das war jedoch nicht mehr auf die schlechte

357 BLHA, Rep. 212, Nr. 41, Bl. 494-497, Rundverfügung MdJ Brandenburg Nr. 320, 25. 11. 1947 mit VO der DJV über das Verfahren in Wirtschaftsstrafsachen, 21. 10. 1947; BLHA, Rep. 212, Nr. 1072, Bl. 9-10, DJV an MdJ Brandenburg, 23. 10. 1947; Ebenda, Bl. 18-19, Vermerk Hoeniger, 6. 11.1947.

358 BLHA, Rep. 217, Nr. 125, Bl. 61, Strafkammer Luckenwalde an Strafkammer II, 3. 10. 1949 (mit Bezug auf Herbst 1947).

359 Spix, Bodenreform in Brandenburg, S. 75-79; Nehrig, Uckermärcker Bauern, S. 47. Löwenthal schätzte die Verurteilungsquote auf nur 10\%, SAPMO, DY 30 IV 2/1.01/70, Bl. 18, Dritte Tagung des Rechtspolitischen Beirats beim ZS der SED, 3./4. 1. 1948.

360 BLHA, Rep. 201, Nr. 212, Bl. 188, Befehlsschreiben Nr. I/1051 SMA, 16. 2. 1948.

36: BLHA, Rep. 212, Nr. 806, Bl. 3, OStA Cottbus an GStA Brandenburg, 28. 7. 1948.

362 Ebenda, Bl. 33-36, GStA Brandenburg an DJV, 17. 10. 1948. 
Ernte oder Ablieferungsmoral zurückzuführen, sondern bereits auf die „klassenmäßige" Festlegung der Ablieferungsnormen.

Ebenso wie an einer rigiden Gesetzgebungspraxis gegen echte und angebliche Sabotage in der Wirtschaft waren die sowjetischen Behörden auch an ersten Plänen zum Erlaß eines politischen Strafrechts interessiert. Die Fälle, die vom NKWD als Widerstand qualifiziert wurden, kamen fast durchweg vor sowjetische Militärgerichte. Hin und wieder urteilte ein deutsches Gericht wegen „Beleidigung der Roten Armee“363. Darüber hinaus sollten jedoch auch Äußerungen verfolgt werden, die unterhalb dieser Schwelle blieben, sich aber gegen den Neuaufbau in der SBZ richteten oder in Kontinuität zum nationalsozialistischen Denken standen.

Im Januar 1946 sprach sich der stellvertretende Chef der SMA für den Erlaß einer Verordnung gegen "Gerüchtemacher" aus. Zwar seien Verhaftungen wegen der Verbreitung von Gerüchten gegen den Neuaufbau erfolgt, jedoch keine Verurteilungen. Die Justizabteilung entwarf daraufhin eine solche Verordnung, welche auch mit der SMAD-Rechtsabteilung abgesprochen wurde. Die DJV bat Hoeniger allerdings, bis zur Länderjustizkonferenz vom März 1946 abzuwarten. Dort forderte Hoeniger sogar die Anwendung des Befehls Nr. 160 gegen „Gerüchtemacher", was von Schiffer abgelehnt wurde. Der SMAD-Vertreter Lysiak wiederum stellte den thüringischen Verordnungsentwurf gegen Gerüchtemacher als vorbildlich dar und plädierte für dessen zonenweite Einführung 364 . Obwohl das weitere Vorgehen somit nicht eindeutig festgelegt war, erließ die Provinzialverwaltung am 6. Juni ihre eigene Verordnung zur Sicherung des Aufbauwillens der Bevölkerung und leitete bereits erste Verfahren ein. Die DJV kündigte jedoch auf der Länderkonferenz vom Juni an, daß die SMAD zusammen mit der DJV selbst eine Strafrechtsergänzung in diesem Bereich plane ${ }^{365}$. Am 12. Juli stoppte die SMAD-Rechtsabteilung deshalb das brandenburgische Vorgehen. Sie befürchtete negative öffentliche Reaktionen bei einem so sensiblen Thema wie dem politischen Strafrecht unmittelbar nach den Erfahrungen mit dem Nationalsozialismus; deshalb wurde die brandenburgische Verordnung als „undemokratisch“ abgelehnt. Hoeniger mußte daraufhin alle Verfahren abbrechen ${ }^{366}$. Als zwei Jahre später in Sachsen nach bayerischem Vorbild der Erlaß eines "Gesetzes gegen die Rassenhetze" diskutiert wurde, setzten sich Hoeniger und Löwenthal für ein "Demokratieschutzgesetz" ein. Auch in Brandenburg war es zu antisemitischen Vorfällen gekommen, so um das bereits erwähnte DP-Lager in Kleinmachnow. Dagegen sah Justizminister Stargardt keinen gesetzgeberischen Handlungsbedarf, vielmehr betonte er die „Gefahr des Abgleitens zu einem reinen Gesinnungsstraf-

363 BLHA, Rep. 212, Nr. 20, Bl. 1-5, 81-87, Bericht der Abt. Justiz an die SMA über die Rechtspflege in Brandenburg vom 20.7.-20. 8. 1946, 29. 8. 1946; dasselbe für 20. 8.-20. 9. 1946, 30. 9. 1946.

364 BA, DP-1 VA 120, Bl. 1, Freis. Justizabt. Brandenburg an DJV, 21. 2. 1946; Vermerk DJV, o.D.; SAPMO, DY 30/IV 2/13/433, Bl. 5, Konferenz der Länderjustizminister, 11. 3. 1946. Hoeniger berief sich hier auf eine Weisung von „Marschall“ Poknakoff. Vgl. die Ansprache des Kreiskommandanten von Luckenwalde am 27.11. 1945, in: Freundschaft - Werden und Wachsen, S. $124 \mathrm{f}$.

365 Lorenz, Deutsche Zentralverwaltung der Justiz, S. 148; BLHA, Rep. 212, Nr. 40, Bl. 273, Runderlaß der Abt. Justiz Nr. 193, 11. 6. 1946; BA, DP-1 VA 120, Bl. 6 RS, Vermerk DJV, 4. 6. 1946.

366 BA, DP-1 VA 120, Bl. 8f., 13, Vermerk DJV (von Stackelberg), 12. 7. 1946; Chef der DJV an Länderjustizabt., 23. 7. 1946; DJV an Lysiak, ca. 25. 7. 1946; Hoeniger an DJV, 20. 8. 1946. 
recht" und hielt die Bestimmungen der Kontrollrats-Direktive 38 gegen neonazistische Propaganda für ausreichend ${ }^{367}$. Strafrechtsergänzungen in diesem Sektor kamen letztendlich erst in den fünfziger Jahren zustande, dann allerdings mit einseitiger politischer Stoßrichtung.

\section{c. Reform und Revolution im Rechtssystem}

Der Handlungsspielraum der deutschen Politiker und Juristen war durch die Vorgaben der Alliierten und ganz besonders der sowjetischen Besatzungsmacht begrenzt. Dennoch war nur in Grundzügen klar, wie die Rechtsreform sich gestalten würde, ob eine Reform oder eine revolutionäre Änderung bevorstand.

An zwei der einschneidendsten Zäsuren im Rechtssystem, der Bodenreform und der sogenannten Sequestrierung von Unternehmen, war die Justiz nur indirekt beteiligt. Zwar bestand bei den Parteien in Berlin durchaus Einigkeit darüber, daß die Eigentumsverfassung in der Landwirtschaft reformiert werden müßte; über das Ausmaß der Enteignungen und vor allem bei der Frage der Entschädigung gingen die Meinungen zwischen KPD, SPD und CDU/LDP auseinander.

Wahrscheinlich auf sowjetische Initiative versuchte allen voran die KPD, eine entschädigungslose Enteignung auf schnellstem Wege durchzuführen. Sie verband damit gesellschaftspolitische Vorstellungen wie die Enteignung der "Junker" als angeblicher sozialer Basis des Nationalsozialismus, aber auch die Schaffung einer neuen Klientel unter den begünstigten Neubauern ${ }^{368}$. Die Federführung hatte das ZK der KPD. Am 5. September 1945 wies das ZK die Bezirksleitung Brandenburg, die sich zu diesem Zeitpunkt ebenfalls noch in Berlin befand, an: „Bodenreform in der Provinz Brandenburg. In Brandenburg das gleiche Gesetz annehmen zu lassen wie in der Provinz Sachsen. " ${ }^{369}$ Am Tag darauf erließ das Provinzial-Präsidium die entsprechende Verordnung 370 . Die „bürgerlichen“ Parteien hatten dem in Brandenburg nur wenig entgegenzusetzen, vor allem weil sie als Provinzialverbände noch gar nicht existierten.

Die Besatzungsmacht versuchte jeden Widerstand gegen die Bodenreform zu ersticken ${ }^{371}$. Doch ihre Vertreter gingen noch weiter: Nachdem sich der für Justiz zuständige Vizepräsident der Provinz, Remak, geweigert hatte, eine Verordnung zur Bodenreform zu unterzeichnen, die keine Entschädigung für die Enteignungen vorsah, geriet er unter massiven Druck und wurde schließlich am 17. Novem-

367 SAPMO, DY 30/IV 2/13/407, Notiz über Gespräch Hoeniger und Max Berger, 5. 11. 1947; BA, DP-1 VA 119, Bl. 48, MdJ Brandenburg (Stargardt) an DJV, 15. 12. 1948 (Zitat). Vgl. Timm, Hammer, Zirkel, Davidstern, S. 102 f., 109.

368 Laufer, UdSSR und die Einleitung der Bodenreform, S. $23 \mathrm{ff}$;; auch Bechler betont den sowjetischen Einfluß bei der Bodenreform: Papadopoulos-Killius, Es gibt zwei Deutschlands, S. 214.

369 Protokolle der erweiterten Sitzungen des Sekretariats, S. 13-18, Anweisung des ZK an die BL zur Durchführung der Bodenreform, (22./23. 8. 1945); Zitat ebenda, S. 78, Protokoll 5. 9. 1945.

370 Abgedruckt in: Reinert, Dokumente zur demokratischen Bodenreform, S. 71-75. Zur Bodenreform in Brandenburg: Bauerkämper, Bodenreform in der Provinz Mark Brandenburg, S. 272ff.; ders., Strukturumbruch ohne Mentalitätenwandel, S. 73-76; Reinert, Bodenreform 1945 in Brandenburg, S. 19-36; Spix, Bodenreform in Brandenburg, S. $37 \mathrm{ff}$.

${ }^{371}$ Scharow teilte Serow am 11. 11. 1945 mit, daß er eine CDU-Veranstaltung untersagt hatte, die sich kritisch mit der Bodenreform auseinandersetzen sollte, Semirjaga, Kak my uprawljali Germaniej, S. 62 . 
ber beurlaubt ${ }^{372}$. Möglicherweise wollte Remak keiner Regelung vorgreifen, bevor ein CDU-Provinzialverband existierte ${ }^{373}$. Sein Nachfolger Frank Schleusener unterzeichnete die Verordnung schließlich trotz seiner Vorbehalte ${ }^{374}$.

Die Bodenreform war a priori weitgehend dem Einfluß der Justiz entzogen. Vizepräsident Bechler leitete die Maßnahmen, die Kommandanturen beaufsichtigten sie, die Kreisbodenreformkommissionen und die Polizei führten sie durch. Am 12. September 1945 ordnete die Polizeiabteilung an, jeglichen Widerstand gegen die Enteignungen zu brechen. Auch das entsprechende Zirkular in der Justiz war von Bechler gezeichnet ${ }^{375}$.

Dennoch war eine gewisse Beteiligung der Justiz unumgänglich. In der Justizverwaltung saß seit einer Woche mit Walther Hoeniger ein Befürworter der Bodenreform. Hoeniger reklamierte später sogar die Ausarbeitung der Bodenreform-Verordnung für die Justizabteilung; in der Folgezeit erließ die Provinzialverwaltung 15 Durchführungsverordnungen. Damit schuf sie das genaueste Regelwerk aller Länder und Provinzen in dieser Frage ${ }^{376}$. Entscheidend war der Beitrag der Justiz bei der grundbuchlichen Durchführung der Neueintragung. Dafür mußte nahezu das komplette Justizpersonal vier Wochen lang eingesetzt werden, das zunächst die Neueintragung in Loseblätter vornahm ${ }^{377}$. Der schwerste Eingriff der Justiz war sicherlich die von der SMA angeordnete Vernichtung der alten Grundbücher. Proteste der DJV dagegen wurden abgeblockt, die CDU-Reichsleitung in Unkenntnis gelassen. Selbst Vizepräsident Bechler scheint bei dieser Aktion Bedenken bekommen zu haben, wie der vormalige Vizepräsident für Ernährung, Edwin Hoernle, an Ulbricht schrieb: „Bechler ist offenbar schwankend geworden in dieser Frage. Ich bitte ihm auf der Parteilinie zu sagen, was notwendig ist." 378 Die offizielle Anweisung der Abteilung Justiz zur Vernichtung der Grundbuchakten erfolgte erst im September 1946379. Durch diesen Akt, der eindeutig jede Rückkehr zum alten Rechtszustand verhindern sollte, wurde die Prüfung der Rechtmäßigkeit der einzelnen Enteignungen erheblich erschwert. So beschlagnahmten die Kommissionen mit der Polizei - vermutlich auf sowjetische Weisung - auch die Güter solcher Großgrundbesitzer, deren Familien sich im Widerstand

372 BLHA, PA Rep. 212, Nr. R/7560, Steinhoff an Remak, 17. 11. 1945.

373 So die Behauptung in BLHA, PA Rep. 212, Nr. R/7560, Steinhoff an Sievert, 5. 12. 1945, mit der Bitte um Weiterverwendung Remaks in Sachsen. Remak wechselte jedoch noch 1945 in den Westen Berlins und machte Karriere in der Justiz der Bundesrepublik, SBZ-Handbuch, S. 1003.

374 Steinhoff, In der Mark Brandenburg, S. 545, schreibt von „mehrfacher persönlicher Rücksprache“, um Schleusener zu überzeugen. Die Entschädigung wurde in der VO zur Bodenreform nicht explizit ausgeschlossen, erst in einer Ergänzungs-VO vom 14. 3. 1946, vgl. Bauerkämper, Neubauernprogramm, S. 185.

375 Errichtung des Arbeiter- und Bauernstaates, S. 140, 235; BLHA, Rep. 212, Nr. 40, Bl. 4, Runderlaß der Abt. Justiz Nr. 24 (gez. Bechler), 22. 10. 1945.

376 SAPMO, DY 30/IV 2/1.01/51, Bl. 16, Protokoll der Sitzung des Ausschusses für Rechtsfragen beim ZS der SED am 21./22. 6. 1947. Vgl. Löwenthal, Der Umfang des der Enteignung unterliegenden landwirtschaftlichen Besitzes.

377 BLHA, Rep. 212, Nr. 40, Bl. 77-81, Runderlaß der Abt. Justiz Nr. 76, 28. 1. 1946; Berichte Landes- und Provinzialverwaltungen, S. 294; BLHA, Rep. 212, Nr. 30, Referat Hoeniger auf der Potsdamer Richtertagung 21. 7. 1948.

${ }^{378}$ SAPMO, NY 4182/853, Bl. 168, Hoernle an Bechler, 9. 4. 1946 (Durchschlag mit Notiz nur für Ulbricht).

379 BLHA, Rep. 212, Nr. 40, Bl. 408, Runderlaß der Abt. Justiz Nr. 271, 16. 9. 1946. Vgl. Tatzkow/ Hennicke, Grundbuchdokumentation und Grundbuchmanipulation, S. VI. 
gegen Hitler befunden hatten ${ }^{380}$. Die gesellschaftliche Umwälzung hatte also Priorität vor der antifaschistischen Legitimation.

Insgesamt 2327 Grundbesitzer wurden enteignet und teilweise auch vertrieben 381 . Die Reichsleitung der CDU legte am 15. November 1945 einen Bericht über Rechtsverletzungen bei der Bodenreform vor, insbesondere die Deportationen enteigneter Familien nach Rügen. Der Bericht blieb jedoch ohne Echo, die DJV erklärte sich für unzuständig382. Eine erneute Ausweisungswelle folgte $a b$ August 1947. Auf Anweisung der SMA waren alle Besitzer von beschlagnahmten Gütern zu vertreiben, nur loyale Gutsverwalter durften bleiben. Diese Anordnung wurde von der Polizei teilweise exzessiv ausgelegt, was wieder zu Protesten der CDU führte ${ }^{383}$. Der Rechtskontrolle entzogen war auch der Abriß von Schlössern und Herrenhäusern, der besonders seit Ende 1947 vorangetrieben wurde, um Baumaterial für Gebäude der Neubauern zu erhalten ${ }^{384}$.

Ab Anfang 1947 hatte die Justizverwaltung der SMA monatlich den Stand der juristischen Arbeiten an der Bodenreform zu melden ${ }^{385}$. Erst 1949 war der grundbuchliche Teil der Bodenreform weitgehend abgeschlossen, nachdem die DJV und die SMA diese Arbeiten mehrfach terminiert hatten. Vielfach wurde vermutet, gerade das alte mittlere Justizpersonal würde diese Eintragungen absichtlich verzögern $^{386}$.

Neben der Bodenreform war die sogenannte „Enteignung der Nazi- und Kriegsverbrecher" in der gewerblichen Wirtschaft der zweite massive Eingriff in die Eigentumsordnung respektive das Rechtssystem ${ }^{387}$. Auch sie beruhte zum Teil auf einem Konsens innerhalb der Regierungen und der zugelassenen deutschen politischen Kräfte. Doch auch hier zeigte sich, daß trotz öffentlicher Bekundungen die Ziele von KPD/SED und CDU/LDP auseinanderliefen ${ }^{388}$.

Erste Beschlagnahmen hatte es schon durch die Demontage-Trupps ${ }^{389}$, die Antifa-Ausschüsse und Kommunalverwaltungen gegeben, ab August 1945 begann dies auf systematischer Grundlage. Formale Basis der Beschlagnahmen war der SMAD-Befehl Nr. 124 vom 30. Oktober 1945, der den Präsidenten der Provinzi-

380 Bauerkämper, Der verlorene Antifaschismus; Reinert, Bodenreform 1945, S. 34 f.; Wachs, Preußische Junker oder ausländische Juden, S. $138 \mathrm{ff}$.

381 Nach Rügen sollten alle aktiven Nazis deportiert werden: BLHA, Rep. 330, Nr. 11, Bl. 7, KPD Kreis Ostprignitz an Bezirksleitung, 11. 10. 1945; BLHA, Rep. 202A, Nr. 39, Bl. 9-15, Bericht des Informationsamtes Brandenburg, o.D.

382 Agethen, CDU, S. 50; Hermes, CDU und die Bodenreform, S. 47, 56.

383 BLHA, Rep. 201, Nr. 212, Bl. 99, Befehlsschreiben Nr. 6080 SMA, 23. 8. 1947; vgl. die ganze Akte BLHA, Rep. 203, Nr. 1525: Maßnahmen gegen enteignete Großgrundbesitzer; SAPMO, NY 4036/722, Bl. 220-224, Zborowski an Bechler, 10.8. 1948; Spix, Bodenreform in Brandenburg, S. $45 \mathrm{f}$.

384 Bauerkämper, Neubauernbauprogramm, S. 196.

385 BLHA, Rep. 212, Nr. 41, Bl. 28, Rundverfügung MdJ Brandenburg Nr. 13, 14. 1. 1947.

386 Zur Geschichte der Rechtspflege 1945-1949, S. 306; BLHA, Rep. 201, Nr. 212, Bl. 209, 253-254, Befehlsschreiben Nr. I/2249 SMA Brandenburg, 12.4. 1948; Befehlsschreiben Nr. 4063 SMA, 10. 7. 1948; BLHA, Rep. 202 A, Nr. 133, Bl. 20, Befehlsschreiben Nr. 111 SMA, 13. 1. 1949.

$387 \mathrm{Vgl}$. Hartisch, Enteignung, S. $19 \mathrm{ff}$.

388 Vgl. die Sitzung des Landesblocks am 5. 6. 1946, Protokolle des Landesblockausschusses, S. 49-51.

389 In Brandenburg bestanden große Trophäenlager mit den größten Eisen- und Stahlbeständen der ganzen SBZ, Karlsch, Allein bezahlt, S. 58. Die Beschlagnahme ganzer Unternehmen zur Übernahme für sowjetische $Z$ wecke war in Brandenburg vergleichsweise gering: Dort wurden nur neun oder zehn Sowjetische Aktiengesellschaften gegründet, darunter allerdings die große SAG Synthese in Ruhland, vgl. Buck, Formen, S. 1091 ff.; Freundschaft - Werden und Wachsen, S. 151. 
alverwaltung für die Registrierung und Verwaltung „herrenlosen“ Eigentums als zuständig erklärte. Darunter fielen nicht nur handlungsunfähige Aktiengesellschaften und verlassene Betriebe, sondern auch Unternehmen, die angeblich den wirtschaftlichen Neuaufbau sabotierten. Allerdings kam es schon frühzeitig zu divergierenden Interpretationen des Befehlstextes, unter anderem durch das Oberlandesgericht Potsdam ${ }^{390}$.

Zur Legitimierung der Enteignungen wurde in Sachsen am 30. Juni 1946 ein Volksentscheid organisiert, der zwar - mit großem propagandistischem Aufwand - eine Mehrheit für die Beschlagnahme erbrachte und auch als Rechtsgrundlage für Enteignungen in den anderen Ländern und Provinzen diente, obwohl er dort nicht wiederholt wurde. Nach den SED-Forderungen in der Potsdamer Beratenden Versammlung vom 2. August 1946 erließ die Provinzialregierung am 5. August eine Verordnung zur entschädigungslosen Übergabe von Betrieben und Unternehmungen in die Hand des Volkes. Waren bis dahin 573 Betriebe von der Beschlagnahme betroffen, so folgten nach Erlaß der Verordnung weitere $1371 \mathrm{Un}$ ternehmen ${ }^{391}$. Insgesamt gab es in der Provinz 3200 Industrie- und 35000 Gewerbebetriebe, davon wurden etwa 2000 beschlagnahmt; von diesen wiederum gelangten 1428 in Staatseigentum. Eigentlich galt dies für „Naziaktivisten, Rüstungsfabrikanten, Kriegsverbrecher und Finanziers der NSDAP“, die gleichzeitig selbst von den Verhaftungen des NKWD betroffen waren. Die Sequesterkommissionen zogen diese Definition jedoch relativ weit, so daß praktisch jeder gröBere Betrieb gemeint sein konnte ${ }^{392}$. Die Verunsicherung des gewerblichen Mittelstandes war erheblich, auch wenn man im Einzelfall nicht selbst von Enteignung heimgesucht wurde. Bei der grundsätzlichen Enteignung aller Bodenschätze spielte eine etwaige NS-Belastung keine Rolle mehr, hier ging es nur noch um pure Verstaatlichung. Das galt auch für die Einziehung von Lichtspieltheatern und Privatbahnen.

Die Landessequesterkommission koordinierte die Beschlagnahmen und kontrollierte ihre politische Opportunität. Die dort anwesenden CDU-Vertreter bemühten sich zwar um ein einigermaßen rechtsförmiges Verfahren ${ }^{393}$; in den Kreissequesterkommissionen, die die Beschlagnahmen faktisch leiteten und genehmigten, waren die „bürgerlichen" Parteivertreter jedoch hoffnungslos in der Minderzahl. Bei der nachträglichen Überprüfung wurden schließlich 553 Betriebe zur Rückgabe, 1521 zur Enteignung vorgeschlagen. Die Beschlüsse der Sequesterkommissionen waren nicht der Nachprüfung der Justiz unterworfen. De facto war die Justizabteilung bei den Betriebsenteignungen weitgehend ausgeschaltet. Nachdem die Deutsche Wirtschaftskommission durch Beschluß S 9/48 vom 31. März 1948 die beschlagnahmten Betriebe zu „Volkseigentum“ erklärte, mußten allerdings die Handelsregister und Grundbücher in aller Eile korrigiert wer$\operatorname{den}^{394}$.

390 Hartisch, Enteignung, S. 26.

391 Die antifaschistisch-demokratische Umwälzung, S. 205; Buck, Formen, S. 1103, gibt 1305 Betriebe nach Erlaß der VO an.

392 Buck, Formen, S. $1079 \mathrm{ff} ., 1103 \mathrm{ff}$.

393 ACDP, III-033-001, Protokoll Besprechung im CDU-Landesverband 29. 1. 1947.

${ }^{394}$ Lochen, Grundlagen der Enteignungen, S. 1032. 
An den Verstaatlichungen übte die CDU im Landtag Kritik, ebenso am Enteignungsverfahren, das vielerorts völlig willkürlich gehandhabt worden war. Nicht zu Unrecht stellte der stellvertretende CDU-Vorsitzende Schütze fest, daß der Befehl Nr. 124 eigentlich Strafrecht darstelle ${ }^{395}$. Auch die LDP drängte 1947 auf eine Überprüfung der Beschlagnahmungen durch die Gerichte. Angesichts der Machtverhältnisse wie auch des massiven Interesses von SMA und SED an den Enteignungen drangen sie damit jedoch nicht durch. Im April 1948 erklärte die SMAD die Sequestrierungen offiziell für abgeschlossen, sie waren damit allerdings bei weitem nicht beendet.

Während diese Umwälzungen von tiefgreifender Bedeutung waren und inhaltlich von der Justizverwaltung kaum beeinflußt werden konnten, entwickelte diese auf ihrem Terrain eigene Reformprojekte, die auf mittlere Sicht immerhin begrenzten Erfolg hatten. Gemeint sind besonders die Bestrebungen zur Reform des Strafvollzugs und des Jugendstrafrechts. Beides speiste sich aus Traditionen der Weimarer Republik ${ }^{396}$.

Beim Strafvollzug flossen Reformbestrebungen und die Zwangslagen der Nachkriegszeit ineinander. Viele der Gefängnisse in Brandenburg waren durch Kriegshandlungen zerstört worden, die Rote Armee hatte nahezu alle Häftlinge egal ob politisch oder unpolitisch - befreit. So mußten zunächst erst einmal die Gefängnisinsassen wieder ergriffen werden, die wegen schwerer nichtpolitischer Delikte eingesessen hatten ${ }^{397}$. Auf die Entleerung folgte dann die Überfüllung der Gefängnisse. Nicht nur Zerstörung, sondern vor allem die Beschlagnahme von Gefängnissen für das NKWD reduzierte den Raum für den deutschen Strafvollzug erheblich. Anfang 1947 waren 15 der 45 Gerichtsgefängnisse in sowjetischer Hand ${ }^{398}$. In den Gerichtsgefängnissen waren Haftstrafen bis zu drei Monaten abzusitzen, für die Dauer bis zu einem Jahr wurden die Häftlinge in die Haftlager Plauerhof oder Niemegk eingewiesen ${ }^{399}$. Die Justizvollzugsanstalten Luckau und Cottbus konnten erst allmählich wieder voll genutzt werden. So mußten auch Strafen bis zu sechs Monaten in den Gerichtsgefängnissen vollstreckt werden ${ }^{400}$.

Innerhalb der Gefängnisse herrschte ein eklatanter Materialmangel. Sie waren im Sommer 1945 fast vollständig geplündert worden. Neben der Einrichtung fehlte es auch an ausreichenden Lebensmittellieferungen. Selbst das Vollzugspersonal hatte sich bis Herbst 1947 von der Lebensmittelkarte IV oder III zu ernähren. Im Winter 1946/47 mußten einige Gerichtsgefängnisse schlichtweg geschlos-

395 Stenographische Berichte, 5. Sitzung, 31. 1. 1947 (Schleusener); Stenographische Berichte, 16. Sitzung, 10.9. 1947, S. 22 f. (Schütze).

396 Hoenigers „Programm“ läßt sich am besten nachlesen in seinem Aufsatz „Über das richtige Strafmaß".

397 BLHA, Rep. 212, Nr. 596, Bl. 1j-1k, Bericht an Oberleutnant Tschaikowski, 12. 8. 1945.

398 BLHA, Rep. 212, Nr. 1195, Bl. 31-34, Tätigkeitsbericht Abt. Strafvollzug MdJ an SMA (Gofschtein), 3. 1. 1947.

399 BLHA, Rep. 212, Nr. 41, Bl. 8, Rundverfügung MdJ Brandenburg Nr. 3, 23. 12. 1946, mit Strafvollstreckungsplan.

400 Rechenschaftsbericht Steinhoff, 21.9. 1945, Berichte Landes- und Provinzialverwaltungen, S. 357-378. In der größtenteils zerstörten JVA Cottbus gab es Anfang 1947 nach dem Wiederaufbau 213 Plätze (statt früher 410), BLHA, Rep. 212, Nr. 1195, Bl. 31-34, 183, Tätigkeitsbericht Abt. Strafvollzug MdJ an SMA (Gofschtein), 3. 1. 1947; Vermerk aus dem MdJ, ca. Februar 1948; BA, DP-1 VA 860, Bl. 2-20, Reisebericht der Abt. IV DJV zu den Anstalten Luckau und Cottbus am 5./6. 4. 1948 (Gentz, Casser). 
sen werden, weil es an Heizmaterial fehlte ${ }^{401}$. Eine erhebliche Entlastung der Gefängnisse brachten erst die Amnestien. Brandenburg erließ 1946 eine besonders weitgehende Amnestie-Verordnung, nicht zuletzt wegen der katastrophalen Lage beim Haftraum. Etwa die Hälfte aller Gefängnisinsassen kam in den Genuß dieser Entlassungsaktion ${ }^{402}$. Anfang 1947 folgte die spezielle „Bauernamnestie“, im Jahr darauf die von der SMAD angeordnete Amnestie anläßlich des 100. Jahrestages der Revolution von 1848. Von ihr profitieren alle bis zu einem Jahr Verurteilten bzw. alle, die eine solche Strafe zu erwarten hatten. Sogenannte Schieber und Spekulanten waren jedoch ausgenommen. Von März bis Ende April 1948 sank die Zahl der Häftlinge von 2784 auf 2188 Personen. Diese Entlassungen brachten dem Strafvollzug zwar eine echte Entlastung, Juristen und Polizisten mußten jedoch ein aufwendiges Prüfungsverfahren in den sogenannten Amnestiekommissionen veranstalten ${ }^{403}$. Zur Gründung der DDR folgte dann eine weitere Amnestie.

Die Reformbestrebungen im Strafvollzug nahmen ihren Ausgang in der DJV, sie wurden personifiziert in Werner Gentz, dem Leiter der zuständigen Abteilung. Sein Grundgedanke war der erzieherische anstelle des repressiven Strafvollzugs. Neben der Einführung des Stufenstrafvollzugs, d.h. einer Trennung der verschiedenen Strafarten und sukzessiver Erleichterung der Haftbedingungen, ging es ihm vor allem um die Verbesserung der Lebensbedingungen der Häftlinge, den Ersatz von kurzen Gefängnisstrafen durch Arbeit und um die Reform des Jugendstrafvollzugs. Gentz pflegte engen Kontakt zu Hoeniger in Brandenburg ${ }^{404}$.

Besonders für den Strafvollzug in Brandenburg und Sachsen-Anhalt war der sogenannte Bewährungseinsatz charakteristisch. Erstverurteilte mit kurzen $\mathrm{Ge}$ fängnisstrafen konnten ihre Strafe in einem Betrieb bei Lohnkürzung „abarbeiten“, ohne in Haft zu gehen. Verhielten sie sich dabei anstandslos, wurde die Dauer der Strafe reduziert. Diese Form des Strafvollzugs wurde besonders von Gentz und Hoeniger favorisiert. Die brandenburgische Verordnung über den Bewährungseinsatz war Hoenigers Werk, das eine Bewährungsfrist von mindestens zwei und höchstens sechs Monaten vorsah; die DJV hatte hingegen einheitlich drei Monate vorgeschlagen. Allerdings beruhte die Bewährungsarbeit sowohl auf dem Elan zur Vollzugsreform und „Arbeitserziehung“ als auch auf dem Mangel an Haftraum:

"Genosse Hoeniger erklärte, daß Bewährungseinsatz kein Strafvollzug ist. Der Bewährungseinsatz ist aus der Not heraus geboren, da keine Gefängnisse und Zuchthäuser zur Verfügung stehen, um die Strafen zu vollziehen. Der Arbeitseinsatz besteht aus schwerer körperlicher Arbeit. Die arbeiten dort wie die freien $\mathrm{Ar}$ beiter mit gleichem Lohn und der entsprechenden Lebensmittelkarte. “"405

401 BLHA, Rep. 212, Nr. 1195, Bl. 46, Schreiben MdJ, 19. 4. 1947; BLHA, Rep. 212, Nr. 41, Bl. 385, Rundverfügung MdJ Brandenburg Nr. 241, 18. 9. 1947; BLHA, Rep. 212, Nr. 6, Bl. 147-153, Tätigkeitsbericht MdJ für 19. 1.-18. 2. 1947, 18. 2. 1947.

402 SAPMO, DY 30/IV 2/13/433, Konferenz der Länderjustizminister, 11. 3. 1946; Tätigkeitsbericht der Abteilung Justiz der Provinzialverwaltung Mark Brandenburg für die Zeit von Mitte 1945 bis 5. Juli 1946, (Juli 1946), Berichte der Landes- und Provinzialverwaltungen, S. 295.

403 BLHA, Rep. 212, Nr. 42, Bl. 246-255, Rundverfügung MdJ Nr. 131, 5. 4.1948 (mit Amnestie-Befehl Nr. 43); BLHA, Rep. 212, Nr. 6, Bl. 77-79, Tätigkeitsbericht MdJ Brandenburg für 1.-31. 5. 1948, 3.[6].1948.

404 Dazu ausführlich: Wentker, Errichtung und Transformation, S. $224 \mathrm{ff}$.

${ }^{405}$ BLHA, Rep. 332, Nr. 829, Bl. 97, Protokoll der Sitzung des Rechtspolit. Ausschusses der SED 
Grundsätzlich wurde der Bewährungseinsatz von den sowjetischen Behörden mit Wohlwollen gesehen, da er stark der sogenannten Besserungsarbeit in der Sowjetunion ähnelte, einer dort sehr verbreiteten Strafform ${ }^{406}$. Auch waren die Besatzungsoffiziere an einer weitgehenden Ausschöpfung jeder Arbeitskraft interessiert; sie vermißten jedoch den Strafcharakter der Maßnahme. Ähnlich dachte man in der SED-Spitze ${ }^{407}$. Offene Kritik an der Bewährungsarbeit kam hingegen aus der Polizei, die statt dessen Zwangsarbeitslager unter eigener Regie in Erwägung zog ${ }^{408}$. Umstritten war, ob der Einsatz in den Betrieben auch bei NS-Tätern oder "Wirtschaftsverbrechern" mit geringen Urteilen in Frage kam. Zugebilligt wurde er bei Nebentätern in Wirtschaftsverfahren, die aber schwere Tätigkeiten wie Schieneneinbau oder Aufräumungsarbeiten verrichten sollten ${ }^{409}$.

Die Realisierung der Bewährungsarbeit ab Oktober 1946 kam - trotz der dramatischen Engpässe im Strafvollzug - eher schleppend voran. Erst im Frühjahr 1948 wurde ein nennenswerter Teil der Verurteilten eingesetzt, von denen die meisten in den Genuß der Amnestie kamen ${ }^{410}$. Etwa 4000 Einsatzstellen standen Mitte 1948 zur Verfügung, bei Jahresende waren es bereits 37 Arbeitsplätze mit 5564 Verurteilten ${ }^{411}$. Im großen und ganzen sah man den Bewährungseinsatz als Erfolg und Vorbild für die anderen Länder an, auch außerhalb der SBZ. Die Quote der Geflüchteten lag bei etwa 4-6\%, die Arbeitskraft ging nicht verloren, und die Betroffenen blieben in die Gesellschaft integriert ${ }^{412}$. Ab 1950 verlor der Bewährungseinsatz aber an Bedeutung. Haftraum war wieder ausreichend vorhanden, die Alltagskriminalität der Nachkriegszeit ging zurück. Die meisten Betriebe lehnten nun die Beschäftigung von Verurteilten ab; vielmehr sollten an ihrer Stelle vor allem Vertriebene eingestellt werden ${ }^{413}$. Noch 1951 plante die Hauptabteilung Justiz eine erneute Expansion der Einsatzstellen. $\mathrm{Zu}$ diesem Zeitpunkt mußte sie sich die Zuständigkeit für den Strafvollzug jedoch bereits mit der

Brandenburg vom 22.8. 1947; im Regelfalle wurde der Lohn aber gekürzt. Ähnlich schon: SAPMO, DY 30/IV 2/13/441, Protokoll der ersten Juristenkonferenz der SED am 1./2.3. 1947, S. 147.

$406 \mathrm{Vgl}$. Schittenhelm, Strafe und Sanktionssystem, S. $184 \mathrm{f}$.

407 BA, DP-1 VA 13, Bl. 12-17, Bericht über die Juristentagung in Potsdam am 22. 11. 1947 (Jakupow); vgl. BLHA, Rep. 332, Nr. 829, Bl. 111-113, Rundschreiben ZS der SED an LV, 21. 1. 1947.

408 BA, DO-1/7/282, Bl. 19-20, Denkschrift Ref. S 6 DVdI „über die Entlastung der Justiz“, 22. 7. 1947.

${ }^{409}$ BLHA, Rep. 201, Nr. 312, Bl. 17, MdJ (Stargardt) an Landtag Brandenburg, 5. 5. 1948; BLHA, Rep. 202A, Nr. 185, Bl. 12, MdJ an Ministerpräsident, 27. 12. 1947. Vgl. Märkische Volksstimme, 14. 12.1947.

410 BLHA, Rep. 212, Nr. 1196, Bl. 121-123, Bericht MdJ Brandenburg über das Strafgefangenenwesen, 12. 11. 1949; BLHA, Rep. 212, Nr. 41, Bl. 464, Rundverfügung MdJ Brandenburg Nr. 297, 4. 11. 1947; BLHA, Rep. 201, Nr. 312, Bl. 14-15, MdJ (Stargardt) an Landtag Brandenburg, 24. 5. 1948.

411 BLHA, Rep. 212, Nr. 31, Bl. 105, Protokoll der Justizkonferenz am 6./7. 8. 1948; BLHA, Rep. 212, Nr. 22, Bl. 11-35, Tätigkeitsbericht MdJ an SMA für das Jahr 1948, 8. 1. 1949.

412 Vgl. SAPMO, NY 4182/1120, Bl. 197, Fragmente Protokoll Erste Juristenkonferenz der SED, $1 . /$ 2. 3. 1947; BLHA, Rep. 332, Nr. 829, Bl. 95-109, Protokoll der Sitzung des Rechtspolit. Ausschusses der SED Brandenburg vom 22. 8.1947.

${ }^{413}$ BLHA, Rep. 212, Nr. 1196, Bl. 202, Bericht MdJ Brandenburg über Strafvollzug, 10. 8. 1950; BLHA, Rep. 212, Nr. 1463, Bericht Abt. Rechtsprechung/Revision MdJ Brandenburg an MdJ der DDR über 1. Halbjahr 1950; BLHA, Rep. 212, Nr. 465, Bl. 99-101, Protokoll Oberreferentenbesprechung MdJ am 18. 2. 1950. 
Polizei teilen; die Aufsicht über die Einsatzstellen ging an die Arbeitsämter über ${ }^{414}$.

Neben dem Strafvollzug galt der Reformelan vor allem der Rechtsprechung und dem Strafvollzug gegen Jugendliche. Die Heranwachsenden waren in der unmittelbaren Nachkriegszeit in einer besonders schwierigen Lage. Vom Nationalsozialismus enttäuscht, vielfach ohne Eltern und in materieller Not, hatten sie sich zusätzlich vor den „Werwolf“-Aktionen des NKWD zu fürchten. Auch sonst waren Erleichterungen für Jugendliche bei den sowjetischen Militärbehörden nur schwer durchsetzbar. Der Vorschlag der SED, nach dem 1. Januar 1919 Geborene von der Entnazifizierung zu befreien, wurde von der SMA teilweise unterlaufen: Sie forderte die Entlassung aller BDM- und HJ-Angehöriger aus der Verwaltung 415 .

Etwa $15 \%$ der Nachkriegskriminalität in Brandenburg ging auf das Konto Unter-Achtzehnjähriger; dies war im Vergleich zu anderen Ländern eine eher geringe Quote ${ }^{416}$. Mitte 1946 forderte die SMAD erstmals einen gesonderten Bericht über die Jugendkriminalitä $t^{417}$. Die brandenburgische Justizverwaltung versuchte aber, nicht nur diesem Problem Herr zu werden, sondern von vornherein einen neuen, menschlicheren Umgang mit jugendlichen Straftätern zu ermöglichen. Wie der „Bewährungseinsatz“ gingen auch die Bestrebungen zur Reform des Jugendstrafrechts zum großen Teil von Gentz und Hoeniger aus. Zwar hielt man in Brandenburg aus Gründen der Praktikabilität die Bestimmungen des Reichsjugendgerichtsgesetzes von 1943 - mit Ausnahme NS-spezifischer Abschnitte - weiter für anwendbar ${ }^{418}$. Vorgesehen war jedoch die Einrichtung von Bezirksjugendgerichten, die eng mit den Jugendämtern kooperieren sollten. Zeitweise wurde sogar die Übergabe der ganzen einschlägigen Rechtsprechung an die Jugendbehörden ins Auge gefaß $\mathrm{t}^{419}$. Das Landesjugendamt in Brandenburg schlug vor, auf Gefängnisstrafen völlig zu verzichten ${ }^{20}$. Beim Strafvollzug, der ebenfalls vom Landesjugendamt überwacht wurde, waren Jugendliche unbedingt von den Erwachsenen zu trennen; sie sollten auch in Haft die Gelegenheit zur Berufsausbildung erhalten. Jugendliche Straffällige waren zunächst in Brandenburg-Görden zur Beobachtung einzuweisen: „In Brandenburg werden die Jugendverbrecher auf die vier Fürsorgeanstalten je nach ihrer Veranlagung verteilt." Dafür gab es in Treuenbrietzen einen halboffenen Strafvollzug für Jugendliche, das Straflager Brandenburg-Plauerhof und den Jugendwerkhof in Strausberg-Müncheberg ${ }^{421}$. Auch im

414 BLHA, Rep. 212, Nr. 1321, HA Justiz an Ministerpräsident, 11. 4. 1951; BLHA, Rep. 212, Nr. 610, Bl. 17-23, Protokoll der Dienstbesprechung des GStA mit den OStA am 19.7. 1951.

415 BLHA, Rep. 332, Nr. 23, Bl. 31, Protokoll der Sekretariatssitzung SED-LV, 17. 2. 1947.

416 Rechenschaftsbericht Steinhoff, 21.9. 1945, Berichte Landes- und Provinzialverwaltungen, S. 357-378; BLHA, Rep. 202A, Nr. 39, BI. 9-15, Bericht Informationsamt Brandenburg, o.D.

417 BLHA, Rep. 212, Nr. 40, Bl. 289, Runderlaß der Abt. Justiz Nr. 205, 19.6. 1946.

418 BLHA, Rep. 212, Nr. 1007, Bl. 9, DJV an MdJ Brandenburg, 20. 1. 1948; BA, DP-1 VA 811, Bl. 69, Vermerk Hartwig für Gentz, 9. 4. 1948.

${ }^{419}$ BLHA, Rep. 212, Nr. 1010, Bl. 10a, Rundverfügung MdJ Brandenburg Nr. 167, 30.4. 1948; BLHA, Rep. 212, Nr. 30, Referat Hoeniger auf der Potsdamer Richtertagung 21. 7. 1948.

420 Vgl. BLHA, Rep. 212, Nr. 1007, Bl. 46, Rundschreiben DJV, 30. 10. 1948.

421 SAPMO, DY 30/IV 2/13/441, Protokoll der ersten Juristenkonferenz der SED am 1./2. 3. 1947

(Zitat Gentz); BLHA, Rep. 212, Nr. 1358, Bl. 6, DJV an MdJ Brandenburg, 1. 2. 1947; BLHA,

Rep. 212, Nr. 40, Bl. 359, Runderlaß der Abt. Justiz Nr. 243, 12. 8. 1946; BLHA, Rep. 212, Nr. 6,

Bl. 1-3, Tätigkeitsbericht für die Zeit 1.-30.6. 1949, 1.7. 1949. Daneben noch Jugendwerkhof 
Westen wurde diese Form des Strafvollzugs gelobt ${ }^{422}$. Allerdings blieb die Realität des Jugendstrafvollzugs weit hinter den Reformvorstellungen zurück ${ }^{423}$. Seit dem Jahre 1950 wurden die Reformen zurückgenommen. Bei den Prozessen wegen sogenannten Buntmetall-Schmuggels nach Westberlin wurden Jugendliche zu drakonischen Zuchthausstrafen verurteilt. Verfahren wegen angeblicher neonazistischer Betätigung führte man in Brandenburg zuerst nicht nach dem Reichsjugendgerichtsgesetz, sondern vor den politischen $201 \mathrm{er}$-Kammern; auch angebliche Sabotagehandlungen von Jugendlichen kamen vor normale Gerichte ${ }^{424}$. Zusehends wurden Prozesse gegen Jugendliche auch zu politischen Schauveranstaltungen genutzt, was Gentz im Justizministerium kritisierte: „Herr Dr. Gentz weist auf die im Lande Brandenburg durchgeführten gesetzwidrigen Verhandlungen gegen Jugendliche in erweiterter Öffentlichkeit hin “425. Erst das Jugendgerichtsgesetz der DDR von 1952 brachte eine flächendeckende Neuregelung in diesem Bereich, die einige Verbesserungen, aber auch Verschlechterungen enthielt.

Ein weiteres Projekt, das teilweise in den sozialistischen Traditionen der Weimarer Republik einerseits und in der Notsituation nach dem Krieg andererseits wurzelte, war die Reform des $\$ 218$ StGB. Schwangerschaftsabbrüche gehörten in der sozialen Not der Frauen und nach den massenhaften Vergewaltigungen zum Alltag ${ }^{426}$. Anfang 1947 untersagte die Justizverwaltung zunächst die Anwendung der verschärften NS-Fassung des Abtreibungsverbots; faktisch wurde die Strafverfolgung weitgehend suspendiert ${ }^{427}$. Im Spätsommer des Jahres forcierte die SED die Behandlung dieses Problems. Hoeniger plädierte für die völlige Streichung des Paragraphen ${ }^{428}$. Zunächst war ein Gesetz über vorläufige Aussetzung von Strafverfahren auf Grund des $\$ 218$ in Planung. Nach ausgiebigen Beratungen stand das Projekt am 4. November 1947 zur Entscheidung im Landtag an. Insbesondere Otto Nuschke begründete die Ablehnung der CDU und versuchte, ein individuelles Landesgesetz zu verhindern. Der SED-Entwurf wurde anscheinend aber schließlich von SED und LDP angenommen ${ }^{429}$, das Gesetz über die Unter-

Stolpe, Erziehungsheim Templin, Werkjugendheim Premnitz, ab 1950 Jugendwerkhöfe „Makarenko" in Waldsieversdorf und Strausberg.

${ }_{422}$ Vgl. Die Welt, 30. 4. 1948. Vgl. auch die Probleme der britischen Reformbemühungen: Smith, Juvenile Delinquency in the British Zone, S. $44 \mathrm{ff}$.

${ }_{423}$ SAPMO, DY 30/IV 2/1/38, Bl. 123, 6. (20.) PV-Tagung u.a. zu Justiz, 14./15. 1.1948 (Fechner).

${ }^{424}$ BLHA, Rep. 212, Nr. 47, Urteil OLG Potsdam 3 ERKs 50/50, 16. 1. 1950; BLHA, Rep. 240 Potsdam, Nr. 19, Protokoll Richterbesprechung AuLG Potsdam am 14.6. 1952.

${ }_{425}$ BA, DP-1 VA 110, Bl. 3, Protokoll der Länderreferentenbesprechung vom 5. 5. 1951 über JVA; vgl. BLHA, Rep. 212, Nr. 610, Bl. 1-8, Protokoll der Dienstbesprechung des GStA mit den OStA am 10.5. 1951.

${ }_{426}$ Vgl. ACDP, III-033-096, Bericht über Tagung der brandenburgischen Kreiskommissionen für Schwangerschaftsunterbrechung am 11. 8. 1948, vermerkt für 1946 nur 350 Anträge auf Abtreibung (1947: 251, 1948: 263). Die meisten stammten von „Umsiedlerfrauen“ und wurden genehmigt.

${ }_{427}$ BLHA, Rep. 212, Nr. 41, Bl. 32, Runderlaß MdJ Brandenburg Nr. 31, 31. 1. 1947; BLHA, Rep. 212, Nr. 878, Bl. 1, Vermerk MdJ, 3. 9. 1948. Die Akte trägt den Titel: „Angriffe auf die Lebenskraft des Deutschen Volkes“. Poutrus, Von den Massenvergewaltigungen zum Mutterschutzgesetz, S. 197, datiert einen solchen Erlaß bereits auf 1946.

428 SAPMO, DY 30/IV 2/1.01/37, Bl. 110, Protokoll der Ersten Juristenkonferenz der SED am 1./ 2. 3. 1947; BLHA, Rep. 332, Nr. 13, B1. 12-25, Bericht über die Sekretariatssitzungen SED-LV 1947, o.D. (hier 11. 8. 1947). In der SED-Spitze wurde die Straffreiheit der Abbrüche eher als zeitlich befristet angesetzt.

${ }^{429}$ BLHA, Rep. 201, Nr. 163, Bl. 82-90, Übersicht der vom Rechts- und Verfassungsausschuß bis De- 
brechung (!) der Schwangerschaft am 6. November ausgefertigt. Die Genehmigungspraxis handhabte man dann in Brandenburg vergleichsweise großzügig; die Sozialbehörden bewilligten $83 \%$ aller Anträge. Allerdings blieb die überwiegende Mehrzahl der Abbrüche illegal, wenn auch die Strafverfolgung anscheinend sehr milde ausfiel ${ }^{430}$. Mit dem Mutterschutzgesetz vom September 1950 beschränkte sich die Straflosigkeit dann auf die sogenannte medizinische und die eugenische Indikation ${ }^{431}$.

Während die „revolutionären“ Veränderungen des Rechtssystems - die Enteignungen - für lange Zeit Bestand hatten, liefen die Bestrebungen zur Reform 1948/49 allmählich aus. Unter "Reform" firmierten dann zusehends nur noch die Änderungen, die die SED-Spitze zur Durchsetzung ihrer Prioritäten anordnete. Lediglich im Familienrecht blieb die Reformlinie erhalten und wurde ausgebaut.

\section{d. Verfabrensänderungen}

In die Zeit der Rechtsreformen fielen auch einige Maßnahmen, die erhebliche Einschnitte in rechtliche Ansprüche der Bürger und ins Verfahrensrecht bringen sollten. Diese Anordnungen trugen zum Teil der desolaten Lage der Justiz Rechnung, zum Teil wiesen sie aber auch auf eine allgemeine Umstrukturierung hin. Mit der sogenannten Aussetzungs-Verordnung vom 20. November 1945 konnten Zivilverfahren auf unbestimmte Dauer vertagt werden. Gleichzeitig waren Richter befugt, einstweilig verfügte Maßnahmen im nachhinein zu billigen ${ }^{432}$. Damit sollten die Gerichte einstweilen von einer Flut von Zivilprozessen, deren Verfahrensinhalte nicht so drängend erschienen, verschont bleiben. Es führte allerdings dazu, daß einige Verfahren für mehrere Jahre auf Eis lagen. Kommunale Körperschaften nutzten die Verordnung, um ihren fälligen Schuldendienst zu verzögern ${ }^{433}$.

Zentrale Initiativen gab es für eine andere verfahrensrechtliche Änderung: die Einführung der Kassation. Auch nach dem Ablauf der Fristen für die Revision sollte die Möglichkeit geschaffen werden, eventuelle Fehlurteile, die durch die Ausnahmesituation nach dem Krieg bedingt waren, a posteriori zu korrigieren. Einerseits entsprach dieses Verfahren der äußerst problematischen Nichtigkeitsbeschwerde des Staatsanwalts, die 1941 eingeführt worden war. Auf der anderen Seite gab es auch im französischen Recht eine Kassation, die allerdings nicht die Rechtskraft bereits ergangener Urteile aufhob, sondern erst auf die weitere Recht-

zember 1947 behandelten Vorgänge (hier 14. 8. 1947); Stenographische Berichte, 17. Sitzung, 11. 9. 1947, S. 7 ff.; BLHA, Rep. 201, Nr. 162, Bl. 146-148, Sitzungsprotokoll des Rechtsausschusses am 17. 10. 1947; Stenographische Berichte, 22. Sitzung, 4.11. 1947, S. 5 ff. Erstaunlicherweise vermerkt Lemmer, Manches war doch anders, S. 277 f., der Gesetzentwurf sei mit den Stimmen von CDU und LDP abgelehnt worden. Vgl. dagegen zum Scheitern eines solchen Gesetzes in SachsenAnhalt: Robra, Ein letzter Erfolg, S. 563.

430 Poutrus, Von den Massenvergewaltigungen zum Mutterschutzgesetz, S. $180 \mathrm{ff}$.

431 Vgl. Harsch, Society, the State, and Abortion, S. $57 \mathrm{f}$.

432 VO über die Aussetzung gerichtlicher Verfahren, 20. 11. 1945.

433 Deshalb drängte die CDU später auf die teilweise Aufhebung der VO, ACDP, III-033-002, Antrag brandenburgische CDU-Fraktion, 15. 9. 1949. 
sprechung wirkte ${ }^{434}$. Vor allem aber waren die neuen Kassationsregelungen auf sowjetisches Vorbild und sowjetische Anordnungen zurückzuführen ${ }^{435}$.

Dem Erlaß einer entsprechenden Verordnung in Brandenburg ging eine längere Diskussion in Berlin und in Potsdam voraus. Die SED-Juristen waren durch die Bank vehemente Befürworter der Kassations-Regelung ${ }^{436}$. Die SMAD untersagte hier jegliche Sonderregelungen der einzelnen Länder und Provinzen ${ }^{437}$. Zeitweise drohte sie sogar damit, die Kassation via SMAD-Befehl einzuführen. Schließlich sandte jedoch das Zentralsekretariat der SED einen entsprechenden Gesetzentwurf an die Landesvorstände der Partei ${ }^{438}$. Selbst unter den SED-Juristen war man sich über die Organisation des Verfahrens uneins. Anfangs waren Kassationshöfe bei den Oberlandesgerichten in Planung ${ }^{439}$.

Nicht nur im Rechtsausschuß, auch im brandenburgischen Parlament zeichneten sich unterschiedliche Meinungen über das Gesetz ab. Die Fronten verliefen diesmal sogar quer durch die CDU-Fraktion. Während der Abgeordnete Webersinn und Stargardt das Gesetz - besonders mit Blick auf die Rechtseinheit der SBZ - verteidigten, blieb Schütze bei seinen Bedenken: Im Grunde sei durch die Kassation die Rechtskraft jedes Urteils um ein Jahr verschoben; das könne Rechtsunsicherheit schaffen. Nichtsdestotrotz wurde das Gesetz schließlich am 11. September 1947 erlassen ${ }^{40}$.

Die Kassation sollte sich bis 1949 kaum als wichtige Neuerung durchsetzen. Schon in der Anfangszeit ging allerdings die Mehrheit der Anträge nicht zugunsten der Angeklagten aus, d.h. sie führten zu Strafverschärfungen ${ }^{441}$. Das brandenburgische Kassationsgesetz wurde durch das Gesetz über das Oberste Gericht Ende 1949 aufgehoben; alle Kassationsanträge gingen nun an die Oberste Staatsanwaltschaft der DDR. Allerdings sollten sie vorher noch vom Oberlandesgericht und vom Generalstaatsanwalt begutachtet werden ${ }^{42}$. Die Neuerung, die zur Vermeidung von Ungerechtigkeiten durch die Justiz der Nachkriegssituation eingeführt worden war, konnte unter der entfalteten SED-Diktatur zu einer politischen Waffe im Strafrecht werden ${ }^{43}$.

${ }^{434}$ Esch, Kassation in Strafsachen, S. $10 \mathrm{ff} . ;$ Reich, Kassation in Zivilsachen, S. 2.

435 Vgl. Wentker, Errichtung und Transformation, S. 203.

436 SAPMO, DY 30/IV 2/13/441, Bl. 112, Protokoll der ersten Juristenkonferenz der SED, 1./2. 3. 1947 (Hoeniger).

437 BA, DP-1 VA 22, Bl. 71, Konferenz der Länderjustizminister am 1./2. 11. 1946 (Jakupow).

438 SAPMO, NY 4182/1120, Bl. 13-14, Entwurf des Kassationsgesetzes, 3. 3. 1947.

439 BA, DP-1 VA 22, Bl. 67, Konferenz der Länderjustizminister am 1./2.11. 1946 (Weiß).

440 Stenographische Berichte Brandenburg, 16. Sitzung, 10. 9. 1947, S. 21 ff.; Brandenburgisches Gesetz über die Nichtigkeitsbeschwerde gegen Strafurteile, 11.9. 1947, GVOBl. 1947, S. 23. Allein das brandenburgische Gesetz enthielt den - politisch vorbelasteten - Begriff „Nichtigkeitsbeschwerde".

441 BA, DP-1 VA 279, Bl. 1-18, Bericht Mdj der DDR über die Kassationspraxis, 19.12. 1949 (in Brandenburg 103 Anträge, davon 81 verhandelt, davon 13 erfolglos; 20\% 201er- und 50\% Wirtschaftsstrafverfahren).

442 Esch, Kassation in Strafsachen, S. 49 ff.; BLHA, Rep. 217, Nr. 14, Bl. 92-96, Bericht OLG-Präsident für 1. Halbjahr 1950, 26.6. 1950.

${ }_{443}$ Vgl. BLHA, Rep. 241 Cottbus, Nr. 1, Bl. 82-95, Protokoll Arbeitsbesprechung der GStA der Länder in Berlin am 16. 11. 1950 (Kassation, wenn Gericht keine Sühnemaßnahmen nach KRD 38, III A III verhängt hat; Kassation mit dem Ergebnis drastischer Strafverschärfung gegen Angeklagten vor LG Potsdam, der für SPD-Ostbüro gearbeitet hatte). 
Quantitativ viel größere Bedeutung hatte die Entlastung der Gerichte von bestimmten Bereichen der Rechtsordnung. Da waren zunächst die arbeitsgerichtlichen Verfahren, die für die SED mit ihrer Fixierung auf die Arbeiterschaft natürlich einen hohen Stellenwert besaßen. Der FDGB hatte frühzeitig eine „revolutionäre Arbeitsgerichtsbarkeit" gefordert, also losgelöst vom bisherigen Justizsystem und dessen Personal. Damit sollte eine arbeitnehmerfeindliche Rechtsprechung a priori ausgeschlossen werden. Noch 1945, also vor Erlaß des einschlägigen SMAD-Befehls Nr. 23 vom 25. Januar 1946, wurden in Brandenburg $26 \mathrm{Ar}$ beitsgerichte und ein Appellationsgericht in Potsdam eingerichtet. Sie gehörten zur Sozialverwaltung. In den einzelnen Arbeitsgerichten waren keine Juristen angestellt ${ }^{444}$. Lediglich der Vorsitzende des Landesarbeitsgerichts mußte ein Volljurist sein. Für diesen Posten bestimmte die SED Walter Klusmann, einen älteren Juristen aus ihren Reihen. Wie viele Juristen dieser Generation wurde er den immer massiveren politischen Ansprüchen seiner Partei jedoch nicht gerecht und kündigte auf eigenen Wunsch im November 1948. Allerdings stieg er danach in die Justizverwaltung ein ${ }^{45}$.

Im großen und ganzen entwickelte sich die Rechtsprechung der Arbeitsgerichte nach den Vorstellungen der SED. Die Arbeitnehmerfreundlichkeit führte in Einzelfällen auch dazu, daß sich entlassene Justizangestellte wieder in ihre Arbeitsstellen einklagen konnten ${ }^{446}$. Mit der Dominanz der staatlichen Industrie drohten diese Gerichte vollends zum „Hemmschuh" der Wirtschaftspolitik der SED zu werden. Die Arbeitsgerichte verloren jedoch bald an Bedeutung, weil sie ab 1953 allmählich durch die sogenannten Konfliktkommissionen ersetzt wurden. Im Jahre 1963 wurde die Neuerung unabhängiger Arbeitsgerichte wieder abgeschafft, es erfolgte ihre Eingliederung in die allgemeine Justiz ${ }^{447}$.

Eine echte faktische Entlastung für die Justiz brachte die Lostrennung der freiwilligen Gerichtsbarkeit, auf die besonders Hoeniger gedrängt hatte. Für Bagatellsachen waren nun Rechtspfleger zuständig, die zur Kommunalverwaltung gehörten ${ }^{448}$.

\section{e. Die Rechtspolitik der ersten Jabre im Kontext}

Die Rechtsprobleme in den ersten Nachkriegsjahren waren grundsätzlich in allen Zonen die gleichen, oftmals wurden sie auf der Basis gemeinsamer Kontrollratsgesetze behandelt. Mehr noch als das Unrecht der NS-Diktatur galt es, die akuten

${ }^{444}$ Zur Geschichte der Rechtspflege 1945-1949, S. 31, 86ff.; Rechenschaftsbericht Steinhoff, 21. 9. 1945, Berichte Landes- und Provinzialverwaltungen, S. 357-378. Vgl. BA, DQ-2/89, Bericht betr. Vorsitzende der Arbeitsgerichte in Brandenburg, 16.9. 1946 (für den Hinweis auf diese Akte danke ich Dierk Hoffmann).

445 BLHA, Landesreg. Brandenburg Abgabe 1988, Bdl. 20, Nr. 12647, Personalakte Klusmann, besonders Vermerk Hentschel, 25. 1. 1949; vgl. BStU, ASt. Erfurt, AIM 147/59, Bl. 78 f., Bericht GI „Horn“, 11. 4. 1953. Auf Klusmann folgte bis April 1950 Otto Brugger (BLHA, Rep. 202A, Nr. 21, Bl. 49).

446 SAPMO, DY 30/IV 2/13/110, Bl. 138, Protokoll der Ersten Staatspolitischen Konferenz von Werder 23./24. 7. 1948 (Benjamin).

${ }^{447}$ Haerendel, Gesellschaftliche Gerichtsbarkeit, S. 54 f.; Entwicklung des Arbeiter- und Bauernstaates, S. 224.

448 VO der DJV, 20. 6. 1947. 
Probleme der Zusammenbruchsgesellschaft zu regeln, die sich bis 1947/48 eher noch steigerten ${ }^{49}$. Viele dieser Problemlagen hielten auch bis in die fünfziger Jahre an, wurden dann aber politisch von anderen Justizkampagnen überlagert.

Auch die Rechtsvorstellungen ähnelten sich in allen Zonen anfangs noch, so die Orientierung am „Volk“, die Abgrenzung zum Nationalsozialismus, die Legitimität der Besatzung und die Reform nach dem Weimarer Vorbild. In den Westzonen wurden ebenfalls verschiedene Reformprojekte für die Justiz diskutiert. Während aber die Reformansätze in der SBZ schon Ende der vierziger Jahre ins Stocken gerieten, setzten sie sich im Westen auf lange Sicht durch.

Im allgemeinen gab es innerhalb der SBZ keine besondere brandenburgische Rechtspolitik, aber eigene Akzente der Justizverwaltung. Auffällig waren auf der einen Seite die Experimente im Strafvollzug, vor allem aber das relativ scharfe Vorgehen in Wirtschaftsstrafverfahren, das allen Ländern der SBZ gemein war. In der britischen Zone hingegen lockerte sich die Strafpraxis in diesem Bereich, so daß im Herbst 1947 beispielsweise der Kompensationshandel freigegeben wurde ${ }^{450}$. Von Anfang an unterschiedlich waren in Ost und West die administrativen Maßnahmen gegen bestimmte Bevölkerungsgruppen, insbesondere die von $\mathrm{KPD}$ und SPD als Gesellschaftspolitik verstandenen Enteignungen in der Wirtschaft. Freilich ging dies weitgehend an der Justiz vorbei, von einer Klassenjustiz läßt sich deshalb kaum sprechen. Statt dessen trafen die rigiden sowjetischen Vorgaben für den Rechtsapparat vor allem die Bauern, die man eigentlich als Klientel umwarb. Während also die deutsche Rechtspolitik im großen und ganzen bis 1947 in Ost und West in ähnlichen Bahnen verlief, drifteteten die einzelnen Alliierten in ihrer eigenen Strafpraxis schon frühzeitig auseinander.

\section{Sowjetjustiz und Internierungen}

Justiz in Brandenburg war bis Anfang der fünfziger Jahre immer auch Justiz unter Besatzungsherrschaft. Das bedeutete, daß die Militäradministration nicht nur einen erheblichen Einfluß auf deutsche Verwaltung und Gerichte hatte, sondern in eigener Regie Verhaftungen, Verurteilungen, Internierungen und auch Hinrichtungen vornahm ${ }^{451}$.

\section{a. Verhaftung und Internierung durch sowjetische Behörden}

Die erste Verhaftungswelle gegen Zivilisten in Brandenburg folgte dem Einmarsch der Roten Armee auf dem Fuße. Sie war zwar nach genau festgelegten Kategorien von Festzunehmenden geregelt, verlief im Einzelfall aber relativ willkürlich. Nach der Kapitulation ging das NKWD ${ }^{452}$ systematischer vor. Besonders

${ }^{449} \mathrm{Vgl}$. für die britische Zone: Kramer, Law-Abiding Germans.

450 Stüber, Kampf gegen den Hunger, S. 599; vgl. auch den sogenannten Kasseler Spinnfaser-Prozeß um Kompensationen: Benz, Zwangswirtschaft und Industrie, S. $437 \mathrm{f}$.

451 Umfassendste Darstellung: Fricke, Politik und Justiz, S. 55-149.

452 Im folgenden wird bis zur Umbenennung in MWD im März 1946 von NKWD gesprochen, desgleichen für NKGB/MGB. 
vom 10. bis 15. August 1945 und nach dem SMAD-Befehl Nr. 42 vom 27. August, der die Registrierung aller Angehörigen von NSDAP, SA, SS und Gestapo gebot, nahmen NKWD und Volkspolizei massenhaft Festnahmen vor. Nach fragmentarisch überlieferten Meldungen setzte die Polizei etwa im Bezirk Cottbus im August 19451400 Personen fest, davon 150 wegen NSDAP-Mitgliedschaft. Die „ehemaligen Faschisten" wurden dann an das NKWD abgegeben ${ }^{453}$.

Formal gesehen unterschied sich das Verfahren in der SBZ nicht wesentlich von dem in den Westzonen. Auch dort galt der ,automatic arrest“ für Angehörige einzelner NS-Gliederungen ab bestimmten Rängen ${ }^{454}$. Die Kontrollrats-Direktive 38 vom 12. Oktober 1946 präzisierte zwar die Belastung der einzelnen Gruppen. Man kann jedoch davon ausgehen, daß bei Festnahmen in der SBZ mehr Willkür im Spiel war.

Seit dem Frühjahr 1945 grassierte in den alliierten Besatzungsdienststellen eine regelrechte "Werwolf"-Hysterie ${ }^{455}$. Angeblich hätte das NS-Regime in seinen letzten Tagen noch Untergrundgruppen aus Jugendlichen gebildet, die im Hinterland der Alliierten für Unruhe sorgen sollten. Besonderes Aufsehen erregte die Ermordung des von der amerikanischen Armee eingesetzten Oberbürgermeisters von Aachen im März 1945. Diese Aktion wurde dem „Werwolf" zugerechnet456. Als dann im Sommer 1945 tatsächlich unorganisierte Jugendgruppen durch Brandenburg zogen und z.T. bewaffnete Raubüberfälle verübten, wurde dies als Beweis für die Existenz des „Werwolf“ gesehen. Offensichtlich ordnete Stalin selbst in der SBZ Massenverhaftungen von Jugendlichen an ${ }^{457}$. Besonders im Raum Fürstenberg vermutete die Besatzungsmacht solche Aktivitäten ${ }^{458}$. Auch die Volkspolizei meldete angebliche „Werwolf“-Gruppen an die SMA459. Bis August 1946 berichtete das NKWD, daß in Brandenburg 81 solcher Gruppen mit 944 Mitgliedern ausgehoben worden seien ${ }^{460}$. Die Gesamtzahl der verhafteten Jugendlichen in Brandenburg ging jedoch wohl schon 1945 in die Tausende, gerade Jungen im Alter von 15 bis 20 konnten sich nachts und außerhalb von Ortschaften nicht mehr sicher fühlen. In sowjetischer Haft mußten die Jugendlichen oftmals schlimmste Mißhandlungen über sich ergehen lassen ${ }^{461}$. Die „Werwolf“-Kampagne erreichte dann im Sommer 1946 einen neuen Höhepunkt. So titelte die Märki-

${ }^{453}$ Semiryaga, Wie Berijas Leute, S. 747; BLHA, Rep. 203 MdI/LBdVP, Nr. 19, Bl. 3, 9-11, Bericht Abt. IX Provinzialverwaltung, 7. 9. 1945; Bericht Abt. IX Provinzialverwaltung, 16. 10. 1945.

$454 \mathrm{Vgl}$. Niethammer, Alliierte Internierungslager, S. $474 \mathrm{ff}$.

455 Vgl. Biddiscombe, Werwolf, S. 262 ff.; Kenkmann, Wilde Jugend, S. $334 \mathrm{ff}$.

${ }_{456}$ Henke, Die amerikanische Besetzung, S. 285, 943; Harvey, Werwolf; Hass, Werwolf 1944/45, S. $212 \mathrm{f}$.

457 Vgl. Bericht Serow an Beria über „Werwolf“-Aktivitäten, 22. 6. 1945, Plato, Sowjetische Speziallager, S. 30 f.; Osobaja papka Stalina, S. 119 f., 142, 186 (Vorlagen 22.5., 20. 9. 1945, 2. 8. 1946). Es gibt Indizien dafür, daß das NKWD die „Werwolf“-Propaganda absichtlich gegenüber der Armee übertrieben hat, um härter vorgehen zu können.

458 Biddiscombe, Werwolf, S. 192 f., 214 f.; Urban, Vereinigung, S. 53; von einer Untergrundgruppe bei Rheinsberg spricht Sägebrecht, Nicht Amboß, S. 322.

459 BLHA, Rep. 203 MdI/LBdVP, Nr. 36, Bl. 7, Abt. Polizei an SMA (Gami), 1. 12. 1945.

t60 Berija an Stalin u. a., 24. 10. 1945, abgedruckt in: Possekel, Sowjetische Speziallager, S. 209.

$461 \mathrm{Vgl}$. Sacharov/Filippovych/Kubina, Tschekisten in Deutschland, S. 308; Beispiele für Massenverhaftungen bei Finn, Die politischen Häftlinge der Sowjetzone, S. 100-102; Fricke, Politik und Justiz, S. 569; Plato, Sowjetische Speziallager, S. 63; Biddiscombe, Werwolf, S. 273; Einzelfall MWDGefängnis Cottbus: Ochs, Werwölfe in sowjetischen Straflagern, S. $217 \mathrm{f}$. 
sche Volksstimme am 17. Mai: „Werwölfe werden rücksichtslos verfolgt.“462 Später, ab 1947, wurde der „Werwolf“-Vorwurf zusehends fallengelassen und durch die Beschuldigung ersetzt, faschistischen Untergrundorganisationen anzugehören ${ }^{463}$. Tatsächlich gibt es für eine koordinierte Untergrundbewegung, gar noch von der SS gesteuert, keine Anhaltspunkte. Es existieren jedoch Hinweise auf einzelne Jugendgruppen, die teils antikommunistische, teils kriminelle Ziele verfolgten. Manche anonymen Flugblätter waren mit "Werwolf" unterzeichnet ${ }^{464}$. Im SED-Landesvorstand wies „Gen. Pfeifer auf die noch stark faschistischen Tendenzen in der Jugend hin und sagte, daß in einem seiner Kreise eine Gruppe Jugendlicher verhaftet wurde, die eine Edelweiß-Organisation gebildet hatten und bei denen nazistische Flugblätter gefunden wurden. " ${ }^{65}$ Die gesamte Jugendkriminalität stieg zwar im ganzen Nachkriegsdeutschland rasant an, hielt sich jedoch in Brandenburg vergleichsweise in Grenzen ${ }^{466}$.

Immer wieder kam es auch zu Festnahmen völlig unbeteiligter Passanten. Bei der Überführung der Häftlinge aus dem Lager Weesow nach Sachsenhausen am 16. August 1945 wurde die Zahl der Häftlinge, die infolge von Flucht abnahm, durch Verhaftungen unterwegs wiederhergestellt. Günter de Bruyn erlebte auf dem Bahnhof von Königs Wusterhausen, wie ein sowjetischer Offizier, der eine Gruppe deutscher Kriegsgefangener bewachte, einen deutschen Zivilisten festnahm, nachdem ein Kriegsgefangener geflüchtet war. Damit sollte die Zahl der Abzutransportierenden wieder aufgefüllt werden ${ }^{467}$.

Während die Kategorien der Festgenommenen in allen Besatzungszonen 1945 mit Ausnahme der systematischen Verhaftung sogenannter Displaced Persons ${ }^{468}$ noch relativ ähnlich waren, erweiterten die sowjetischen Behörden sie ab 1946 allmählich auch auf andere politische Gegner als nur die Nationalsozialisten. Gefährdet waren zunächst solche SPD-Mitglieder, die sich vehement dem Zusammenschluß ihrer Partei mit der KPD widersetzten. Obwohl derartige Verhaftungen in Berlin und den anderen Ländern zahlreich nachweisbar sind, konnten für Brandenburg bisher nur wenige ermittelt werden. Beispielsweise verhaftete das NKWD den Kreisvorsitzenden der Partei für Niederbarnim, den SPD-Bürgermeister von Lehnin und andere ${ }^{469}$. Daß es sich hier aber um ein breiteres Phänomen handelte, zeigt die erste Diskussion über die Verhaftungen im Parteivorstand der SED am 14./15. Mai 1946. Einer der beiden brandenburgischen SED-Vorsitzenden, Friedrich Ebert, plädierte für die Einrichtung einer Auskunftsstelle für

462 Märkische Volksstimme, 17. 5. 1946.

$463 \mathrm{Vgl}$. den MGB-Bericht über die angebliche Aushebung von Gruppen der „Edelweißpiraten“ Ende 1946-Anfang 1947, Murphy/Kondrashev/Bailey, Battleground Berlin, S. 417.

464 BStU, Allg. S 317/66, Bl. 2 ff., Bericht [DVdI] Referat K 5/C 3 über Provokationen vom 1. 7. - 15. 8. 1948, u. a. in Brandenburg. Vgl. Geschichte der Deutschen Volkspolizei Band 1, S. 52, deren Angaben allerdings mit Vorsicht zu genießen sind.

465 BLHA, Rep. 332, Nr. 22, Bl. 36-41, Protokoll Sekretariatssitzung SED Brandenburg am 13.5. 1946; vgl. die Verhaftungsmeldung in der Täglichen Rundschau vom 13. 8. 1946.

466 BLHA, Rep. 202A, Nr. 39, Bl. 9-15, Bericht Informationsamt Brandenburg, o.D.

467 Kühle/Titz, Speziallager Nr. 7, S. 13; de Bruyn, Zwischenbilanz, S. 302.

468 Vgl. Lipinsky, Ketschendorf, S. 366.

469 Hurwitz, Demokratie und Antikommunismus, Band 4, S. 720 f.; Malycha, Auf dem Weg zur SED, S. 137; auch Reinert, Brandenburgs Parteien, S. 72 f., konnte nur wenige Belege für solche Verhaftungen in Brandenburg finden. 
Angehörige der Verhafteten ${ }^{470}$. Auch SED-Angehörige gerieten seit 1947 in die Fänge des MWD/MGB, wenn sie aus Sicht der Besatzungsmacht negativ auffielen. Einer der spektakulärsten Fälle betraf Wilhelm Lohrenz, der am 18. November 1946 in Finsterwalde verhaftet und dem MWD in Cottbus übergeben wurde. Lohrenz hatte Kontakt zum Ostsekretariat der SPD in den Westsektoren Berlins. Nach seiner Verhaftung wurde er "umgedreht" und diente 1948 für Propagandazwecke der SED gegen die SPD ${ }^{471}$. Die Zahl der ab Mitte 1948 verhafteten Vertrauensleute des SPD-Ostbüros geht vermutlich in die Hunderte. Ab 19. Oktober 1948 startete die politische Polizei K 5 in Brandenburg eine großangelegte Festnahme-Aktion gegen "Schumacher-Anhänger"; beispielsweise sind Verhaftungen im Dezember 1948 für Frankfurt bekannt ${ }^{472}$.

$\mathrm{Ab}$ Mitte 1946 liefen auch LDP- und CDU-Funktionäre bei Unbotmäßigkeit Gefahr, vom MWD verhaftet zu werden. Eine Welle von Festnahmen folgte auf die Absetzung der CDU-Vorsitzenden Kaiser und Lemmer im Dezember 1947. Der Ortsgruppenvorsitzende von Schönwalde, der Bürgermeister von Liebenwalde, der Kreisvorsitzende von Potsdam, Hans Egidi, und der Leiter der Jungen Union in Frankfurt/Oder waren davon betroffen ${ }^{473}$. LDP-Mitglieder, die Kontakte zur FDP in Westberlin - im kommunistischen Jargon: „Schwennicke-Partei“ - hielten, wurden von sowjetischen Stellen als potentielle Spione angesehen ${ }^{474}$. Als der vormalige geschäftsführende Landesvorsitzende der LDP, Wilhelm Falk, der inzwischen FDP-Funktionär im Westen geworden war, 1948 nach Potsdam reiste, wurde er verhaftet und kurzerhand vom SMT zu zehn Jahren Lager wegen angeblicher „antisowjetischer Agitation" verurteilt 475 .

Für Festnahmen waren vor allem die Volkspolizei und das NKWD-Personal zuständig. Oftmals bedienten sich die sowjetischen Geheimpolizisten ihrer deutschen Kollegen, um den Schein der Legalität zu wahren ${ }^{476}$. Vielfach griffen aber auch Angehörige der sowjetischen Truppenverbände oder der Kommandanturen zu. Verhaftungen deutscher Zivilisten durch die sowjetische Gegenspionage Smersch werden hin und wieder behauptet ${ }^{477}$, sind aber nach dem Sommer 1945 schwer zu belegen. Smersch war vor allem für die Überwachung der Rotarmisten

470 Bouvier, Ausgeschaltet, S. 72, $209 \mathrm{ff}$; Hurwitz, Stalinisierung der SED, S. 53-57.

471 Hurwitz, Stalinisierung der SED, S. 88; Buschfort, Ostbüro, S. 38 f.

472 AdsD, Ostbüro 0046 a, Quelle 1183/1 über Aufbau K 5 in Brandenburg, 19. 10. 1948; Bericht über Aufbau K 5 Potsdam, 9. 11. 1948; Buschfort, Geheimagenten, S. 696 (schätzt 1000 für die ganze SBZ); ders., Ostbüro, S. 47.

${ }^{473}$ Richter, Ost-CDU, S. 49; Gradl, Anfang unter dem Sowjetstern, S. 147. Egidi wurde wieder entlassen und flüchtete in den Westen, Schollwer, Potsdamer Tagebuch, S. $28 \mathrm{f}$. 1947 wurde der Regierungsdirektor im Finanzministerium, Kurt Grünbaum (CDU), für sechs Wochen verhaftet, Besier/Wolf, Pfarrer, S. 900. Vgl. auch den Fall des Landesgeschäftsführers Henke, der im Juli 1948 vom MWD bzw. MGB verhört und anscheinend zur Mitarbeit gepreßt wurde, „Henke arbeitete für die NKWD“, in: Tagesspiegel vom 24.7. 1949.

${ }^{474}$ Schollwer, Potsdamer Tagebuch, S. 23; Bode, Liberaldemokraten und deutsche Frage, S. $95 \mathrm{f}$. Der spätere LDP-Landesvorsitzende von Koerber galt im Herbst 1947 als zeitweise vom MWD/MGB verhaftet; ebenda, S. 53.

475 Protokolle des Landesblockausschuß, S. 50; „Dr. Falk im Konzentrationslager“ in: Tagesspiegel, 24. 5. 1949. Vgl. Hagemann, Untersuchungsausschuß, S. $214 \mathrm{f}$.

476 AdsD, Ostbüro 0046 a, Bericht über Aufbau K 5 Potsdam, 9. 11. 1948. Vgl. zu Einweisungen aus Brandenburg nach Torgau: Oleschinski/Pampel, Feindliche Elemente, S. 36; und die Aussage des übergelaufenen MWD-Mitarbeiters Delik, 20. 8. 1954, Unrecht als System, Teil II, S. 92-94.

477 Beispielsweise Otto, Entnazifizierung, S. 31; Ritscher, NKVD-MVD-„Speziallager“, S. 77. 
zuständig, beschäftigte sich aber auch mit dem deutschen Hilfspersonal bei sowjetischen Einheiten und Dienststellen ${ }^{478}$.

Nach bisherigen Erkenntnissen stieg die Zahl der Verhaftungen von 1945 bis Januar 1947 kontinuierlich und sank dann ab Mai 1947 stark ab. Es folgten zwei Verhaftungswellen, April bis Juli 1948 und September bis November 1949. Im Jahre 1948 waren wohl die meisten Zugriffe überhaupt zu verzeichnen. Ab Herbst 1950 sind kaum noch sowjetische Verhaftungen zu ermitteln ${ }^{479}$.

Das Ausmaß sowjetischer Festnahmen in Brandenburg ist bisher noch nicht erforscht. Mit Sicherheit handelt es sich um mehrere zehntausend Personen ${ }^{480}$. Nur ein Teil der Festgenommenen kam auch vor Sowjetische Militärtribunale. Viele von ihnen wurden verhört und nach einiger Zeit wieder freigelassen. Gerade gegenüber den „bürgerlichen“ Parteien konnte so hin und wieder Druck ausgeübt werden ${ }^{481}$. Viele Mitglieder von NS-Organisationen, die man nur wegen ihrer nominellen Zugehörigkeit ohne konkrete Belastungen verhaftet hatte, gelangten ohne Verurteilung in ein Internierungslager.

In der Provinz Brandenburg befand sich die Mehrzahl der sogenannten Spezialoder Sonderlager des NKWD/MWD, so Speziallager Nr. 5 in Ketschendorf bei Fürstenwalde ${ }^{482}$ und Nr. 6 in Jamlitz bei Lieberose. Den größten Komplex bildete das Speziallager Nr. 7 (ab 1948: Nr. 1) in Sachsenhausen auf dem Gelände des nationalsozialistischen Konzentrationslagers. Nur kurzzeitig existierten die Lager in Weesow bei Werneuchen und das Durchgangslager in Frankfurt/Oder. An die 100000 internierte Personen durchliefen diese Haftstätten, etwa jeder Vierte starb dort ${ }^{483}$. Die Insassen aller dieser Lager kamen aber nur zum Teil aus Brandenburg. Vielmehr gab es zwischen den verschiedenen Speziallagern in der ganzen SBZ eine Aufteilung der Internierten. Insbesondere ab Anfang 1946 gelangten immer mehr Personen ohne NS-Belastung nach Sachsenhausen, politische Häftlinge aller Couleur. Ende 1946 wurde das Lager in zwei Zonen eingeteilt, für Internierte ohne Urteil und für SMT-Verurteilte ${ }^{484}$.

Die Lebensbedingungen in allen drei Lagern waren katastrophal. Im Hungerwinter 1946/47 sanken die dürftigen Lebensmittel-Rationen noch weiter ab, so daß Häftlinge massenhaft an Krankheiten und Unterernährung starben. In Jamlitz

478 Naimark, Russians in Germany, S. 26; vgl. Höhne, Krieg im Dunkeln, S. 521; Parrish, Lesser Terror, S. 113 ff.; Murphy/Kondrashev/Bailey, Battleground Berlin, S. 32.

479 Oleschinski/Pampel, „Nazis“, „Spione“, „Sowjetfeinde“, S. 461; Foitzik, Der sowjetische Terrorapparat, S. 13.

480 Für die erste Dezemberhälfte 1946 wurde die Zahl von 432 verhafteten Deutschen in der ganzen SBZ nach Moskau gemeldet, Murphy/Kondrashev/Bailey, Battleground Berlin, S. 38. Angeblich wurden von Januar bis August 1947 vom MWD in der SBZ 3921 Personen verhaftet, Semiryaga, Wie Berijas Leute, S. 749. Die offizielle Zahl nach SMAD-Kartei von 157837 Verhaftungen in der ganzen SBZ vom 15. 5. 1945 bis 1. 3. 1950 ist sicher zu niedrig, Kusch/Beckmann, Gott in Bautzen, S. 20. Zur Abgrenzung von kurzzeitiger Festnahme und Verhaftung: Foitzik, Der sowjetische Terrorapparat, S. 13.

481 Vgl. Lemmer, Manches war doch anders. S. 319-321, der eine Nacht beim MWD verbringen mußte; vgl. Creuzberger, Opportunismus oder Taktik.

482 Vgl. Lipinsky, Straße.

${ }^{483}$ Morré, Speziallager des NKWD, S. 9-82 (mit niedrigeren Zahlen); Agde, Sachsenhausen bei Berlin, S. 67-71.

${ }^{484}$ Kühle/Titz, Speziallager Nr. 7, S. 14 ff.; Finn, Sachsenhausen, S. 30 ff.; Fricke, Politik und Justiz, S. 70. 
und Ketschendorf überlebten insgesamt nur etwa $60 \%$ der Insassen. Bis Mitte 1947 waren die Häftlinge völlig von der Außenwelt isoliert. Entlassungen erfolgten 1946/47 nur in Einzelfällen. Erst im Sommer 1948 konzedierte die SMAD Massenentlassungen, so für 5000-6000 Internierte aus Sachsenhausen. Das Lager Ketschendorf war schon im Februar 1947 aufgelöst worden, Jamlitz folgte im Oktober 1948. Ein Teil der Sachsenhausener SMT-Verurteilten wurde vom 16. Januar bis 8. März 1950 in die Freiheit entlassen, 5600 an den DDR-Strafvollzug übergeben und 550 Internierte nach Waldheim zur Aburteilung gebracht $t^{485}$.

Neben den Speziallagern verfügte das NKWD in Brandenburg noch über eine Reihe eigener Gefängnisse, allen voran die Trakte 2 und 3 des Zuchthauses Brandenburg, die dann 1947 der deutschen Justiz übergeben wurden. Dort saßen vornehmlich sowjetische Staatsbürger, etwa aus den Hilfsverbänden der Wehrmacht. Die meisten Operativgruppen des NKWD, dann MGB, verfügten über eigene Untersuchungsgefängnisse. Dabei nutzten sie oftmals ehemalige Gerichtsgebäude oder -gefängnisse, so etwa in der Potsdamer Lindenstraße und in der Leistikowstraße $\mathrm{e}^{486}$. Daneben sind diese „Inneren Gefängnisse“ in Brandenburg/Havel, Cottbus, Eberswalde, Frankfurt/Oder (Gefängnisse Nr. 6 und 7), Forst und Neuruppin nachweisbar ${ }^{487}$. In ihnen herrschten übelste Haftbedingungen; im Frühjahr 1947 stiegen die Belegungen auf unerträgliche Maße an. Zahllose Häftlinge starben an den schlechten Lebensbedingungen oder wurden bei Verhören zu Tode geprügelt. In einem besonders eklatanten Fall führte dies dazu, daß zwei Untersuchungsführer des Operativen Sektors in Brandenburg selbst eine dreijährige Haftstrafe erhielten ${ }^{488}$.

Die massenhaften Festnahmen sorgten für erhebliche Unruhe in der brandenburgischen Bevölkerung. Meist blieben die Angehörigen über lange Zeit ohne Nachricht. Deshalb bemühten sich besonders die Kirchen und ihre Hilfswerke intensiv um Aufklärung. Die Bischöfe Dibelius und Preysing wurden mehrmals bei der SMAD vorstellig489.

${ }^{485}$ Kühle/Titz, Speziallager Nr. 7, S. 40-43.

486 Wernicke, Staats-Sicherheit, S. $13 \mathrm{f}$.; ders., Deutsches aus der Lindenstraße, S. $37 \mathrm{f}$. In der Lindenstraße 54/55 hatte sich im Mai/Juni 1945 das Stadt- und Stadtobergericht befunden. Literarische Verarbeitung der Haft in Bienek, Die Zelle, der 1951 vom SMT Potsdam verurteilt wurde. Zur Leistikowstraße: Von Potsdam nach Workuta, S. 14-16. 1945/46 befand sich ein Smersch-Gefängnis in der Kastanienallee.

${ }^{487}$ Erler, Zum Wirken der Sowjetischen Militärtribunale, S. 56; Lipinsky, Speziallager Torgau, S. 159, 162. Das Gefängnis Nr. 7 wurde am 17. 5. 1946 von Frankfurt nach Torgau verlegt: Oleschinski/ Pampel, Feindliche Elemente, S. 78; Forst: SAPMO, DY 30/IV 2/13/407, Bericht Kontrollfahrt Forst, 31. 10. 1946 (gez. Benjamin); Neuruppin: BLHA, Rep. 212, Nr. 595, Bl. 4, Vermerk Abt. Justiz, 4. 10. 1945; Liste sogenannter „GPU-Keller“ in Morré, Speziallager des NKWD, S. 17.

488 Petrov, Apparate des NKVD/MVD, S. $148 \mathrm{f}$. Zahlen der MGB-Häftlinge liegen bisher nur für Mecklenburg vor: Dort saßen im Oktober 19461460 Personen ein. In Brandenburg dürfte die Ziffer höher gelegen sein, Sacharov/Filippovych/Kubina, Tschekisten in Deutschland, S. 304.

489 Lipinsky, Ketschendorf, S. 387; Seidel, „Neubeginn“ in der Kirche, S. 408 f.; Stupperich, Otto Dibelius, S. 401-403; Schreiben von Dibelius und Preysing an Tschuikow, 8. 10. 1949, Dokumente zur Deutschlandpolitik, II. Reihe, Band 2, S. 623. 


\section{b. Die Sowjetischen Militärtribunale}

Eine besondere Bedeutung im Justizsystem hatten die Sowjetischen Militärtribunale (SMT). Sie besaßen bis 1947 das Monopol für fast alle politischen Prozesse; Verfahren sind in Brandenburg bis 1954 nachweisbar. Die Existenz der Militärtribunale war insofern wichtig für die Justizentwicklung, als sie die Gleichschaltung der deutschen Justiz eher verlangsamte.

Die Tätigkeit der sowjetischen Militärjustiz in Brandenburg läßt sich bisher nur indirekt aus einer Vielzahl von Zeugenaussagen erschließen ${ }^{490}$. Über Organisation und den Umfang der SMT-Verfahren im Lande liegen noch kaum verläßliche Angaben vor. Bisher feststellbar sind Militärtribunale der Armeen, der Divisionen, der Etappe und Eisenbahntransportgerichte ${ }^{491}$. Ab Dezember 1945 ist die Existenz eines SMT des Landes Brandenburg überliefert, vermutlich das Militärtribunal des NKWD in Potsdam 492. Vor diesem Gericht fand ab 1946/47 die Mehrheit aller solcher Verfahren statt, an die Stelle von Divisions- und Armeegerichten traten nun regionale SMT493.

Über Brandenburger urteilten darüber hinaus das Militärtribunal des Militärkollegiums des Obersten Gerichts der Sowjetunion und das Gericht der Gruppe der sowjetischen Streitkräfte. Einige wenige Verfahren wurden als Fernprozesse vor dem sogenannten Sonderkolleg des MWD/MGB in Moskau geführt. Dabei bekam der Angeklagte lediglich das Urteil mitgeteilt ${ }^{494}$. Es gibt Indizien dafür, daß die Militärjustiz nach 1945 personell noch aufgestockt wurde ${ }^{495}$. Nach der Bildung der Bezirke 1952 existierte im brandenburgischen Territorium ein SMT nur noch in Potsdam.

Ihre eigentliche Funktion war die Bestrafung der Verbrechen innerhalb der Roten Armee, seien sie politischer oder krimineller Natur. So wurden durchaus auch die grassierenden Ausschreitungen von Rotarmisten gegen Deutsche vor den SMT geahndet ${ }^{496}$. Daneben gerieten zahlreiche sowjetische DPs in die Mühlen der Militärtribunale497. Deutsche Zivilisten kamen zunächst aus zwei Gründen vor sowjetische Gerichte: entweder wegen ihrer nationalsozialistischen Vergangenheit oder wegen echter bzw. vermeintlicher Verstöße gegen das Besatzungsregime. Obwohl nach sowjetischen Angaben die Verfahren wegen NS-Belastung mehr als die Hälfte aller Prozesse ausmachten, ist darüber sehr wenig bekannt ${ }^{498}$. Ein spek-

490 Eine Teilauswertung der Verfahrensakten, die in den Archiven des russischen Innenministeriums und des Sicherheitsdienstes liegen, ist im Gange, vgl. Wagenlehner, Akten der SMT-verurteilten Deutschen, S. 52 f.; ders., Vier Jahre Auswertung.

${ }^{491}$ Erler, Zum Wirken der Sowjetischen Militärtribunale, S. 51 f., auch zum folgenden.

${ }^{492}$ Militärtribunale einzelner MWD-Truppenteile konnten in Brandenburg bisher noch nicht ermittelt werden; vgl. Fricke, Politik und Justiz, S. $101 \mathrm{f}$.

${ }^{493}$ Einzelfälle sind belegt für Cottbus (schon 1945), Eberswalde, Ravensbrück/Fürstenberg, Frankfurt/Oder, Wünsdorf.

${ }_{494}$ Beispiel aus Potsdam: Recht in Fesseln, S. 317-319. Das Sonderkolleg des MWD bestand bis 21.7. 1950, das des MGB parallel ab 2. 11. 1946, Lubjanka, S. 131.

495 Arlt, Wirken der Sowjetischen Militäradministration, S. 130

${ }^{496}$ Naimark, Russians in Germany, S. 92; alle Verfahren wegen Verbreitung von Geschlechtskrankheiten, die in Zusammenhang mit Rotarmisten standen, waren der SMA zu melden, BLHA, Rep. 212, Nr. 41, Bl. 300, Rundverfügung MdJ Brandenburg Nr. 195, 6. 8. 1947.

497 Todesurteile erwähnt Lipinsky, Ketschendorf, S. 366.

498 Eine späte - nicht repräsentative - Auflistung der Urteilsgründe vor SMT in Morré, Speziallager 
takulärer Fall wie der Sachsenhausen-Prozeß vom 23. bis 31. Oktober 1947 wurde öffentlich in Berlin und nicht am Tatort in Brandenburg verhandelt. Ursprünglich war es nicht klar gewesen, ob das Verfahren einem deutschen oder einem sowjetischen Gericht übergeben werden sollte; die Ermittlungen wurden auch vom brandenburgischen Generalstaatsanwalt betrieben. Dabei standen die Massenmorde der Lagerbesatzung an sowjetischen Kriegsgefangenen im Vordergrund ${ }^{499}$. Dieser und andere Schauprozesse wurden zentral von Moskau aus gelenkt, um ein Höchstmaß an internationaler Öffentlichkeit auf sich zu ziehen ${ }^{500}$. Darüber hinaus wurden nur wenige andere SMT-Verfahren öffentlich geführt. Deshalb kann über die materielle Substanz der Anklagen wegen NS-Belastung meist keine Aussage getroffen werden. Der spektakulärste Militärprozeß wegen NS-Verbrechen, der in Brandenburg abgehalten wurde, richtete sich gegen Angehörige des Polizeibataillons 9 aus Berlin-Spandau, die 1941 in den sogenannten Einsatzgruppen an Massenmorden in der Sowjetunion beteiligt gewesen waren. Von den nicht weniger als 245 Angeklagten wurden in Oranienburg mit einer Ausnahme alle zu je 25 Jahren Haft verurteilt 501 .

Nachweisbar ist die Verhaftung des Leiters der „Euthanasie“-Anstalt Brandenburg-Görden, Heinze, ebenso wie von 30 Wachbeamten aus dem Zuchthaus Brandenburg-Görden, die als belastet angesehen wurden ${ }^{502}$. Meist reichte anscheinend aber die Zugehörigkeit zur SS oder zu einer bestimmten Einheit für eine Verurteilung aus; im späteren Amtsdeutsch hieß das „Kollektivschuld“503. Offensichtlich schon einige Monate vor Erlaß des Befehls Nr. 201 vom August 1947 stellte die Besatzungsmacht die eigene Verfolgung von NS-Belasteten offiziell ein und übergab sie der deutschen Justiz.

Die andere große Gruppe von Angeklagten war beschuldigt, sich gegen die sowjetische Besatzungsmacht vergangen zu haben. Das betraf zunächst alle Personen, bei denen Waffen aufgefunden worden waren. Bei Jugendlichen führte dies unweigerlich zum „Werwolf“-Verdacht. Besonders die Verfahren gegen Jugendliche trugen der sowjetischen Militärgerichtsbarkeit den Ruf der Erbarmungslosigkeit ein ${ }^{504}$. So verurteilte das SMT Brandenburg am 31. Dezember 1945 einen

des NKWD, S. 20 (28\% NS-Taten, $48 \%$ Agitation/Spionage/Sabotage, $16 \%$ Waffenbesitz, $8 \%$ normale Delikte).

499 Wieland, Der sowjetische Sachsenhausen-Prozeß, S. $238 \mathrm{ff}$.; vgl. die Broschüre Todeslager Sachsenhausen; Meyer, Britischer oder sowjetischer Sachsenhausen-Prozeß, S. 981; BLHA, Rep. 212, Nr. 1451, Bl. 2, Monatsbericht des GStA für 21. 3. bis 20. 4. 1947, 30. 4. 1947.

500 Ausführlich zum Prozeß: Meyer, Ein stalinistischer Schauprozeß; nahezu tägliche Berichterstattung in der Täglichen Rundschau ab 22.10. 1947. Vgl. zu den zeitlich parallelen Verfahren: NKWD-Vorlage für Stalin, 6. 9. 1947, „Über die Zweckmäßigkeit der Durchführung von öffentlichen Prozessen gegen Kriegsverbrecher" ${ }^{\star}$, Regest in: Osobaja papka Stalina, S. 231; Zeidler, Stalinjustiz, S. $31 \mathrm{f}$.

501 „97.000 Sowjetbürger ermordet“, in: Neues Deutschland vom 9. 8. 1947; Finn, Die politischen Häftlinge, S. 209; Kopien der Verfahrensakten befinden sich in der Zentralen Stelle der Landesjustizverwaltungen, Ludwigsburg (deutsche Übersetzungen verstreut über die deutschen Ermittlungen zu den Einsatzgruppen-Verbrechen in der Sowjetunion).

502 Hübener, Brandenburgische Heil- und Pflegeanstalten, S. 240 (Heinze wurde 1952 aus der Haft entlassen); IfZ, ED 106/86, Bl. 161-163, Notiz Walter Hammer, 6. 5. 1947. Möglicherweise wurde Heinze aber deshalb verhaftet, weil sein Sohn als "Werwolf“-Angehöriger galt, Klee, Irrsinn Ost, S. 93.

503 SAPMO, NY 4090/445, Listen von SMT verurteilter und begnadigter Personen 1953-1955.

504 Britische und amerikanische Militärgerichte verhängten zahlreiche Todesurteile gegen jugendliche 
14jährigen wegen angeblicher Zugehörigkeit zu einer illegalen faschistischen Partei! Am 3. Januar und 9. Februar 1946 verhängte dasselbe Gericht über zwei 15jährige unter dem gleichen Vorwurf und der Beschuldigung des Waffensammelns je zehn Jahre Haft. Für die angebliche Zugehörigkeit zum „Werwolf“" wurden in dieser Zeit regelmäßig zwanzigjährige Haftstrafen über Minderjährige ausgesprochen ${ }^{505}$. Das Tribunal der 16. Luftarmee verhängte am 22. Januar viermal die Todesstrafe gegen 15- und 16jährige; drei wurden erschossen ${ }^{506}$.

Die härtesten Urteile fällte das SMT gegen eine Gruppe von acht Jugendlichen am 1. März 1946: In allen Fällen wurde die Todesstrafe verhängt und bei sechs Angeklagten vollstreckt ${ }^{507}$ ! Hin und wieder wagte die SMAD es sogar, einen Prozeß gegen Jugendliche öffentlich zu führen. Die Verhängung von je 25 Jahren Zwangsarbeit für fünf Jugendliche durch ein SMT in Berlin wegen eines Überfalls mit Todesfolge traf in der brandenburgischen Bevölkerung aber auf ablehnende Resonanz ${ }^{508}$. Die Verfahren gegen Heranwachsende gingen auch in den fünfziger Jahren weiter. 1950 wurden neun Jugendliche aus Teltow und acht Schüler der Försterschule in Eberswalde wegen der angeblichen Gründung einer illegalen Organisation „Grünwald“ vor ein SMT gestellt ${ }^{509}$. In der Tat scheint es so, daß Jugendliche oder junge Erwachsene unter diesen Vorwürfen einen erheblichen Teil, wenn nicht gar die Mehrheit der Angeklagten vor SMT ausmachten ${ }^{510}$.

Zahlreiche Deutsche standen wegen direkter Schädigung sowjetischer Dienststellen vor Gericht, etwa bei Diebstahl; aber auch Chauffeure, Eisenbahner usw., die an Unfällen mit Rotarmisten beteiligt waren, wurden angeklagt. Seit Ende 1945 gab es bei jeder Reichsbahndirektion einen sowjetischen Militärstaatsanwalt; bis Februar 1947 wurden alle größeren Transportsachen noch vom „Kriegstribunal für Eisenbahntransport " und von den SMT bearbeitet, danach nur noch, wenn sowjetische Interessen berührt waren ${ }^{511}$.

„Banden“, u.a. wegen Mordes. Vor und unmittelbar nach Kriegsende wurden diese Strafen auch vollstreckt, Henke, Die amerikanische Besetzung, S. 948; Etscheit, Der deutsche „Werwolf“, S. 159. Alle späteren Strafen wurden jedoch im Mai 1946 auf 8-10jährige Haftstrafen reduziert, Kenkmann, Wilde Jugend, S. 338. Zum Vergleich die relativ milden Urteile der US-Militärjustiz

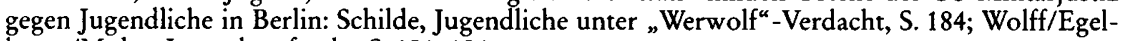
kamp/Mulot, Jugendstrafrecht, S. 151-156.

505 SAPMO, DY 30/IV 2/13/428, Liste von zur Begnadigung vorgeschlagenen SMT-Verurteilten. Exemplarisch für Thüringen die Dokumentation von Agde, Greußener Jungs, bes. S. $63 \mathrm{ff}$.

506 Artikel „86 Tage in den Todeszellen des KGB“, in: Potsdamer Neueste Nachrichten, 22. 11. 1997; Prieß, Erschossen im Morgengrauen, S. 128-155, auch zum folgenden.

507 Aussagen von Verurteilten in: Wernicke, Staats-Sicherheit, S. 23-28 (darin wird auch ein Zusammenhang mit der im März 1946 erfolgten FDJ-Gründung in Potsdam angedeutet); Von Potsdam nach Workuta, S. 26-29. Finn, Die politischen Häftlinge, S. 208; Uhlemann, Hoffnungen, S. 50, sprechen von sechs Angeklagten und vier Hinrichtungen. Möglicherweise fand also am selben Tag ein weiterer Prozeß statt.

508 BLHA, Rep. 201, Nr. 308, Bl. 232, Bericht Amt für Information Brandenburg, 6. 9. 1948; Fricke, Politik und Justiz, S. 116. Vgl. auch den öffentlichen Prozeß in Eberswalde: Artikel „Die Eberswalder Banditen vor Gericht“, in: Der Märker, 10. 1. 1946; und in Frankfurt: BLHA, Rep. 201, Nr. 308, Bl. 263, Bericht Amt für Information, 21. 9. 1948.

509 Prieß, Erschossen im Morgengrauen, S. 198-200; Kopalin, Rehabilitierung deutscher Opfer, S. 29. 510 So Kersebom/Niethammer, Kompromat 1949, S. 529 f.

511 BA, DP-1 VA 128, Bl. 325-326, Schreiben Eisenbahndirektion Bezirk Schwerin, 9. 8. 1947; BLHA, Rep. 212, Nr. 41, Bl. 91, Rundverfügung MdJ Brandenburg Nr. 56, 28. 2. 1947 (mit SMAD-Befehl Nr. 31, 10. 2. 1947); BLHA, Rep. 212, Nr. 894, Bl. 4-10, Dienstanweisung zum SMAD-Befehl Nr. 60 vom 12. 4. 1948; Fricke, Politik und Justiz, S. 569. 
Relativ selten waren SMT-Verfahren wegen schwerer Erntesabotage. Normalerweise fiel dieses Delikt in die deutsche Jurisdiktion. In Ausnahmefällen zog die SMA jedoch das Verfahren an sich. So wurde auch in Brandenburg ein Urteil eines mecklenburgischen SMT bekanntgemacht, das die Todesstrafe gegen einen Bauern wegen Verheimlichung von Saatflächen verhängt hatte ${ }^{512}$. Ein Bauer aus dem Kreis Seelow, der zur Nichtablieferung von Kontingenten aufgerufen hatte, landete ebenfalls vor einem SMT. Ebenso erging es dem Landrat von Angermünde, dem man Erntesabotage vorwarf ${ }^{513}$.

Im allgemeinen waren die Haftstrafen 1946/47 anscheinend niedriger als in der späteren Zeit. Bis 1947 verhängten die Militärgerichte meist Gefängnisstrafen von zehn Jahren, vereinzelt Todesstrafen. Die Mehrzahl der Todesurteile wurde nicht in NS-Verfahren ausgesprochen ${ }^{514}$. Neun Todesurteile verhängte das SMT Brandenburg am 9. Februar 1946 in einem Prozeß gegen 28 Jugendliche und einen Erwachsenen aus Wittenberge, die angeblich eine Untergrundorganisation „Deutschnationale Demokratische Partei“ gegründet hatten. Fünf der Urteile wandelte man in Haftstrafen um ${ }^{515}$. Ab dem Frühjahr 1947 dominierte mehr und mehr die Einheitsstrafe von 25 Jahren Haft. Dies dürfte mit der Abschaffung der Todesstrafe für Gerichte in der Sowjetunion im Mai 1947 zusammenhängen, möglicherweise aber auch mit dem härteren politischen Kurs in der SBZ und der Sowjetunion selbst ${ }^{516}$. Die ständigen Schwankungen der Verurteilungspraxis der SMT waren auch der SED-Zentrale bekannt, die Beschuldigten "haben bekanntlich im Laufe der Jahre eine völlig unterschiedliche Behandlung erfahren" 517.

Im Februar 1947 informierte das brandenburgische Justizministerium noch einmal darüber, in welchen Sachen die Akten der SMA vorzulegen seien, die dann über die Zuständigkeit eines sowjetischen oder deutschen Gerichts zu entscheiden hatte: bei Waffenbesitz (auch Hieb- und Stichwaffen), antisowjetischen Beleidigungen, Mißhandlungen ausländischer Arbeiter, bei Delikten, die in russischer Uniform verübt wurden, bei Delikten aus einer "aktiven faschistischen Haltung“ und bei Spionage-Verdacht nach Einreise aus dem Westen ${ }^{518}$. Zivilprozesse mit sowjetischen Beteiligten durften grundsätzlich nur vor den SMT verhandelt wer-

512 BLHA, Rep. 240 Potsdam, Nr. 6, Rundverfügung Abt. Justiz Provinzialverwaltung (gez. Bechler), 17. 9. 1945, mit SMAD-Befehl Nr. 30 vom 22. 8. 1945.

513 BLHA, Rep. 203, Nr. 25, Bl. 120-134, Abt. Justiz Provinzialverwaltung an Gami, 27. 10. 1946; BLHA, Rep. 203, Nr. 26, Bl. 26, Befehl Nr. 221 SMA, 30. 10. 1946. AdsD, Ostbüro 0046 a, Bericht über Aufbau K 5 Potsdam, 9. 11. 1948, erwähnt die Hinrichtung von vier Bauern im Kreis Cottbus wegen Sabotage und Nichtablieferung.

514 Semiryaga, Wie Berijas Leute, S. 750.

515 Kilian, Stalins Prophylaxe, S. 554; Finn, Die politischen Häftlinge, S. 208.

516 Es ist nicht sicher, ob die Abschaffung auch für die SMT galt. Evans, Rituals of Retribution, S. 806, spricht von 23 Todesurteilen in der SBZ 1948/49, die allerdings nicht vollstreckt worden seien.

517 SAPMO, DY 30/IV 2/13/420, ZK-Sektor Justiz, Bemerkungen zum Bericht der Rechts- und Gnadenabteilung für das IV. Quartal 1956.

518 BLHA, Rep. 212, Nr. 41, Bl. 67, Runderlaß MdJ Brandenburg Nr. 43, 15. 2. 1947. Vgl. die Bekanntmachung eines Todesurteils eines SMT gegen einen Fürstenwalder Bürger wegen Waffenbesitz, 8. 8. 1945, Wir waren damals 19, S. 99; Artikel "Strenge Strafen für Waffenbesitz“, Der Märker vom 26. 1. 1946, der Todesstrafen androhte, falls Waffen nicht innerhalb von zehn Tagen abgeliefert werden. 
den $^{519}$, Spionage-Verfahren blieben bis in die fünfziger Jahre in sowjetischer Hand 520 .

Ab 1947 führten die SMT zunehmend politische Verfahren gegen echte oder vermeintliche Gegner. Die Vorwürfe lauteten nun "antisowjetische Tätigkeit“ oder „antisowjetische Propaganda“, so etwa wegen Verteilung „antisowjetischer“ Flugblätter. Drastische Eingriffe in die politische Szene nahmen die SMT ab 1948 vor: So wurde der Geschäftsführer der LDP in Rathenow am 12. Juli 1948 wegen Spionage von einem SMT zu 25 Jahren Haft verurteilt ${ }^{521}$. Diese politischen Verfahren erreichten 1950 ihren Höhepunkt. Danach verfolgten die SMT vor allem Militärspionage oder das, was sie dafür hielten ${ }^{522}$. Opfer dieser Kriminalisierung waren oftmals Studenten, die ihren Wohnsitz in Brandenburg hatten und täglich in eine der Berliner Universitäten pendelten ${ }^{523}$. Die Verurteilungszahlen nahmen nach 1950 allmählich ab.

Während die Festnahmen regelmäßig von der deutschen Volkspolizei oder den Operativen Gruppen des NKWD vorzunehmen waren, zeichnete das NKGB/ MGB für die Ermittlungen und Verhöre verantwortlich. Ab Oktober 1946 und erneut 1948 dehnten sich die exekutiven Befugnisse des von der SMA weitgehend unabhängigen MGB weiter aus ${ }^{524}$. Die Leitung des Verfahrens lag beim Militärstaatsanwalt, d.h. ab 1947 auch bei einem MWD-Offizier525. Durch viele Zeugen ist bekannt, daß die Vernehmer gerade bei politischen Strafsachen Beschuldigte mißhandelten, wie es auch in der Sowjetunion üblich war. In Brandenburg/Havel erlitt eine Frau nach einem MWD-Verhör eine Fehlgeburt ${ }^{526}$. Auf die brutalen Methoden sind vermutlich auch einige Todesfälle zurückzuführen.

Die Beweisführung in den Militärverfahren war denkbar dünn und entsprach in keiner Weise rechtsstaatlichen Prinzipien. Mit Ausnahme der Schauprozesse wurden die Gerichtsverfahren meist unter Ausschluß der Öffentlichkeit in äußerster Kürze abgewickelt. Zahlreiche Verfahren wurden als Massenprozesse veranstaltet, ohne Einzelprüfung der Schuld. Am 28. März 1948 verurteilte das SMT Potsdam 51 Einwohner Frankfurts wegen ,illegaler Gruppenbildung“ zu je 25 Jahren Haft ${ }^{527}$.

Die SMT verfuhren formal nach dem Strafgesetzbuch der RSFSR, insbesondere dem ausufernden Artikel 58 wegen „konterrevolutionärer Verbrechen“, und den SMAD-Befehlen, vorzugsweise Nr. 160 wegen Sabotage. In Verfahren wegen NS-

519 BLHA, Rep. 212, Nr. 41, Bl. 360, Rundverfügung Mdj Brandenburg Nr. 223, 2. 9. 1947.

520 Benjamin, Aus den ersten Jahren des Obersten Gerichts, S. 391.

521 Finn, Die politischen Häftlinge der Sowjetzone, S. 140; Verurteilung eines Angehörigen des LDPKV Potsdam zu 25 Jahren im Jahre 1948.

522 Krönig/Müller, Anpassung - Widerstand - Verfolgung, S. 316; BLHA, Rep. 203, Nr. 77, Bl. 206, Bericht Amt für Information Brandenburg über Stimmen aus der Bevölkerung Westprignitz zum Urteil des Militärtribunals, 25. 11. 1950.

${ }^{223} \mathrm{Vgl}$. die Namensliste in: Dokumentation des Terrors. Einzelschicksal: Schlüter, Workuta, bes. S. 228.

524 Vgl. Marquardt, Zusammenarbeit zwischen MfS und KGB, S. 53; Semiryaga, Wie Berijas Leute, S. 751; Foitzik, Organisationseinheiten und Kompetenzstruktur, S. 125; Murphy/Kondrashev/ Bailey, Battleground Berlin, S. 38.

525 Fricke, Politische Verfolgung und sowjetische Militärjustiz, S. 167, hält die Rolle des Militärstaatsanwalts für eher gering.

526 Finn, Die politischen Häftlinge, S. 22.

527 Ebenda, S. 19, 210. 
Verbrechen wandten die Tribunale das Kontrollratsgesetz Nr. 10 an. In der Regel wurde das Vermögen der Abgeurteilten eingezogen und dann an die Landesbehörden abgegeben ${ }^{528}$.

Die Vollstreckung der Strafen gestaltete sich im Laufe der Jahre unterschiedlich. Ein Teil der Verurteilten gelangte in die Strafabteilungen der Speziallager. Vermutlich ebenso viele wurden direkt aus den NKWD-Gefängnissen in Zwangsarbeitslager in die Sowjetunion deportiert. Haftentlassungen waren nur mit Zustimmung der sowjetischen Geheimpolizei möglich. Im April 1948 amnestierte die SMAD einen Teil der verurteilten Jugendlichen. Hinrichtungen wurden in den Gefängnissen Brandenburg/Havel und Frankfurt/Oder durch Erschießung vollstreckt, oftmals aber auch erst nach der Deportation in der UdSSR ${ }^{529}$. Die Todesstrafe wurde nach ihrer Wiederanwendung ab dem 12. Januar 1950 in zahlreichen Fällen verhängt. So fällte am 4. April 1951 ein Militärtribunal Todesurteile gegen elf von 21 Angeklagten aus Guben 530 .

Soweit bisher bekannt, wurde das letzte Urteil eines SMT in der DDR im September 1955 gesprochen. Auf brandenburgischem Gebiet datiert die letzte bisher ermittelte Verurteilung vom 28. Juli 1954. Das SMT Potsdam verurteilte einen Studenten der Freien Universität wegen angeblicher Spionage zu sechs Jahren $\mathrm{Haft}^{531}$.

Der Umfang der SMT-Verfahren in Brandenburg kann momentan nur grob geschätzt werden. In einer Liste mit rund 800 SMT-Verurteilungen entfielen $17 \%$ auf Brandenburg532. Bei geschätzten 40000 SMT-Verurteilungen deutscher Zivilisten $^{533}$ kann man also annehmen, daß etwa 6000 davon auf die Provinz bzw. das Land fallen, möglicherweise aber erheblich mehr.

Die sowjetischen Militärtribunale hatten anfangs noch ein Doppelgesicht aus harter Besatzungsjustiz und stalinistischem Repressionsinstrument. Spätestens ab 1948 blieb nur noch letztere Funktion übrig, bis die politischen Prozesse an die Justiz der DDR übergingen.

528 Vgl. BLHA, Rep. 212, Nr. 410, Bl. 150, Landwirtschaftsministerium an HA Justiz Brandenburg, 6. 4. 1951, betr. Bodeneigentum von SMT-Verurteilten.

529 Kilian, Stalins Prophylaxe, S. 558; Erler, Zum Wirken der Sowjetischen Militärtribunale, S. 58-61; Naimark, Russians in Germany, S. 395.

530 Fricke, Entführungsopfer postum rehabilitiert, S. 717; vgl. BLHA, Rep. 203, Nr. 21, B1. 437, MilitärStA der Feldpostnummer 48240 an Abt. Justiz Brandenburg, 12. 3. 1946 (gez. Wysozki). Dieses Militärtribunal mit der Truppenkennzeichnung 48240 hat in der ganzen SBZ Urteile verhängt, vgl. Wagenlehner, Akten der SMT-verurteilten Deutschen, S. 56; ders., Vier Jahre Auswertung, S. 433. 1950 bis 1953 verhängten SMT in der ganzen DDR jährlich um die hundert Todesurteile, Evans, Rituals of Retribution, S. 845.

531 Dokumentation des Terrors, Eintrag Frank-Wolfgang Kurz; AdsD, Ostbüro 0048 f, Informationsbüro West, 9. 7. 1954, meldete, daß Mitte Juni 1954 drei Deutsche vom SMT Potsdam wegen Spionage zum Tode verurteilt wurden.

532 SAPMO, DY 30/IV 2/13/428, Liste von 773 zur Begnadigung vorgeschlagenen SMT-Verurteilten (davon 126 in Brandenburg).

533 Kopalin, Rehabilitierung deutscher Opfer, S. 22 (40.000). Die Zahl der verurteilten Rotarmisten dürfte in etwa gleich hoch sein. Wagenlehner, Vier Jahre Auswertung, S. 435, geht von 85000 verurteilten Deutschen insgesamt aus (incl. Kriegsgefangene in der Sowjetunion). Finn, Die politischen Häftlinge, S. 208-220, listet SMT-Verfahren gegen 455 Personen in Brandenburg auf, Dokumentation des Terrors 50 Personen. 


\section{c. Die Auswirkungen der sowjetischen Strafaktionen}

Die bis in die fünfziger Jahre reichenden Verhaftungen erzeugten für die Bevölkerung in Brandenburg ein Klima der Rechtsunsicherheit, insbesondere für bestimmte Gruppen wie männliche Jugendliche. Andere wiederum waren indirekt betroffen, da Verwandte oder Bekannte in den sowjetischen Lagern und Gefängnissen einsaßen. Durch diese Brandenburger sah sich die deutsche Verwaltung, die auch für die Behandlung des in SMT-Urteilen enteigneten Besitzes zuständig war, mit dem Problem der Lager konfrontiert ${ }^{534}$. Im Februar 1951 schickte die Landesregierung eine Kommission zur Ortsbesichtigung auf das ehemalige Lagergelände von Ketschendorf. Den meisten Beteiligten war bekannt, was in den Lagern geschah $^{535}$.

Die Verhaftungen der sowjetischen Besatzungsmacht stellten den schwersten Eingriff in die brandenburgische politische und gesellschaftliche Ordnung nach 1945 dar. Insbesondere die massenhaften und willkürlichen Festnahmeaktionen waren auch innerhalb der SMA nicht unumstritten, wie einige interne sowjetische Kritiken zeigen ${ }^{536}$. Aber nicht die Verhaftungen an sich wurden beklagt, sondern die Reaktion in der Bevölkerung und die daraus resultierenden Schwierigkeiten in der politischen Arbeit. Vor dem gleichen Problem stand die SED seit 1947. Die brutalen Maßnahmen der Besatzungsmacht wurden mit der von dieser geförderten Partei identifiziert. In Kenntnis der Willkür der Verfahren drängte die SED ihre sowjetischen Vorgesetzten periodisch dazu, Erleichterungen zuzulassen ${ }^{537}$.

Um die Härte des sowjetischen Vorgehens deutlicher zu machen, genügt ein vergleichender Blick auf die Militärjustiz der Westalliierten ${ }^{538}$. Im Sommer 1945 fällten westliche Militärgerichte noch drakonische Urteile; ab 1946 reduzierten sich Strafmaße und Strafvollstreckung. Die NS-Verfahren der Briten, Amerikaner und Franzosen waren stärker zentralisiert und betrafen weit weniger Personen, die wiederum fast durchweg schwer belastet waren. Sie wurden öffentlich geführt, die Beweiserhebung war umfangreicher und folgte weitgehend rechtsstaatlichen Prinzipien. Vor allem aber: Die Verfahren unterlagen massiver öffentlicher Kritik ${ }^{539}$. Der interalliierte Konsens über die Bestrafung der NS-Verbrecher, der beim Nürnberger Hauptkriegsverbrecherprozeß noch weitgehend bestand, löste sich $1947 / 48$ zusehends auf. Auslieferungen aus dem Westen in die SBZ wurden eingestellt.

${ }^{534}$ Allerdings hatte die Verwaltung keinen Überblick über einschlägige Urteile: BLHA, Rep. 203, Nr. 101, Bl. 203, AVE Brandenburg an AVE bei DWK, 23. 3. 1949.

${ }_{535}$ Schatz, Die gesellschaftliche Wahrnehmung der sowjetischen "Speziallager“, S. $105 \mathrm{f}$.; zahlreiche Beispiele in Lipinsky, Ketschendorf, S. $384 \mathrm{ff}$.

536 Naimark, Russians in Germany, S. 392 (undatierter Bericht über Bezirk Cottbus und Beschwerde vom 6. 9. 1946).

${ }^{537}$ Offensichtlich hat sich Sägebrecht verschiedentlich um Haftentlassungen bemüht, Stößel, Positionen, S. 191.

538 Zu Prinzipien und Struktur der amerikanischen Militärgerichte: Waibel, Von der wohlwollenden Despotie, S. $241 \mathrm{ff}$.

${ }^{339}$ Vor US-Militärgerichten standen wegen NS-Verbrechen insgesamt 1941 Personen (davon 1517 verurteilt), vor britischen 1085 und vor französischen 2130 Angeklagte. Rückerl, NS-Verbrechen vor Gericht, S. $98 \mathrm{f}$. Vgl. zu den frühen US-Verfahren: Henke, Die amerikanische Besetzung, S. $181 \mathrm{ff}$.; zu den Dachauer Prozessen: Sigel, Im Interesse der Gerechtigkeit, bes. S. 139ff.; Pendaries, Les procès de Rastatt, S. $314 \mathrm{f}$. 
Auch in den Westzonen wurden politische Prozesse vor Militärgerichten geführt ${ }^{540}$. Diese verhandelten aber direkte Verstöße gegen Besatzungsanordnungen und hatten nicht den massenhaften Kampagnen-Charakter wie bei den SMT. In den direkten Interventionen der Besatzungsmächte läßt sich frühzeitig die Auseinanderentwicklung zwischen West- und Ostdeutschland festmachen. Lediglich in der zeitweiligen Abschaffung der Todesstrafe wich die sowjetische Militärjustiz von ihrem harten Vorgehen ab.

Indirekt war auch die deutsche Justiz in Brandenburg von den sowjetischen Urteilen betroffen. So traten vereinzelt Fälle auf, in denen Angeklagte behaupteten, wegen derselben Sache schon einmal von einem SMT verurteilt worden zu sein. Erlittene Internierungshaft in den Speziallagern konnte später nicht auf deutsche Haftstrafen angerechnet werden ${ }^{541}$. Bis 1947 wurde die deutsche Justiz in Brandenburg durch die Besatzungsbehörden allerdings von politischen Verfahren grundsätzlich ferngehalten. Dies verzögerte indirekt den Zugriff der SED auf das Gerichtssystem, da für die Staatspartei noch nicht die Notwendigkeit bestand, auf politische Verfahren Einfluß zu nehmen.

Erst die NS-Verfahren vor deutschen Gerichten sollten ein Hebel der Gleichschaltung der Justiz werden. Zahlreiche NS-Belastete kamen jedoch weder vor deutsche noch vor sowjetische Gerichte, sondern blieben ohne Verfahren interniert. Viele von ihnen starben im Lager, andere gerieten in die Maschinerie der Waldheim-Prozesse 1950. Deshalb war die Zahl der mutmaßlichen NS-Verbrecher, die in Brandenburg vor deutsche Gerichte gelangten, von vornherein begrenzt.

\section{Nachkriegsjustiz unter Besatzung}

Man wird kaum übertreiben, wenn man feststellt, daß der Gang der brandenburgischen Justizgeschichte in der Sowjetischen Besatzungszone auch von der Weltlage bestimmt war. Solange sich die Besatzungsmächte um eine gemeinsame Politik in Deutschland bemühten, liefen auch viele politische Entwicklungen in den verschiedenen Zonen parallel. Die sowjetische Deutschlandpolitik, so der momentane Kenntnisstand, orientierte sich an dieser Gemeinsamkeit bis in den Herbst 1947, in eingeschränktem Ausmaß auch darüber hinaus.

Die Rolle der sowjetischen Besatzungsmacht in der Innenpolitik der SBZ ist kaum zu überschätzen. Die Offiziere bestimmten die Grundlinien der ganzen Politik, sie hatten eine weitgehende Kontrolle über Personalfragen, und sie griffen immer dann ein, wenn ihre Prioritäten berührt schienen. Die SED dominierte zwar die parteipolitischen Bereiche, war aber bis 1947 in der Landesjustiz nur beschränkt vertreten und hatte wenig Gestaltungsspielraum gegenüber den Besatzungsbehörden. Zudem überwogen in der Justiz bei weitem solche SED-Mitglie-

${ }^{540}$ Zum Beispiel das Militärverfahren gegen KPD-Funktionäre in Schöneberg, 2./3. 4. 1946, vgl. Berlin 1945-1946, S. 408.

${ }^{541}$ BLHA, Rep. 212, Nr. 884, Bl. 85, MdJ an LG-Präsident Eberswalde, 2. 8. 1948; BLHA, Rep. 203, Nr. 85, Bl. 387 f., DJV an MdJ Brandenburg, 30. 9. 1949. 
der, die aus der SPD stammten und sich deren Weimarer Rechtstraditionen verpflichtet fühlten.

In der unmittelbaren Nachkriegszeit bestimmten die lokalen Militärkommandanturen meist das Personal der Gerichte. Ab 1946 begannen Sowjetoffiziere, Verfahren anzuordnen, z.B. gegen Bauern wegen unzureichender Ablieferung von Agrarprodukten. Zentrale Fragen der Landesjustiz wurden zunächst mit der SMAD in Karlshorst besprochen. Erst Ende 1947 ist die Tätigkeit einer Rechtsabteilung in der Militärverwaltung des Landes spürbar. Insgesamt war die sowjetische Justizpolitik bis 1948 vor allem auf politische und ökonomische Sicherung der Besatzungsherrschaft ausgerichtet, erst nach dieser Zeit dominierte das Streben nach Umgestaltung der Justiz.

Die politische Gesamtentwicklung in Brandenburg wie in der ganzen SBZ war bis ins Jahr 1948 durch eine Gemengelage gekennzeichnet. Die politischen Parteien distanzierten sich entschieden von der NS-Diktatur, die KPD/SED war in Grenzen zu einem Kooperationskurs mit „bürgerlichen“ Kräften bereit. Durch die Wahlen von 1946 erhielt das politische System - trotz der Manipulationen davor und danach - einen Legitimationsschub. Dennoch kann man nur schwerlich von einer demokratischen Vorgeschichte der DDR sprechen ${ }^{542} .1945$ herrschte in allen Besatzungszonen zunächst eine uneingeschränkte Militärherrschaft, d.h. demokratische Strukturen bildeten sich erst allmählich heraus. Während in den Westzonen der politische Druck auf die Bevölkerung im Laufe der Jahre nachließ, kann davon in der SBZ keine Rede sein. Mit Massenverhaftungen, den Speziallagern und einer brachialen Militärjustiz zeigte die Besatzungsmacht deutlich ihre Anbindung an die stalinistische Sowjetunion. Ein Klima von Freiheit und Rechtssicherheit konnte sich so nur sehr begrenzt entwickeln, am ehesten noch für Arbeiter und sogenannte Neubauern. Durch sowjetischen Eingriff konnte die SED die Niederlage bei den Landtagswahlen in eine Mehrheit innerhalb der Regierung ummünzen. Deshalb kann auch nur in Grenzen von einem Föderalismus in der SBZ gesprochen werden. Für die Besatzungsmacht war die Existenz gewachsener Länderstrukturen nützlich, weil hier schon ein funktionsfähiger Apparat bestand. Im allgemeinen lehnte Stalin den Föderalismus aber $a^{543}$.

In dieser Gemengelage befand sich auch die deutsche Justiz. Bis ins Jahr 1948 konnte sich das Rechtswesen in Brandenburg relativ eigenständig gegenüber der Deutschen Justizverwaltung entwickeln. Letztere besaß zunächst weder die Mittel noch die Kompetenzen, eine zonale Justizpolitik zu betreiben. Vielmehr konstituierten die Länder die eigentliche Justizverwaltung, wobei die Provinz Brandenburg als Neukonstruktion vom Vorbild der „alten“ Länder profitieren konnte.

Der Einfluß der SED auf die Justiz wurde in dieser Zeit nicht durch den Landesverband, sondern indirekt durch das Zentralsekretariat und direkt durch die SED-Mitglieder in der Justizverwaltung ausgeübt. Auf der anderen Seite hatten auch die „bürgerlichen“ Blockparteien ihre Vertreter in der Justiz, allen voran den Minister. Die Masse der Justizangestellten blieb aber bis Ende 1947 parteilos;

542 Ähnlich Weber, Gab es eine demokratische Vorgeschichte; dagegen Heydemann/Beckmann, Zwei Diktaturen, S. 21.

${ }_{543}$ Vgl. Stalins Ausführungen vor der SED-Spitze am 31.1. 1947, Bonwetsch/Bordjugow, Stalin und die SBZ, S. 300. 
unter den Richtern und Staatsanwälten zeichnete sich erst allmählich ein Übergewicht der SED-Mitglieder ab. Ein großer Teil dieser SED-Juristen befand sich aber nach der Gleichschaltung Anfang der fünfziger Jahre schon nicht mehr auf seinem Posten.

Auch die Justizpolitik bewegte sich bis 1947 durchaus in den politischen Bahnen des Blocks. Sie war dominiert von der Bewältigung des Zusammenbruchs und der NS-Diktatur. Die massivsten Eingriffe von SMAD und KPD/SED, die für Konflikte im Block sorgten, also die Enteignungen von Boden und Betrieben, gingen an der Justiz weitgehend vorbei. Gewisse Differenzen zeichneten sich auch in der Personalpolitik ab; die rigorose Entnazifizierung war allerdings sowjetischer Befehl, und die Volksrichter spielten in dieser Zeit noch eine marginale Rolle.

Von Ausnahmen abgesehen, trug die deutsche Rechtsprechung der ersten Nachkriegsjahre kaum das Signum einer SED-Justiz. Vielmehr mußte man die überwältigenden Rechtsprobleme der Zusammenbruchsgesellschaft in den Griff bekommen. Hier forderten sowjetische Stellen eine harte Strafpolitik. Viel stärker als in der Rechtsprechung spürte man in den ersten Nachkriegsjahren den Einfluß der SED bei der Formulierung neuer Verfahrensregelungen. Diese sollten zwar auf der Grundlage des Block-Konsenses gestaltet werden, aber SMAD und SEDRechtspolitiker versuchten frühzeitig, sich alle Optionen offenzuhalten: eine Verfassung mit Aufhebung der Gewaltenteilung, die Kassation, gestutzte Verwaltungsgerichte, vor allem aber die Aufwertung der Polizei durch Befehl Nr. 201, wie zu zeigen sein wird.

Aus Sicht der Bevölkerung war nicht die politische Beeinflussung das Hauptproblem der Justiz, sondern die Schwäche des Rechtswesens. Einerseits reagierten Gerichte oft überaus hart auf die Kompensationen und die Defizite bei der Pflichtablieferung. Andererseits schien sie nicht in der Lage zu sein, die grassierende Kriminalität einzudämmen. Statt dessen wurden immer wieder Fälle von Inkompetenz und Korruption publik. Schon machte - ähnlich wie in Berlin - das Wort von der „Justizkrise“ die Runde ${ }^{544}$.

Bis Anfang 1948 verlief die Entwicklung der deutschen Justiz in Brandenburg nicht grundlegend anders als in den Ländern der Westzonen ${ }^{545}$. Noch im Jahre 1947 herrschte ein reger Rechtsverkehr zwischen Ost und West. So konnten Verhaftungen in der jeweils anderen Zone erwirkt werden; man las im Westen erscheinende juristische Zeitschriften, es konnten auch Urteile westlicher Gerichte angefordert werden ${ }^{546}$. Erst 1948 kam die Weisung der SMA, keine Rechtshilfeersuchen von dort mehr zu beantworten. Die westlichen Behörden wurden mit Überstellungen von Gefangenen immer zurückhaltender, Ende 1948 kam diese Form des Rechtsaustausches zum Erliegen ${ }^{547}$.

$\mathrm{Da} ß$ sich die Zonen bis dahin noch nicht so weit auseinanderentwickelt hatten, zeigen die zahlreichen Parallelen. Analytisch besonders interessant ist ein Vergleich mit der Berliner Entwicklung, da hier bis Mitte 1948 ein gemeinsames

544 Vgl. die Pressekonferenz der Berliner Justiz vom 15. 7. 1947, Berlin 1946-1948, S. 275.

545 Ein früheres Auseinanderdriften sieht Stolleis, Rechtsordnung und Justizpolitik, S. 391.

546 BA, DP-1 VA 14, Bl. 12, Konferenz der GStA am 25.-26. 4. 1947; BLHA, Rep. 216, Nr. 10, Bl. 2, VerwG an Magistrat Berlin, 23. 1. 1948.

547 Vgl. BLHA, Rep. 212, Nr. 6, Bl. 83-85, Tätigkeitsbericht für 3.3.-3.4.1948, 1. 4. 1948. 
Rechtssystem von West- und Ostsektoren bestand. Die DJV war nicht für den Sowjetsektor zuständig; statt dessen übernahm diese Funktion ein Rechtsamt beim Magistrat. Bis 1948 existierten keine Richterkurse und wurden keine Volksrichter eingesetzt. An ihrer Stelle zog man Rechtsanwälte als Richter und Staatsanwälte heran, wie es etwa auch in Hessen vielfach der Fall war. Im Juli 1948 zeigten sich erste Anzeichen einer Auseinanderentwicklung in der Berliner Justiz, schließlich kam es 1949 zur Spaltung des Kammergerichts und zum Aufbau zweier getrennter Justizverwaltungen ${ }^{548}$.

Innerhalb dieser Gemeinsamkeiten läßt sich also bis Anfang 1948 von fünf verschiedenen Entwicklungswegen der deutschen Justiz sprechen, in den drei Westzonen, wo durchaus nicht alles einheitlich ablief, in der SBZ und in Berlin. Die Hauptunterschiede von Ost und West lagen in dieser Zeit bei der alliierten Militärjustiz, vor allem aber bei den politischen Rahmenbedingungen, die in der SBZ grundsätzlich anders waren als in den Westzonen. Innerhalb der deutschen Justiz lag die auffälligste Differenz zwischen Westzonen und SBZ bis 1947 in der Personalpolitik. Zwar waren anfänglich auch die Westalliierten betrebt, alle Richter und Staatsanwälte mit NSDAP-Parteibuch zu entlassen, und stellten dafür bisweilen Richter „im Soforteinsatz“ ein. Bald jedoch wurde diese Maßnahme in den Westzonen rückgängig gemacht, und die ersten NS-Juristen kehrten zumeist auf ihre Posten zurück. Lediglich in der Justizspitze sowie in Berlin und im Saarland wußten die Besatzungsverwaltungen dies zu verhindern; eigentlich wollten sie ehemalige NSDAP-Mitglieder auch von Prozessen mit politischem Hintergrund fernhalten ${ }^{549}$. Trotz dieser Differenzen war Anfang 1948 noch nicht offensichtlich, daß die Justiz im Osten einen ganz anderen Weg gehen würde.

$548 \mathrm{Vgl}$. Scholz, Berlin und seine Justiz, bes. S. $111 \mathrm{ff}$.

549 Rüping, Staatsanwälte und Parteigenossen, S. 31 ff. (OLG-Bezirk Celle); Niermann, Zwischen Amnestie und Anpassung, S. 68 ff. (OLG-Bezirk Hamm); für Bayern vgl. Wengst, Thomas Dehler, S. $95 \mathrm{f}$. 